REFERENCE

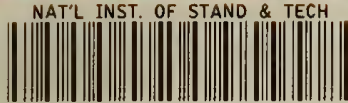

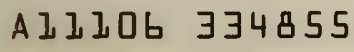

NBS TECHNICAL NOTE 270-6

NIST

PUBLICATIONS

REFERENCE

NBS

Publi.

cations

\title{
Selected Values of \\ Chemical Thermodynamic \\ Properties
}

Tables for the Alkaline Earth Elements

(Elements 92 through 97 in the

Standard Order of Arrangement)

U.S. DEPARTMENT

OF

COMMERCE

National

$-Q C-$

100

.45753

no. $270-6$

1971 
The National Bureau of Standards ${ }^{1}$ was established by an act of Congress March 3 , 1901. The Bureau's overall goal is to strengthen and advance the Nation's science and technology and facilitate their effective application for public benefit. To this end, the Bureau conducts research and provides: (1) a basis for the Nation's physical measurement system, (2) scientific and technological services for industry and government, (3) a technical basis for equity in trade, and (4) technical services to promote public safety. The Bureau consists of the Institute for Basic Standards, the Institute for Materials Research, the Institute for Applied Technology, the Center for Computer Sciences and Technology, and the Office for lnformation Programs.

THE INSTITUTE FOR BASIC STANDARDS provides the central basis within the United States of a complete and consistent system of physical measurement; coordinates that system with measurement systems of other nations; and furnishes essential services leading to accurate and uniform physical measurements throughout the Nation's scientific community, industry, and commerce. The Institute consists of a Center for Radiation Research, an Office of Measurement Services and the following divisions:

Applied Mathematics-Electricity-Heat-Mechanics-Optical Physics-Linac Radiation ${ }^{2}$ - Nuclear Radiation ${ }^{2}$ - Applied Radiation ${ }^{2}$ - Quantum Electronics ${ }^{3}$ Electromagnetics ${ }^{3}$ - Time and Frequency ${ }^{3}$ - Laboratory Astrophysics ${ }^{3}$-Cryogenics ${ }^{3}$.

THE INSTITUTE FOR MATERIALS RESEARCH conducts materials research leading to improved methods of measurement, standards, and data on the properties of well-characterized materials needed by industry, commerce, educational institutions, and Government; provides advisory and research services to other Government agencies; and develops, produces, and distributes standard reference materials. The Institute consists of the Office of Standard Reference Materials and the following divisions:

Analytical Chemistry-Polymers-Metallurgy-Inorganic Materials-Reactor Radiation-Physical Chemistry.

THE INSTITUTE FOR APPLIED TECHNOLOGY provides technical services to promote the use of available technology and to facilitate technological innovation in industry and Government; cooperates with public and private organizations leading to the development of technological standards (including mandatory safety standards), codes and methods of test; and provides technical advice and services to Government agencies upon request. The Institute also monitors NBS engineering standards activities and provides liaison between NBS and national and international engineering standards bodies. The Institute consists of the following technical divisions and offices:

Engineering Standards Services-Weights and Measures-Flammable FabricsInvention and Innovation-Vehicle Systems Research-Product Evaluation Technology-Building Research-Electronic Technology-Technical AnalysisMeasurement Engineering.

THE CENTER FOR COMPUTER SCIENCES AND TECHNOLOGY conducts research and provides technical services designed to aid Government agencies in improving cost effectiveness in the conduct of their programs through the selection, acquisition, and effective utilization of automatic data processing equipment; and serves as the principal focus within the executive branch for the development of Federal standards for automatic data processing equipment, techniques, and computer languages. The Center consists of the following offices and divisions:

Information Processing Standards-Computer Information-Computer Services -Systems Development-Information Processing Technology.

THE OFFICE FOR INFORMATION PROGRAMS promotes optimum dissemination and accessibility of scientific information generated within NBS and other agencies of the Federal Government; promotes the development of the National Standard Reference Data System and a system of information analysis centers dealing with the broader aspects of the National Measurement System; provides appropriate services to ensure that the NBS staff has optimum accessibility to the scientific information of the world, and directs the public information activities of the Bureau. The Office consists of the following organizational units:

Office of Standard Reference Data-Office of Technical Information and Publications-Library-Office of Public Information-Office of International Relations.

\footnotetext{
${ }^{1}$ Headquarters and Laboratories at Gaithersburg, Maryland, unless otherwise noted; mailing address Washington, D.C. 20234.

2 Part of the Center for Radiation Research.

3 Located at Boulder, Colorado 80302 .
} 


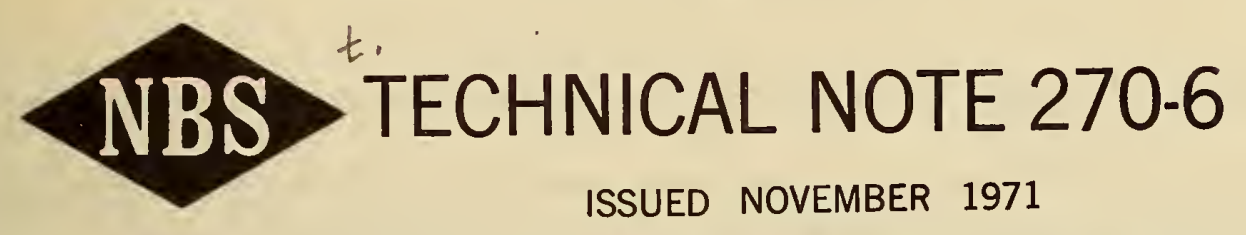

Nat. Bur. Stand (U.S.), Tech. Note 270-6, 119 pages (Nov. 1971)

CODEN: NBTNA

\title{
Selected Values of Chemical Thermodynamic Properties
}

\section{Tables for the Alkaline Earth Elements \\ (Elements 92 through 97 in the Standard Order of Arrangement)}

\author{
V. B. Parker, D. D. Wagman, and W. H. Evans \\ Physical Chemistry Division \\ Institute for Materials Research \\ U.S. National Bureau of Standards \\ Washington, D.C. 20234
}

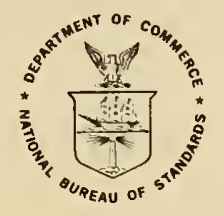

NBS Technical Notes are designed to supplement the Bureau's regular publications program. They provide a means for making available scientific data that are of transient or limited interest. Technical Notes may be listed or referred to in the open literature. 


\section{ABSTRACT}

Contains tables of values for the standard heats and Gibbs (free) energies of formation, entropies and enthalpies at $298.15 \mathrm{~K}$ and heats of formation at $0 \mathrm{~K}$ for compounds of beryllium, magnesium, calcium, strontium, barium, and radium (elements $92-97$ in the Standard Order of Arrangement). These tables are a continuation of the comprehensive revision of NBS Circular 500.

Key words: Enthalpy; entropy; Gibbs energy of formation; beryllium compounds; magnesium compounds; calcium compounds; strontium compounds; barium compounds; radium compounds. 


\section{PREFACE}

This is the sixth of a series of Technical Notes containing the tables of material prepared as a revision of National Bureau of Standards Circular 500, Selected Values of Chemical Thermodynamic Properties, by F. D. Rossini, D. D. Wagman, W. H. Evans, S. Levine and I. Jaffe. This Note contains data for compounds of six elements, numbered 92 through 97 in the Standard Order of Arrangement.

The continued encouragement and support of the Office of Standard Reference Data of the National Bureau of Standards is gratefully acknowledged. 
Preface . . . . . . . . . . . . . . . . . iii Introduction . . . . . . . . . . . . . . . . . . . v

Standard Order of Arrangement of the Elements, Figure $1 . . \quad x$

Table A. Conversion Factors for Units of Molecular Energy . xi Table 92 Beryllium . . . . . . . . . . . . 1

Table 93 Magnesium . . . . . . . . . . . . 9

Table 94 Calcium . . . . . . . . . . . 30

Table 95 Strontium ............. . . 57

Table 96 Barium . . . . . . . . . . . . 78

Table 97 Radium ............... . . 103

Index of Contents. . . . . . . . . . . . . . . 104 


\section{INTRODUCTION}

Substances and Properties Included in the Tables

The tables contain values where known of the enthalpy and Gibbs energy of formation, enthalpy, entropy and heat capacity at $298.15 \mathrm{~K}$ $\left(25^{\circ} \mathrm{C}\right)$, and the enthalpy of formation at $0 \mathrm{~K}$, for all inorganic substances and organic molecules containing not more than two carbon atoms. In some instances such as metal-organic compounds, data are given for substances in which each organic radical contains one or two carbon atoms.

No values are given in these tables for metal alloys or other solid solutions, fused salts, or for substances of undefined chemical composition.

\section{Physical States}

The physical state of each substance is indicated in the column headed "State" as crystalline solid (c), liquid (liq), glassy or amorphous (amorp), or gaseous (g). Solutions in water are listed as aqueous (aq). For non-aqueous systems the physical state is that normal for the indicated solvent at $298.15 \mathrm{~K}$.

\section{Definition of Symbols}

The symbols used in the se tables are defined as follows: $P=$ pressure; $\mathrm{V}=$ volume; $\mathrm{T}=$ absolute temperature; $\mathrm{E}=$ intrinsic or internal energy; $\mathrm{S}=$ entropy; $\mathrm{H}=\mathrm{E}+\mathrm{PV}=$ enthalpy (heat content); $\mathrm{G}=\mathrm{H}-\mathrm{TS}=$ Gibbs energy (formerly the free energy); $\mathrm{C}_{\mathrm{p}}=(\mathrm{dH} / \mathrm{dT})_{\mathrm{P}}=$ heat capacity at constant pressure. 


\section{Conventions Regarding Pure Substances}

The values of the thermodynamic properties of the pure substances given in these tables are for the substances in their standard states (indicated by the superscript ${ }^{\circ}$ on the thermodynamic symbol). These standard states are defined as follows:

For a pure solid or liquid, the standard state is the substance in the condensed phase under a pressure of one atmosphere.

For a gas the standard state is the hypothetical ideal gas at unit fugacity, in which state the enthalpy is that of the real gas at the same temperature and at zero pressure.

The values of $\Delta \mathrm{Hf}^{\circ}$ and $\Delta \mathrm{Gf}{ }^{\bullet}$ given in the tables represent the change in the appropriate thermodynamic quantity when one gram-formula weight of the substance in its standard state is formed, isothermally at the indicated temperature, from the elements, each in its appropriate standard reference state. The standard reference state at $25^{\circ} \mathrm{C}$ for each element except phosphorus has been chosen to be the standard state that is thermodynamically stable at $25^{\circ} \mathrm{C}$ and at one atmosphere pressure. For phosphorus the standard reference state is the crystalline white form; the more stable forms have not been well characterized thermochemically. The same reference states have been maintained for the elements at $0 \mathrm{~K}$ except for the liquid elements bromine and mercury, for which the reference states have been chosen as the stable crystalline forms. The standard reference states are indicated in the tables by the fact that the values of $\Delta \mathrm{Hf}^{\circ}$ and $\Delta \mathrm{Gf}{ }^{\circ}$ are exactly zero.

The values of $\mathrm{H}_{298}^{\circ}, \mathrm{H}_{0}^{\circ}$ represent the enthalpy difference for the given substance between $298.15 \mathrm{~K}$ and $0 \mathrm{~K}$. If the indicated standard state at $25^{\circ} \mathrm{C}$ is the gas, the corresponding state at $0 \mathrm{~K}$ is the hypothetical ideal gas; if the state at $25^{\circ} \mathrm{C}$ is solid or liquid, the corresponding state at $0 \mathrm{~K}$ is the thermodynamically stable crystalline solid, unless otherwise specifically indicated.

The values of $S^{\circ}$ represent the virtual or "thermal" entropy of the substance in the standard state at $298.15 \mathrm{~K}$, omitting contributions from nuclear spins. Isotope mixing effects, etc, are also excluded except in the case of the hydrogen-deuterium $\left({ }^{1} \mathrm{H}_{-}{ }^{2} \mathrm{H}\right)$ system. Where data have been available only for a particular isotope, they have been corrected when possible to the normal isotopic composition.

The values of the enthalpies of formation of gaseous ionic species are computed on the convention that the value of $\Delta H^{\circ}$ for the electron is zero. Conversions between 0 and $298.15 \mathrm{~K}$ are calculated using the value of $\mathrm{H}_{298}-\mathrm{H}_{0}=1.481 \mathrm{kcal}$ per mole of electrons, and assuming that the values of $\mathrm{H}_{298}-\mathrm{H}_{\delta}$ for the ionized and un-ionized molecules are the same. 
Solutions in water are designated as aqueous (aq); other solvents are designated by name or chemical formula. The concentration of the solution is expressed in terms of the number of moles of solvent associated with one mole of the solute. If no concentration is indicated, the solution is assumed to be "dilute".

The standard state for a solute in aqueous solution is taken as the hypothetical ideal solution of unit molality (indicated as "std. state, $\left.m=l^{\prime \prime}\right)$. In this state the partial molal enthalpy and heat capacity of the solute are the same as in the infinitely dilute real solution. For nonaqueous solutions the standard state of the solute is the hypothetical ideal solution of unit mole fraction of solute ("std. state, $\mathbf{x}_{2}=1$ ").

The value of $\Delta \mathrm{Hf}^{\circ}$ given in the tables for a solute in its standard state is the apparent molal enthalpy of formation of the substance in the infinitely dilute real solution. At this dilution the partial molal enthalpy is equal to the apparent molal quantity. At concentrations other than the standard state, the value of $\Delta \mathrm{Hf}^{\circ}$ represents the apparent enthalpy of the reaction of formation of the solution from the elements comprising the solute, each in its standard reference state, and the appropriate total number of moles of solvent. In this representation the value of $\Delta \mathrm{Hf}^{\circ}$ for the solvent is not required. The experimental value for a heat of dilution is obtained directly as the difference between the two values of $\Delta \mathrm{Hf}^{\circ}$ at the corresponding concentrations.

The values of the thermodynamic properties tabulated for the individual ions in aqueous solution are based on the usual convention that the value $\mathrm{s}$ of $\Delta \mathrm{Hf}^{\circ}, \Delta \mathrm{Gf}^{\circ}, \mathrm{S}^{\circ}$ and $\mathrm{C}_{\mathrm{p}}{ }^{\circ}$ for $\mathrm{H}^{+}(\mathrm{aq}, \mathrm{std}$. state, $\mathrm{m}=1$ ) are zero. The properties of a neutral electrolyte in aqueous solution in the standard state are equal to the algebraic sum of the se values for the appropriate kinds and number of individual ions assumed to constitute the molecule of the given electrolyte. When the undissociated species, rather than the sum of the ions, is meant, the notation "undissociated" or "un-ionized" is used. For an ionic species the properties tabulated refer to that undissociated ion. By adopting the above convention with respect to aqueous $\mathrm{H}^{+}$, it follows that the the rmodynamic relation $\Delta \mathrm{Gf}^{\circ}$ $=\Delta \mathrm{Hf}^{\circ}-\mathrm{T} \Delta \mathrm{Sf}^{\circ}$ will not hold for an individual ionic species. However no problem arises when neutral chemical systems are considered. 


\section{Unit of Energy and Fundamental Constants}

All of the energy values given in the se tables are expressed in terms of the thermochemical calorie. This unit, defined as equal to 4.1840 joules, is generally accepted for the presentation of chemical thermodynamic data. Values reported in other units have been converted to calories by means of the conversion factors for molecular energy given in Table A.

The following values of the fundamental physical constants have been used in these calculations:

$$
\begin{aligned}
& \mathrm{R}=\text { gas constant }=8.3143 \pm 0.0012 \mathrm{~J} / \mathrm{deg} \mathrm{mol}=1.98717 \pm 0.00029 \\
& F=\text { Faraday constant }=96487.0 \pm 1.6 \text { coulombs } / \mathrm{mol} \\
& =23060.9 \pm 0.4 \mathrm{cal} / \mathrm{volt} \text { equivalent } \\
& Z=\mathrm{Nh}^{\prime}=11.96258 \pm 0.00107 \mathrm{~J} / \mathrm{cm}^{-1} \mathrm{~mol}=2.85912 \pm 0.00026 \mathrm{cal} / \mathrm{cm}^{-1} \mathrm{~mol} \\
& c_{2}=\text { second radiation constant }=\mathrm{hc} / \mathrm{k}=1.43879 \pm 0.00015 \mathrm{~cm} \text { deg } \\
& 0^{\circ} \mathrm{C}=273.15 \mathrm{~K}
\end{aligned}
$$

These constants are consistent with those given in the Table of General Physical Constants, recommended by the National Academy of Sciences -

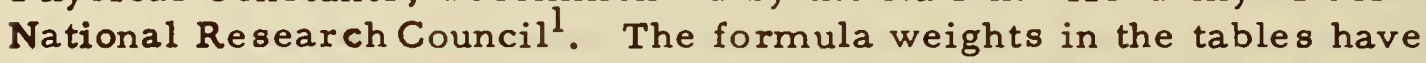
been calculated for the molecular formula given in the Formula and Description column using the 1961 Table of Relative Atomic Weights based on the atomic mass of ${ }^{12} \mathrm{C}=12$ exactly ${ }^{2}$.

\section{Internal Consistency of the Tables}

All of the values given in these tables have been calculated from the original articles, using consistent values for all subsidiary and auxiliary quantities. The original data were corrected where possible for differences in energy units, molecular weights, temperature scales, etc. Thus we have sought to maintain a uniform scale of energies for all the substances in the tables. In addition the tabulated values of the properties of a substance satisfy all the known physical and thermodynamic relationships among these properties. The quantities $\Delta \mathrm{Hf}^{\circ}, \Delta \mathrm{Gf}{ }^{\circ}$, and $\mathrm{S}^{\circ}$ at $298.15 \mathrm{~K}$ satisfy the relation:

$$
\Delta \mathrm{Gf}^{\circ}=\Delta \mathrm{Hf}^{\circ}-\mathrm{T} \Delta \mathrm{Sf}^{\circ} \text {. }
$$

INBS Technical News Bulletin, October 1963.

${ }^{2}$ A. E. Cameron and E. Wichers, J. Am. Chem. Soc. 84, 4192 (1962). 
Furthermore the calculated value of any thermodynamic quantity for a reaction is independent of the path chosen for the evaluation.

In some cases newer data may have become available on certain substances after the values were selected for the se tables. Because of the need to maintain the internal consistency of the tables, it is not always possible to incorporate these newer data into the tables without a detailed analysis of the effect of such a change. Unless great care is used, relatively significant errors in calculated values of $\Delta \mathrm{H}^{\circ}$ or $\Delta \mathrm{G}^{\circ}$ for specific reactions may result from the introduction of such data.

\section{Uncertainties}

The uncertainty in any value in the tables depends on the uncertainties of all the determinations in the total chain of reactions used to establish the value.

A discussion of the uncertainties will be included in the final publication of the se tables in the National Standard Reference Data System. However we have followed certain rules with respect to significant figures to indicate these uncertainties. Values are tabulated in general such that the overall uncertainty lies between 2 and 20 units of the last figure. On the other hand, values are given so that the experimental data from which they are derived may be recovered with an accuracy equal to that of the original quantities. Thus the number of significant figures for any one value in the tables need not represent the absolute accuracy of that value. For solutions of varying composition values are frequently tabulated to more figures to make possible the recovery of enthalpies of solution and dilution. Similarly values of $\Delta \mathrm{Hf}_{0}^{\circ}$ and $\Delta \mathrm{Hf}_{298.15}$ may be given to different numbers of significant figures. In this instance the quantity with the lesser number of figures is used to represent the uncertainty estimate. The larger number of figures is used for the other quantity to retain the significance of the temperature correction term.

\section{Arrangement of the Tables}

The compounds in the tables are entered according to the Standard Order of Arrangement, (see Figure 1), by the principle of latest position. In this scheme, a compound is listed under the element occurring latest in the list; water of hydration is neglected. Within a given element table will be found all of the compounds of that element with elements occurring earlier in the order; the arrangement within a table follows the same ordering. An exception occurs in the carbon tables (Table 23), which is divided into subgroups consisting of all compounds with one carbon atom, then all with two carbon atoms, etc. 


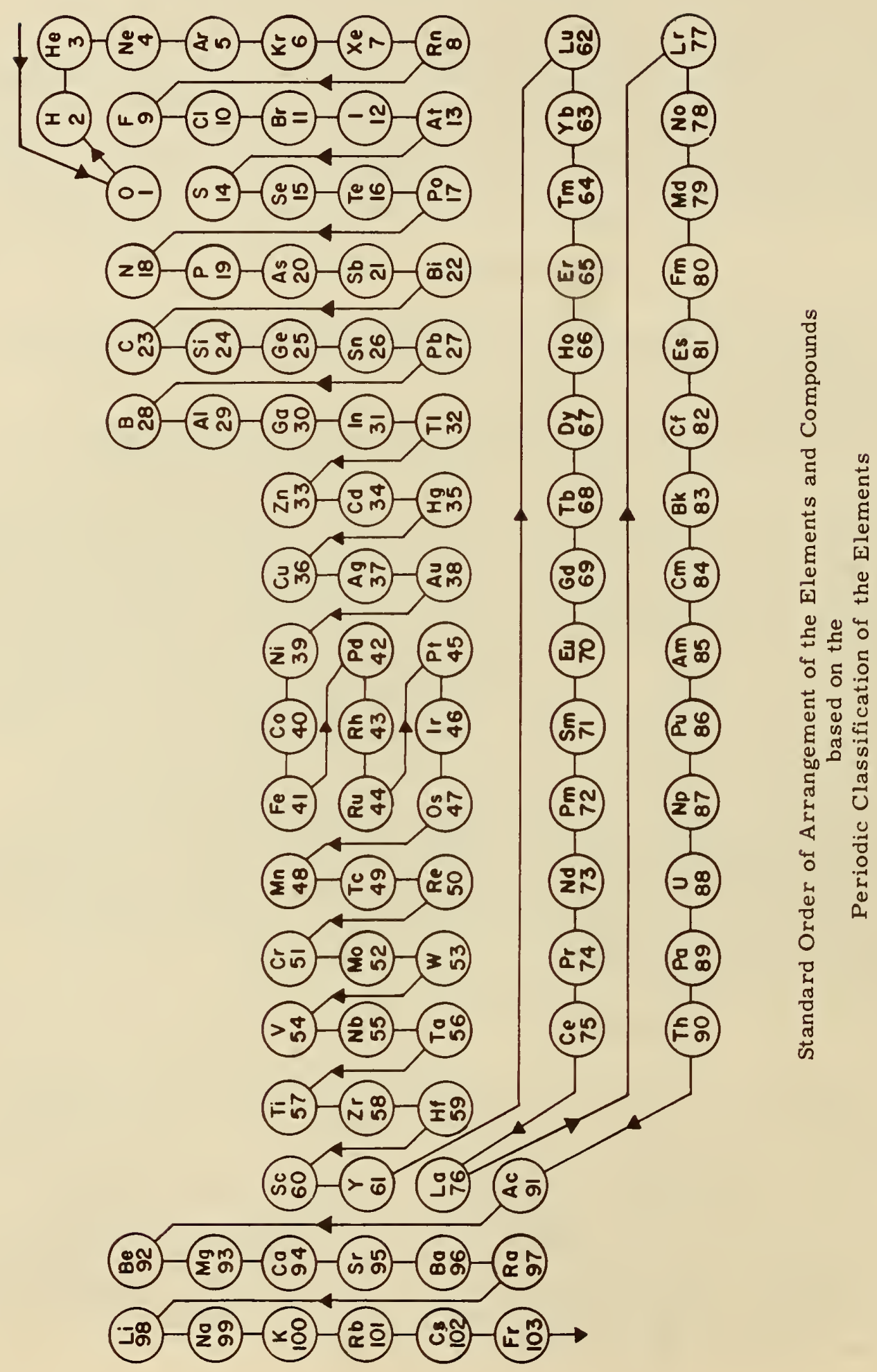




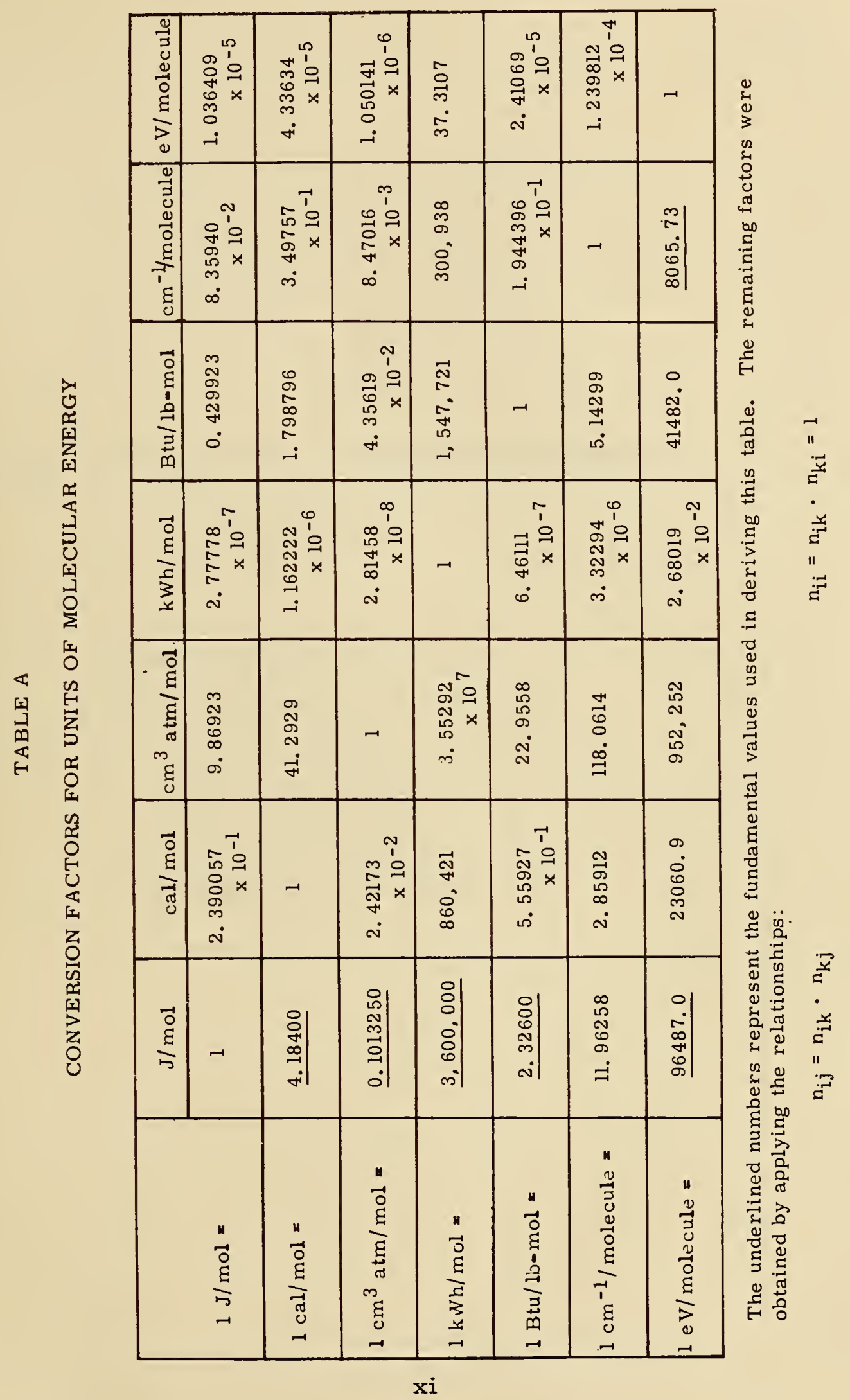



TABLES OF SELECTED VALUES OF PROPERTIES

\section{SERIES I}

Enthalpy of Formation at $0 \mathrm{~K}$ Enthalpy of Formation at 298.15 K Gibbs Energy of Formation at 298.15 K Enthalpy at $298.15 \mathrm{~K}$ Entropy at $298.15 \mathrm{~K}$ Heat Capacity at 298.15 K 


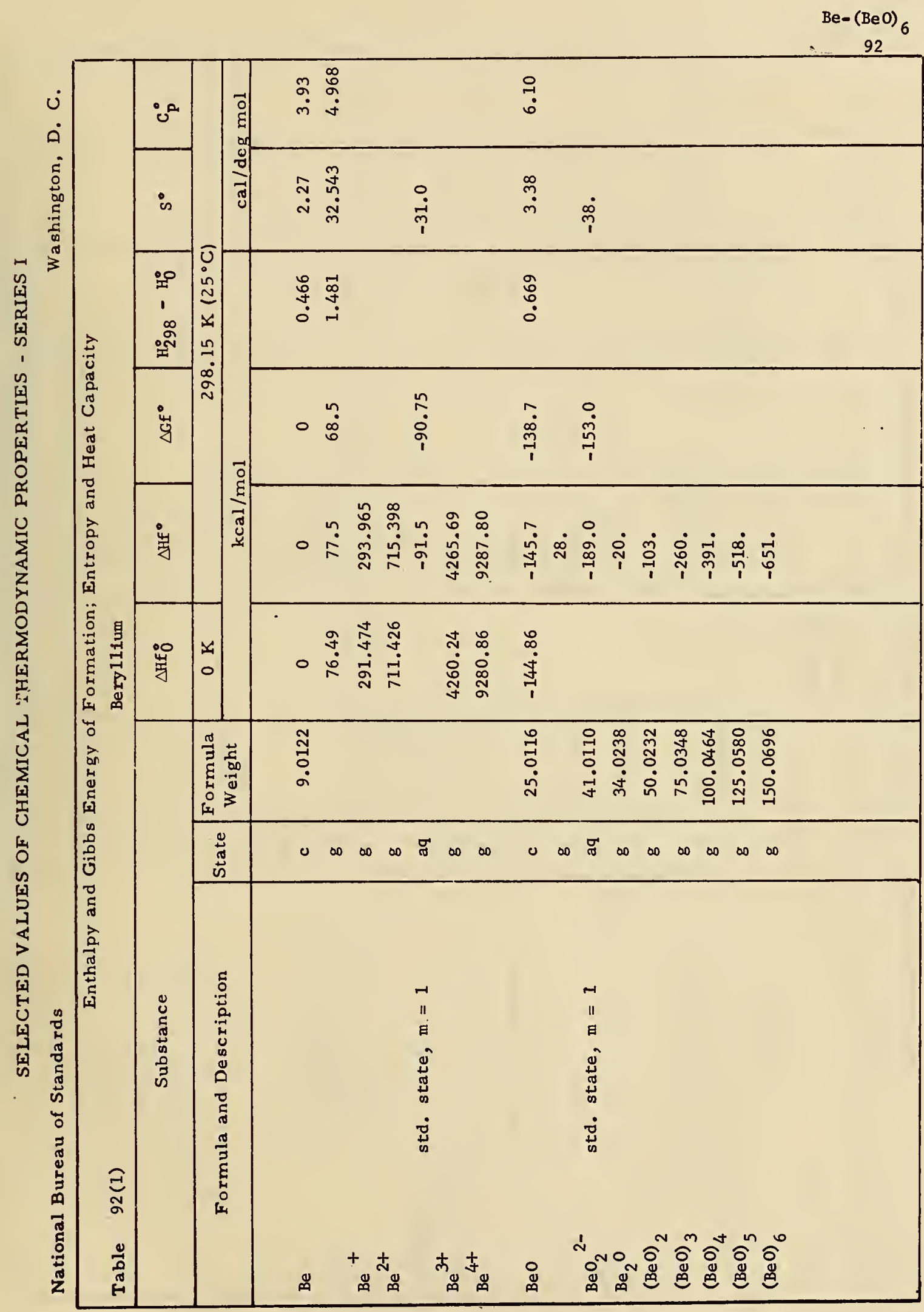




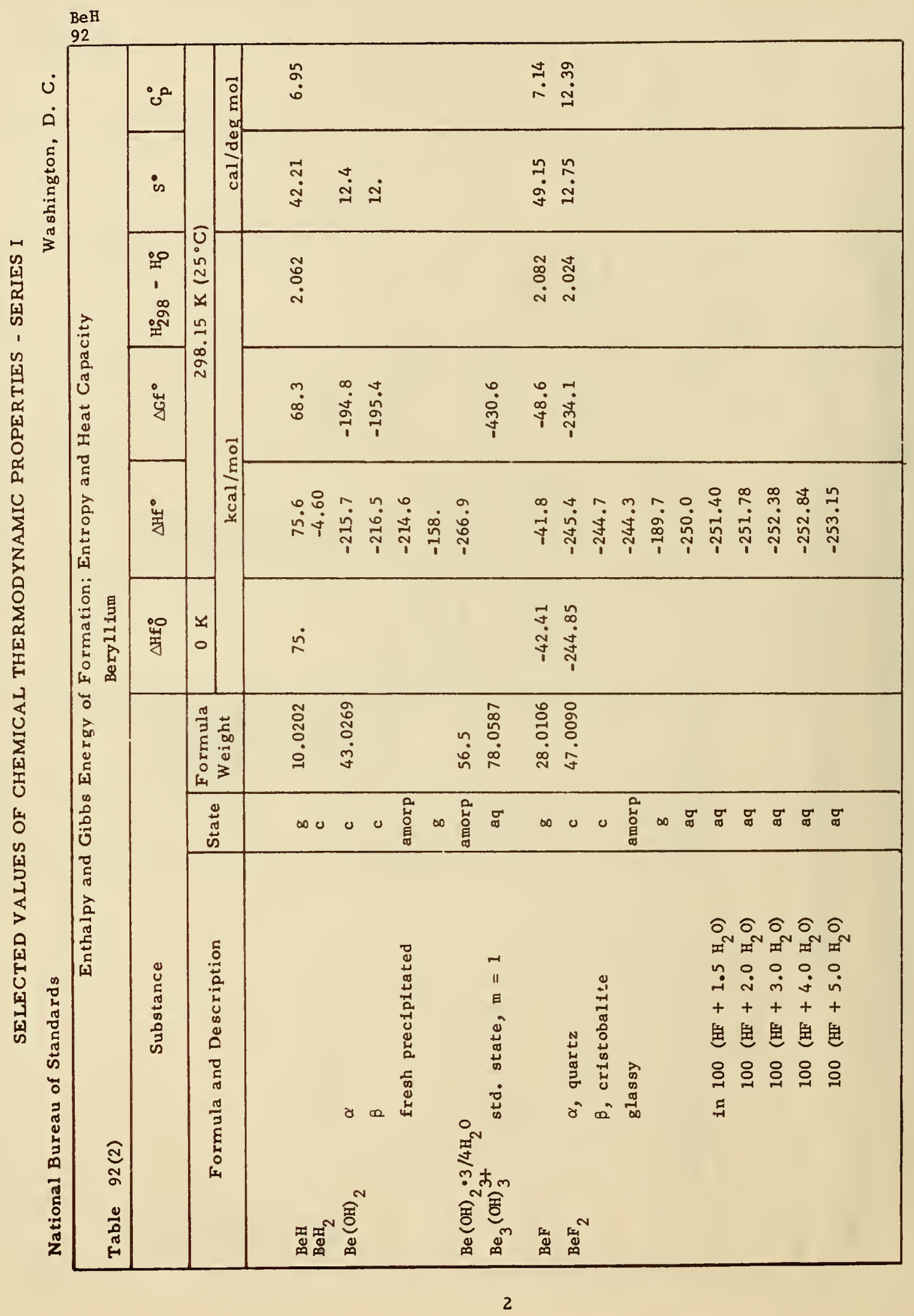




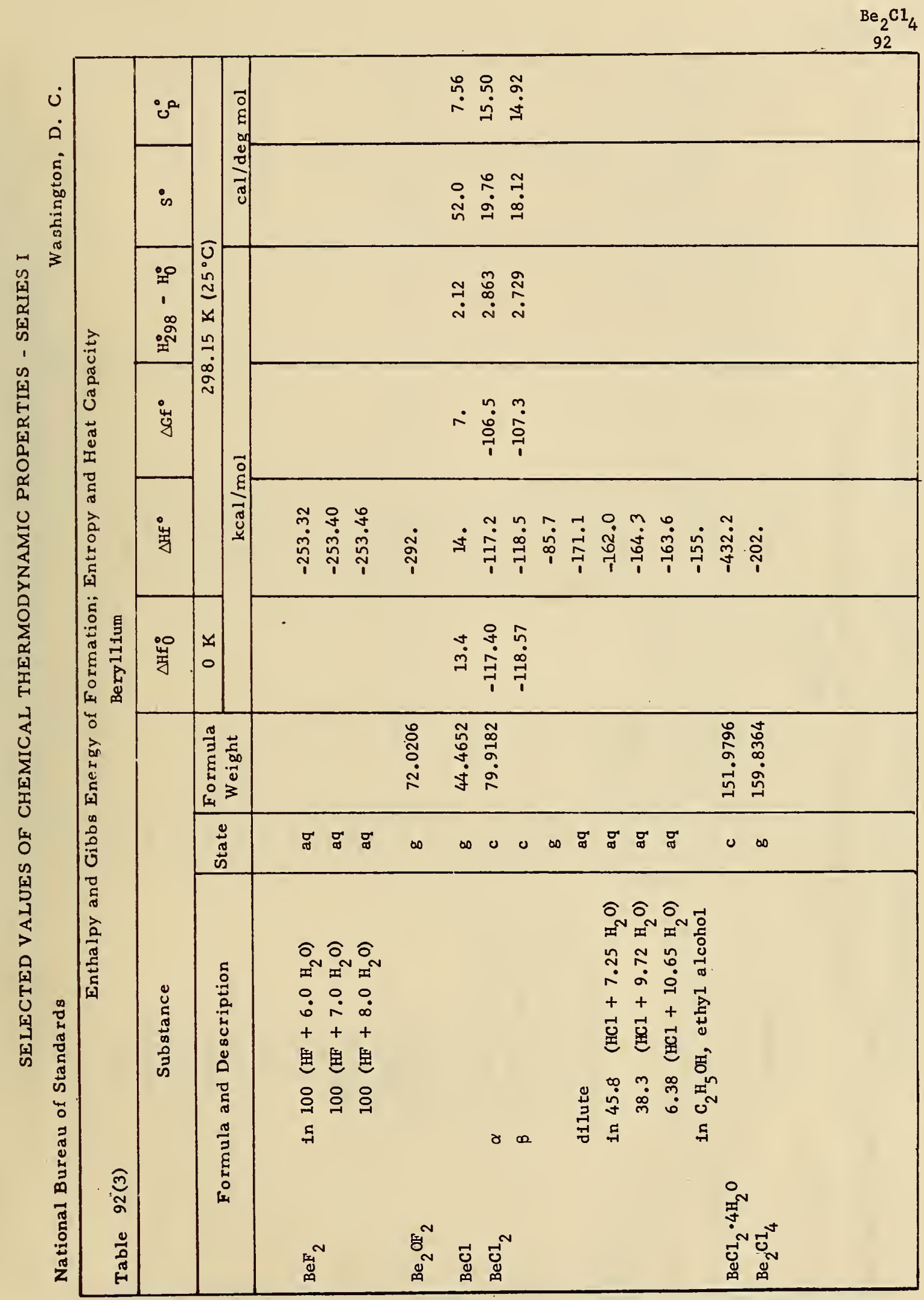




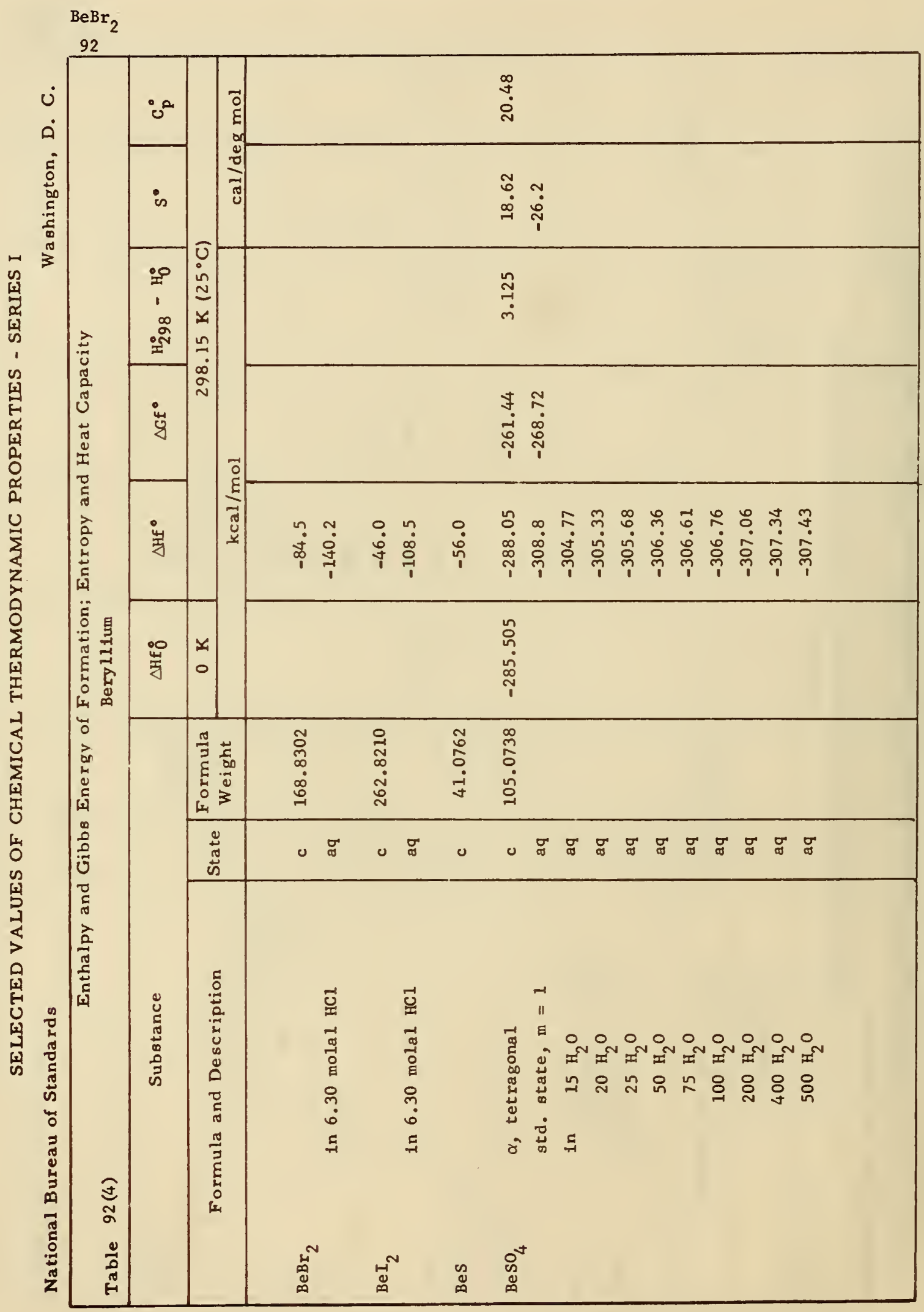




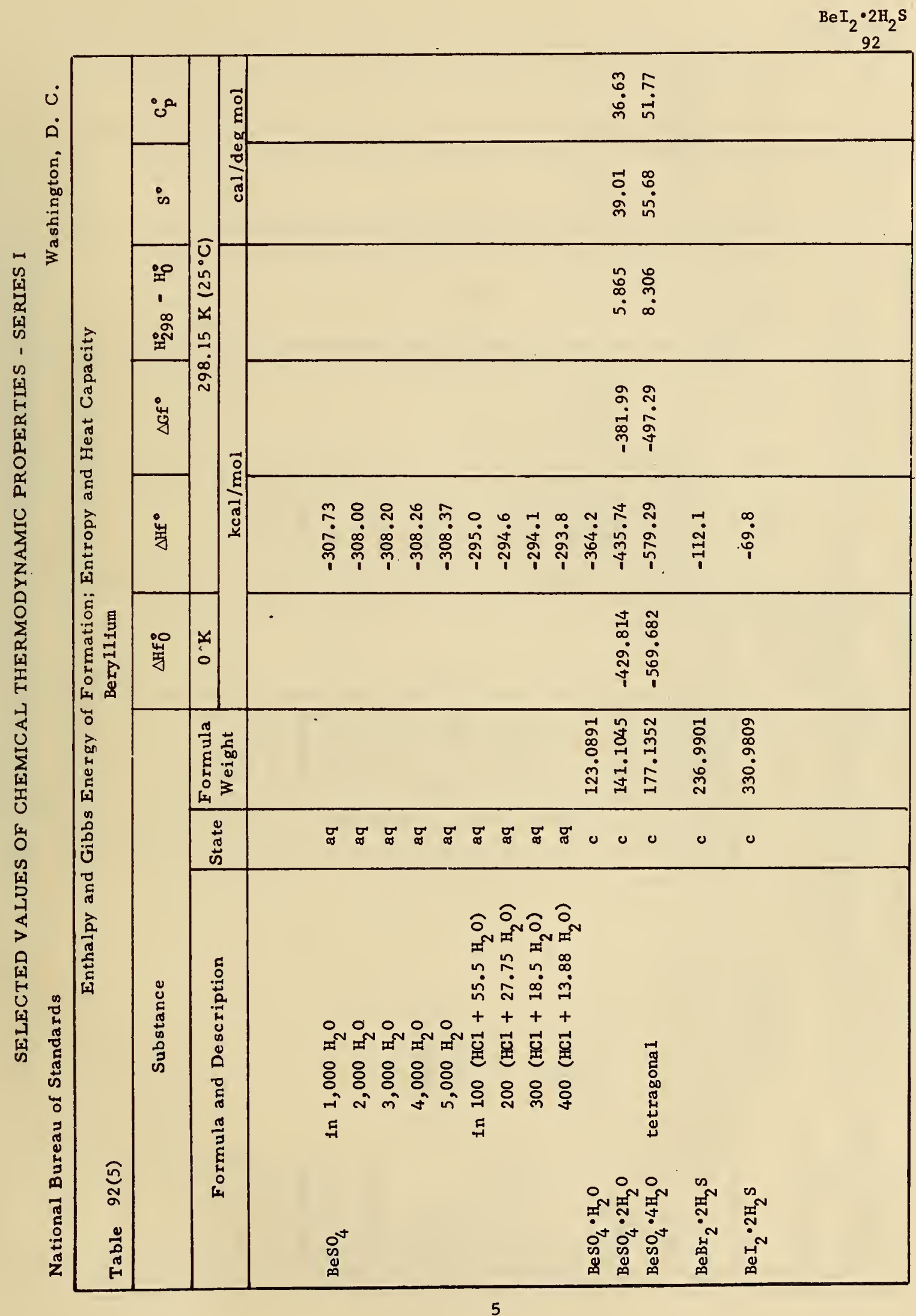




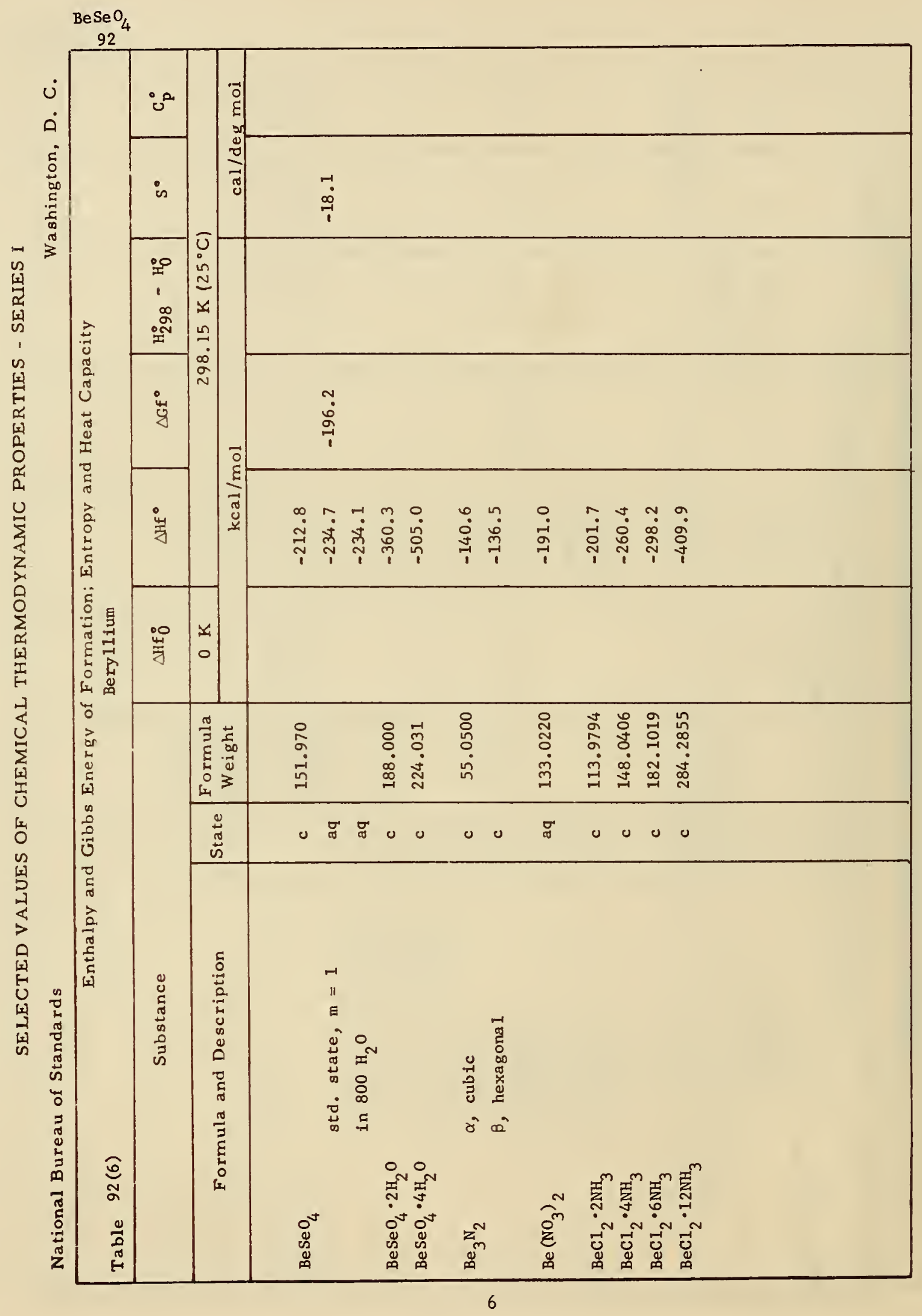




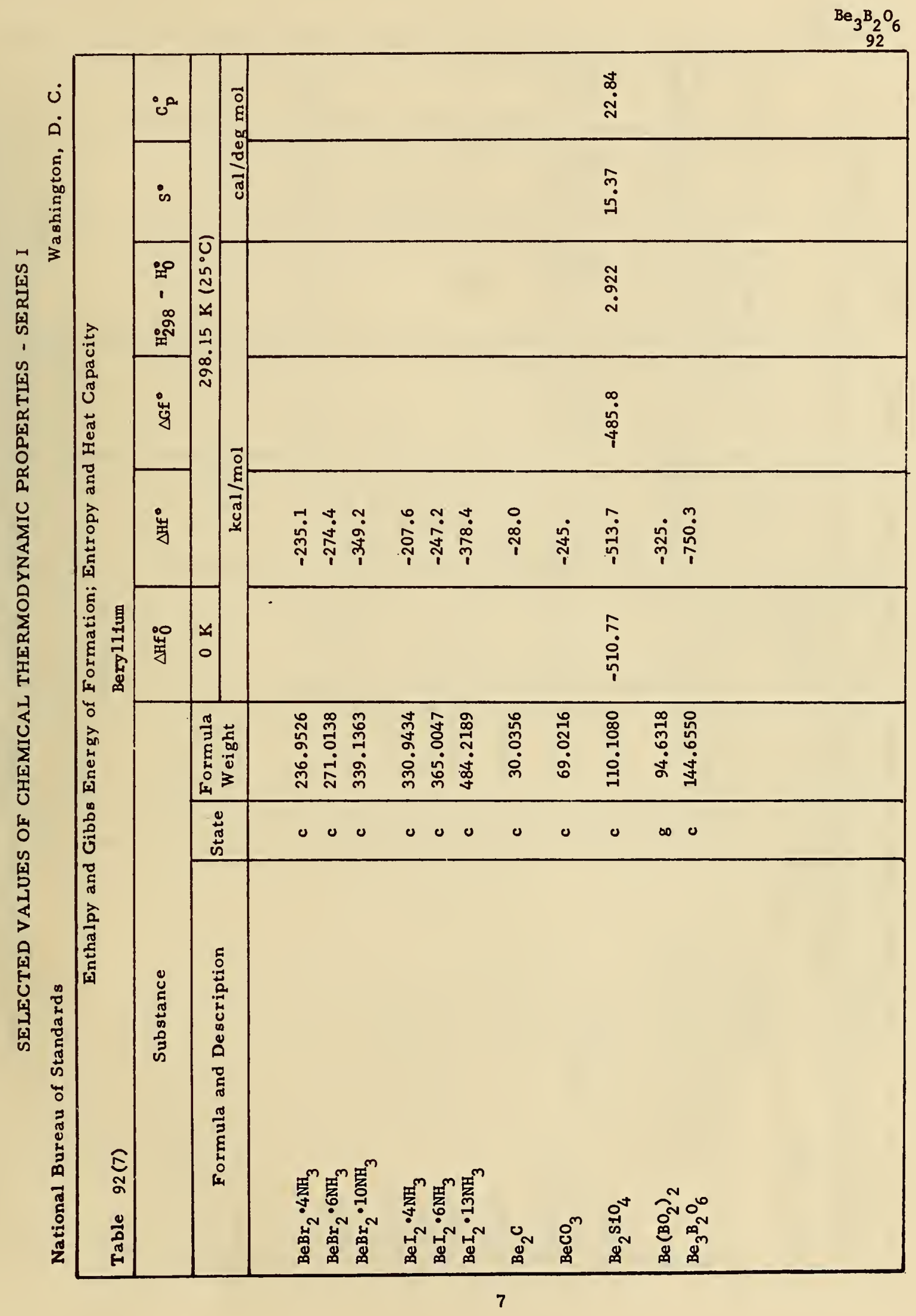




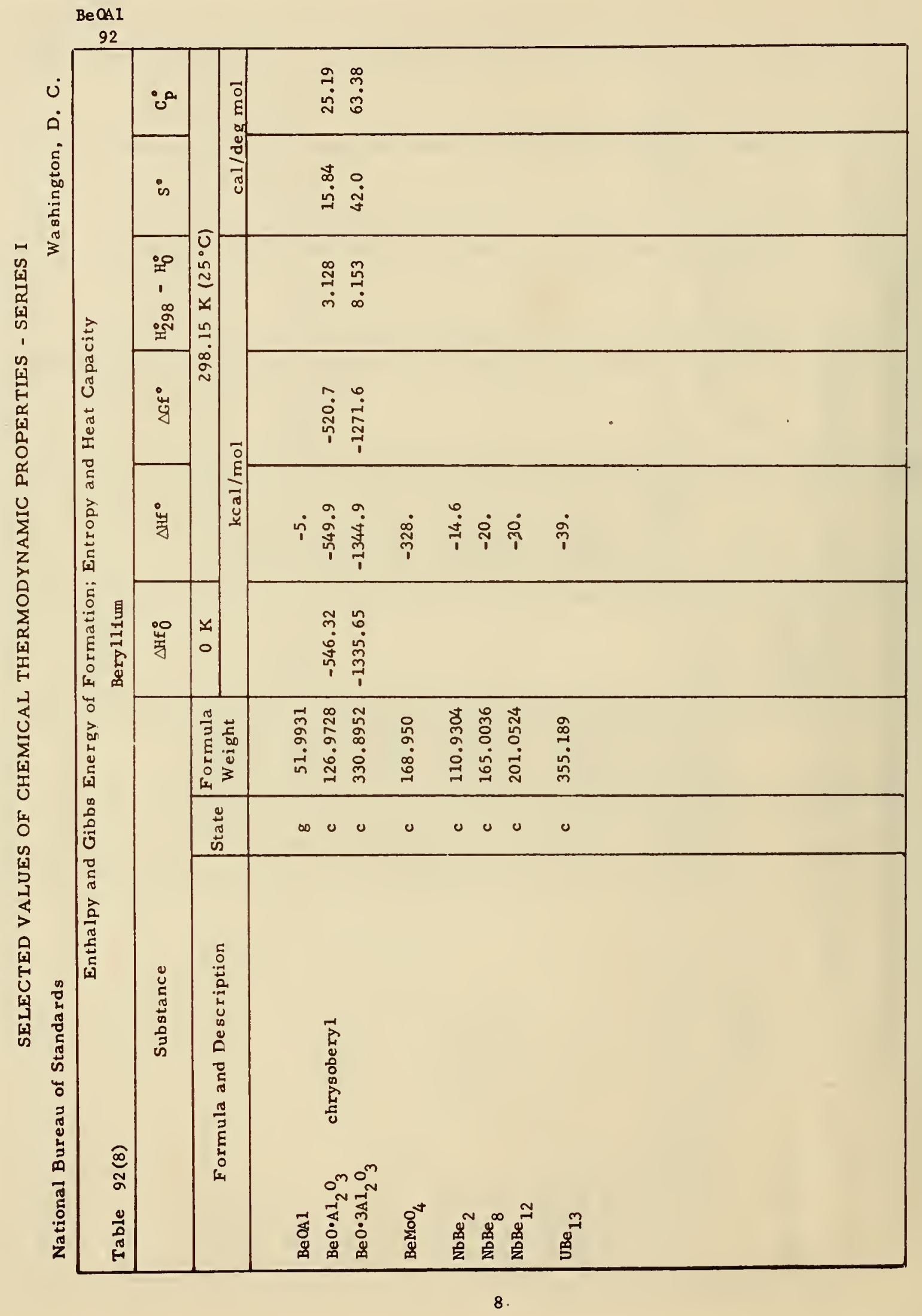




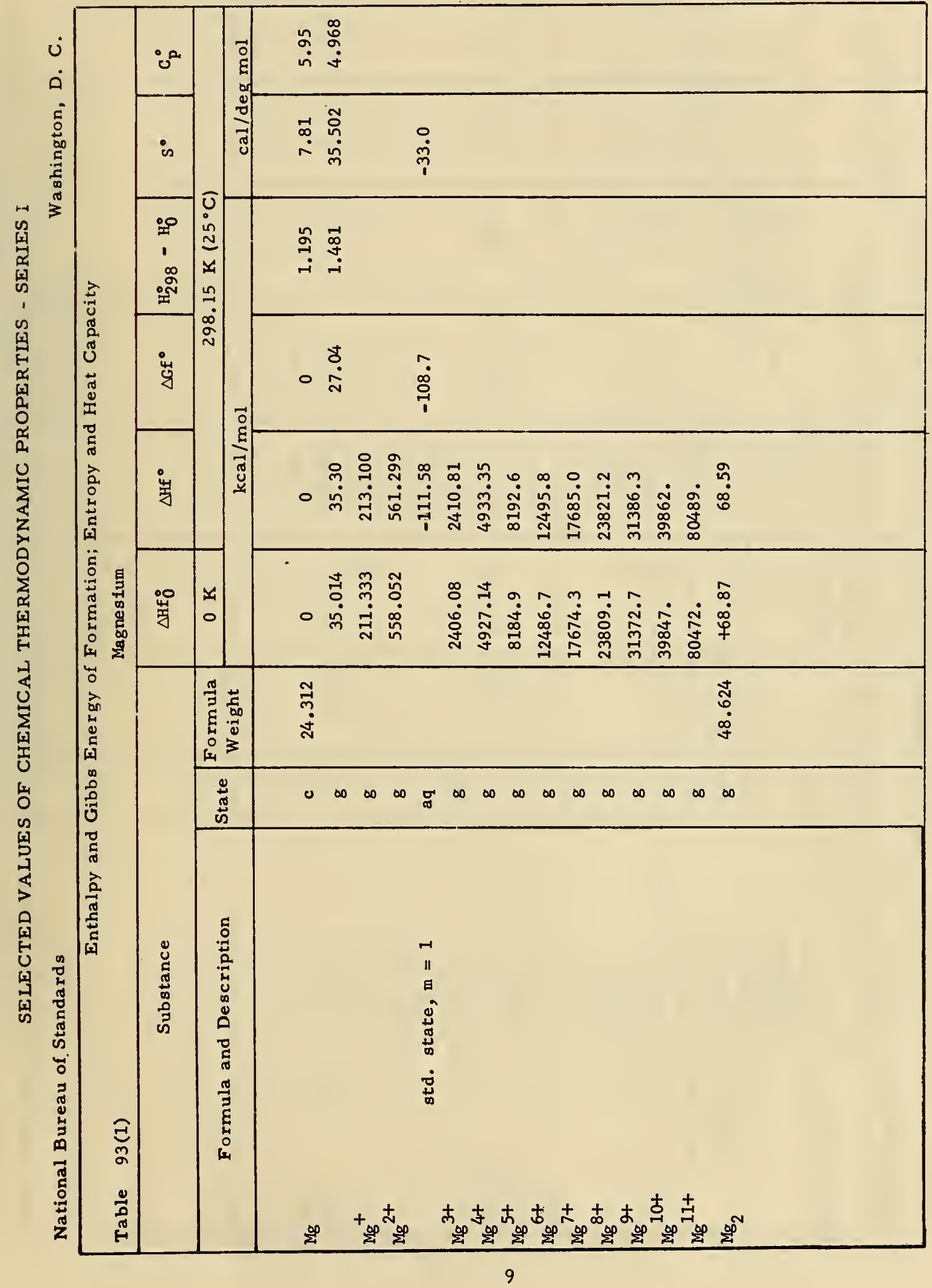




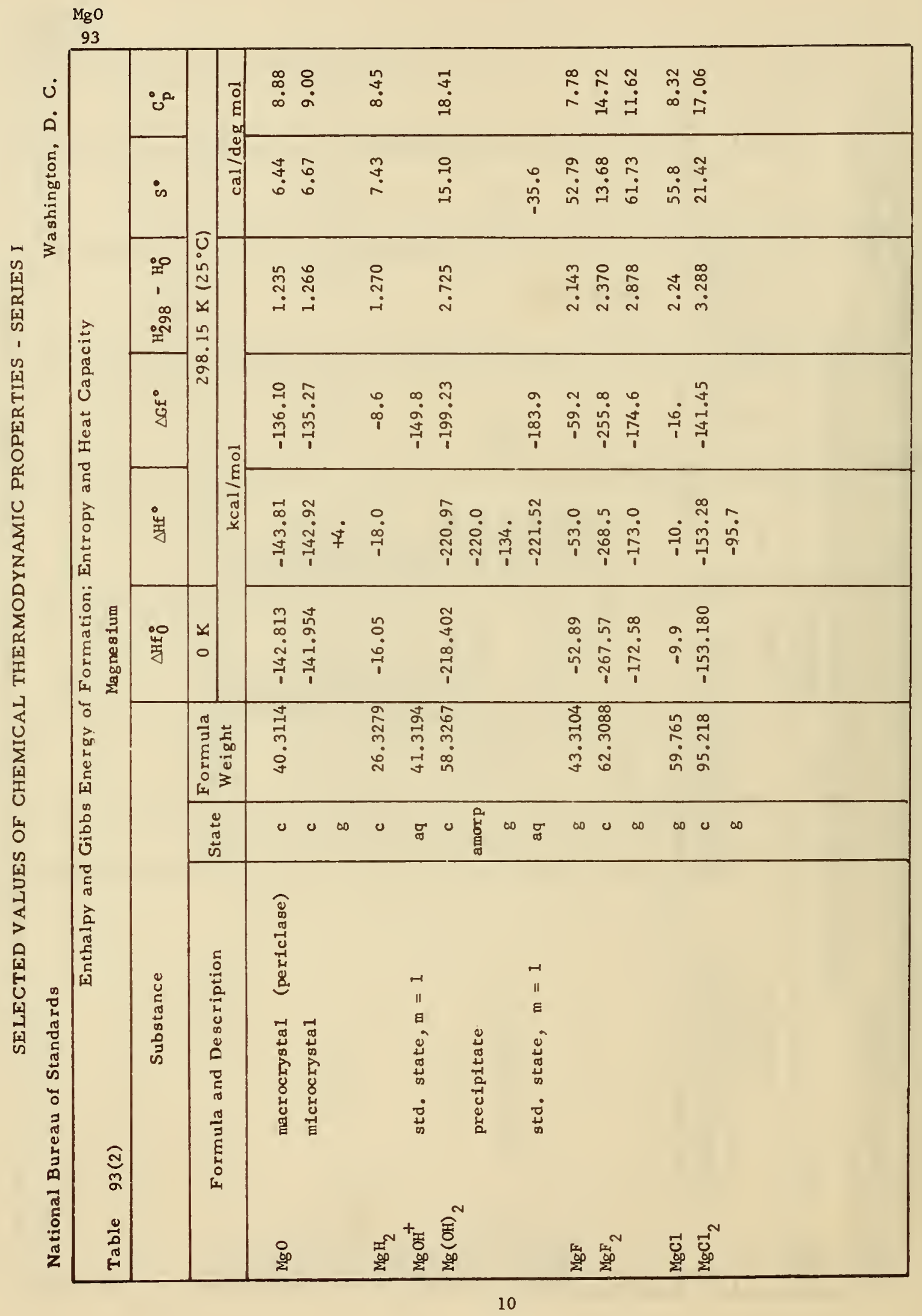




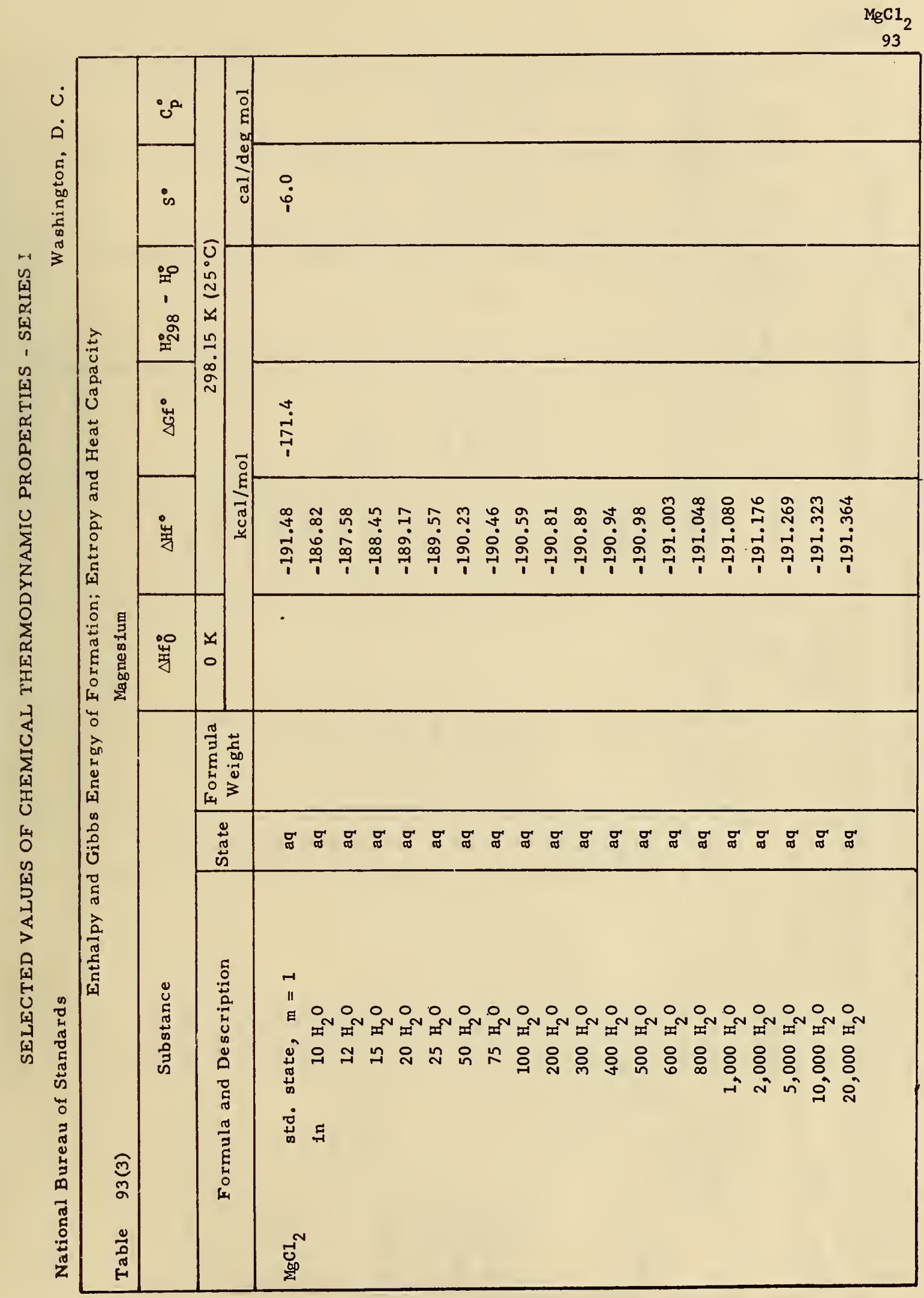




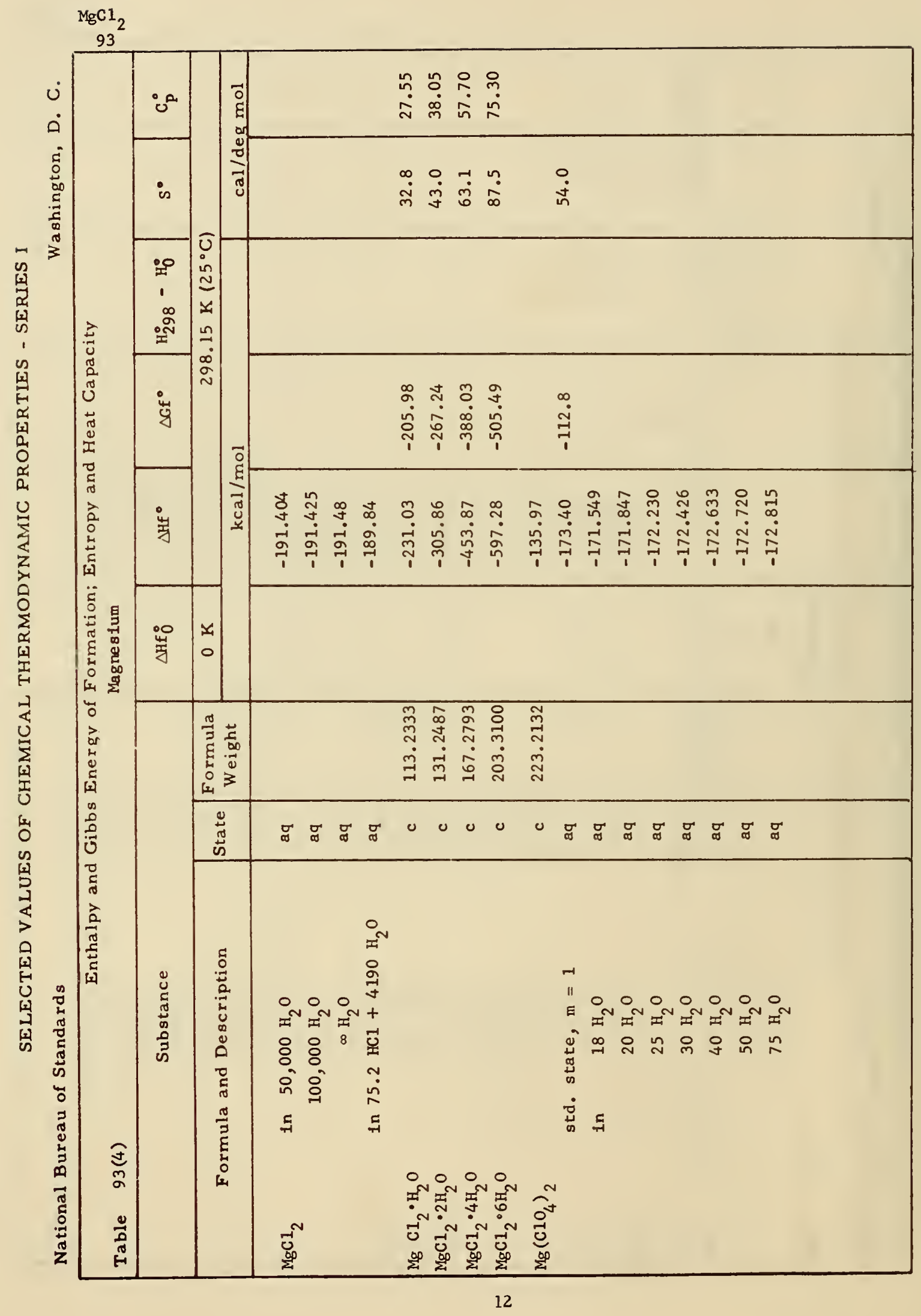




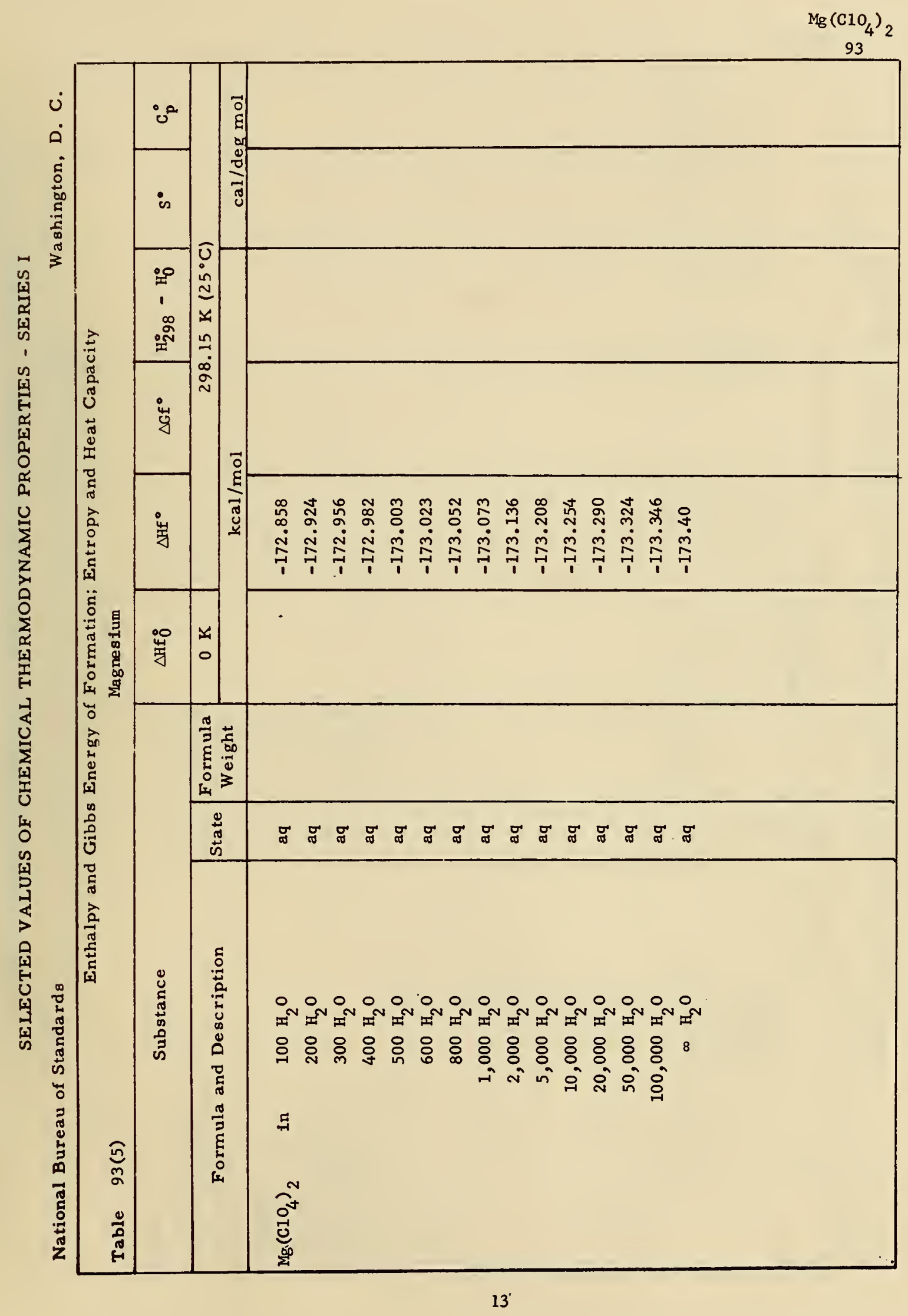




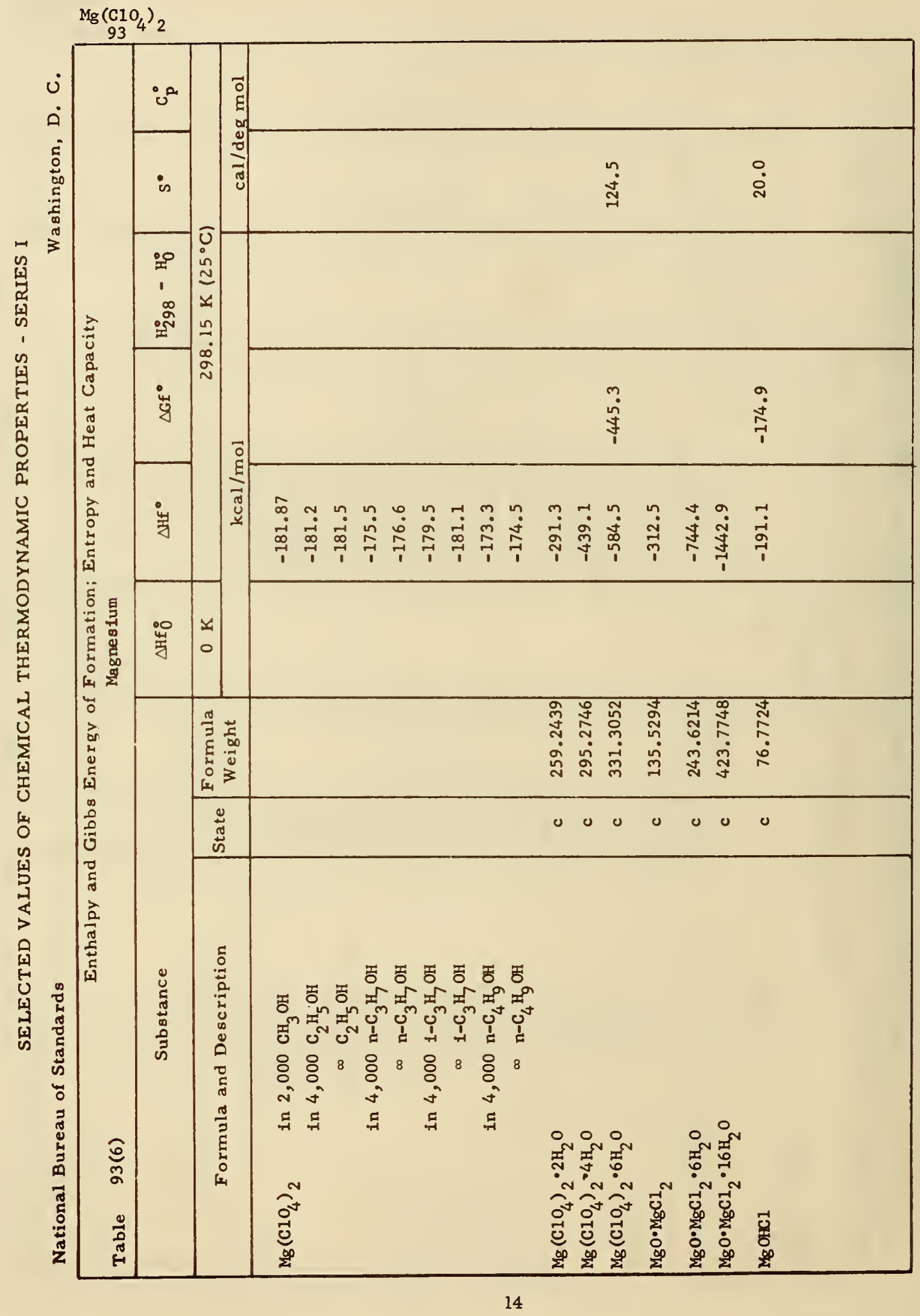




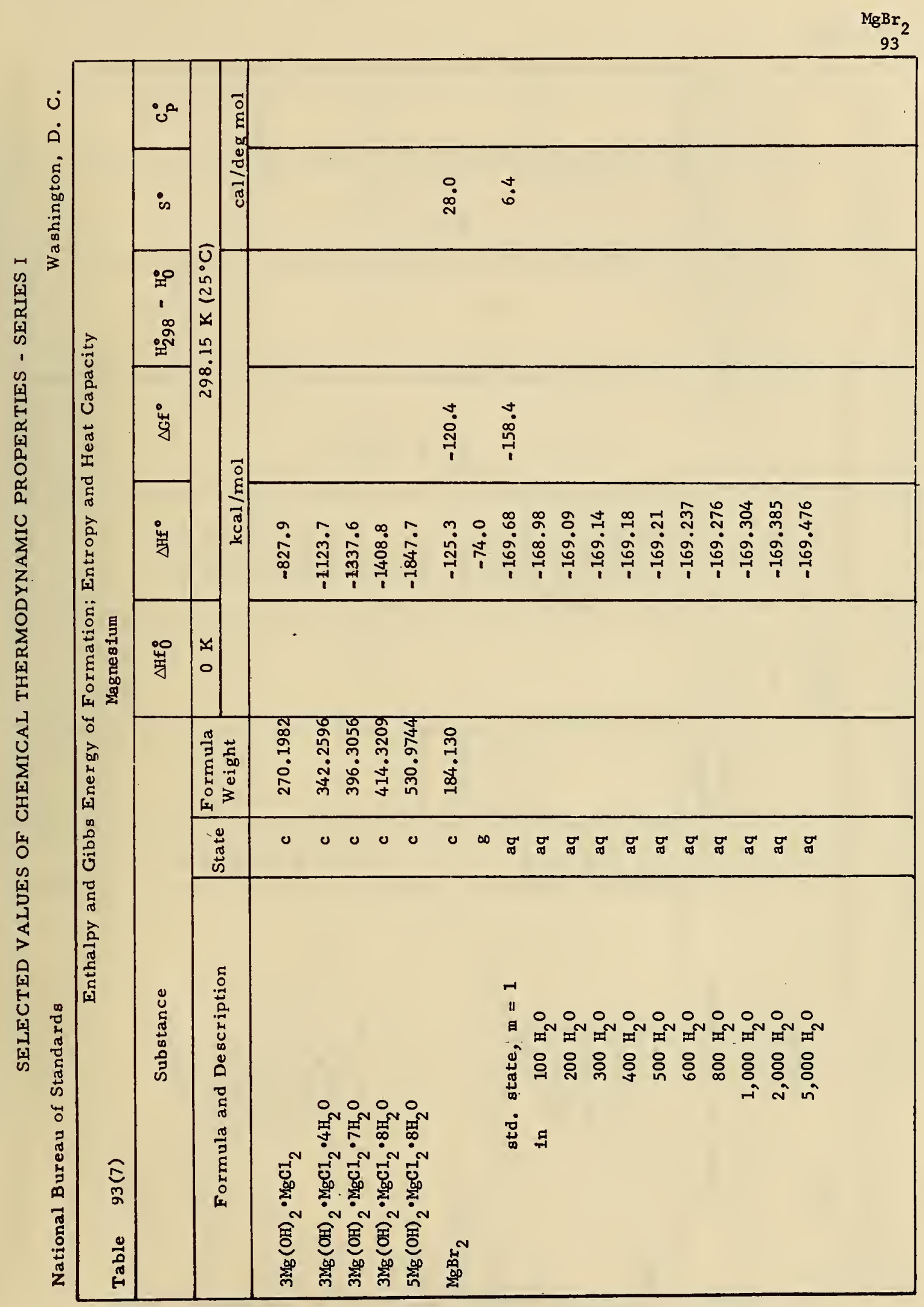




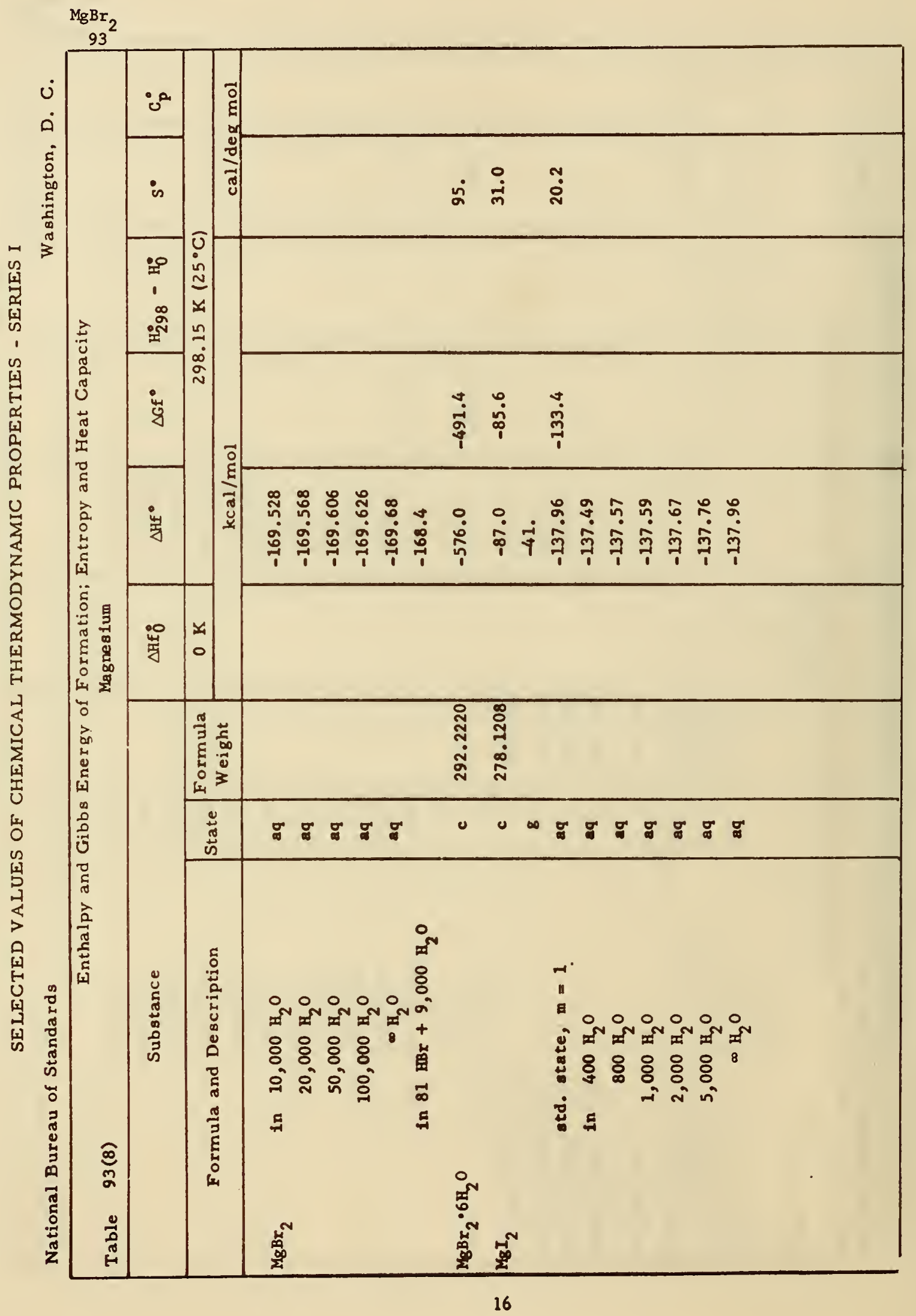




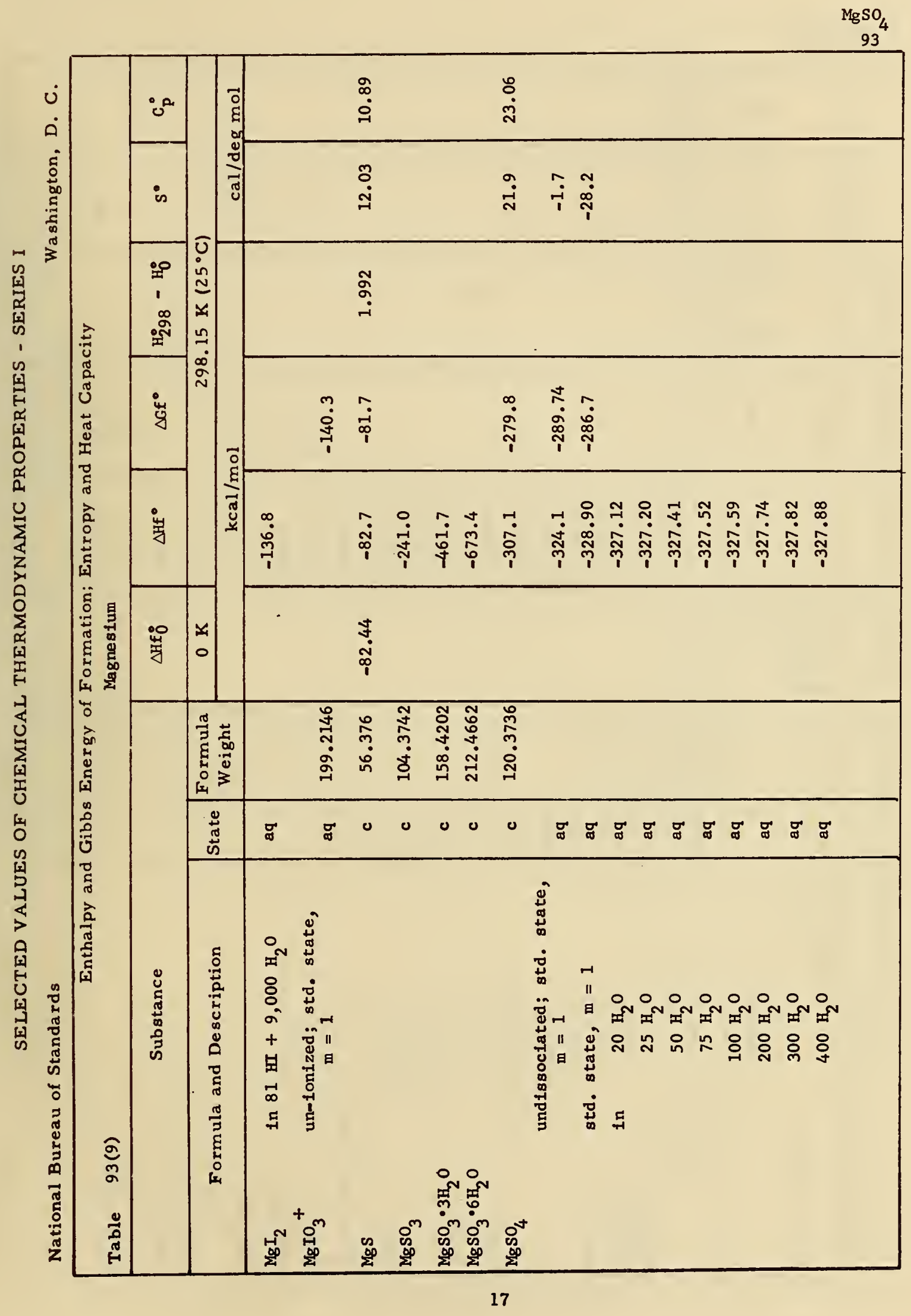




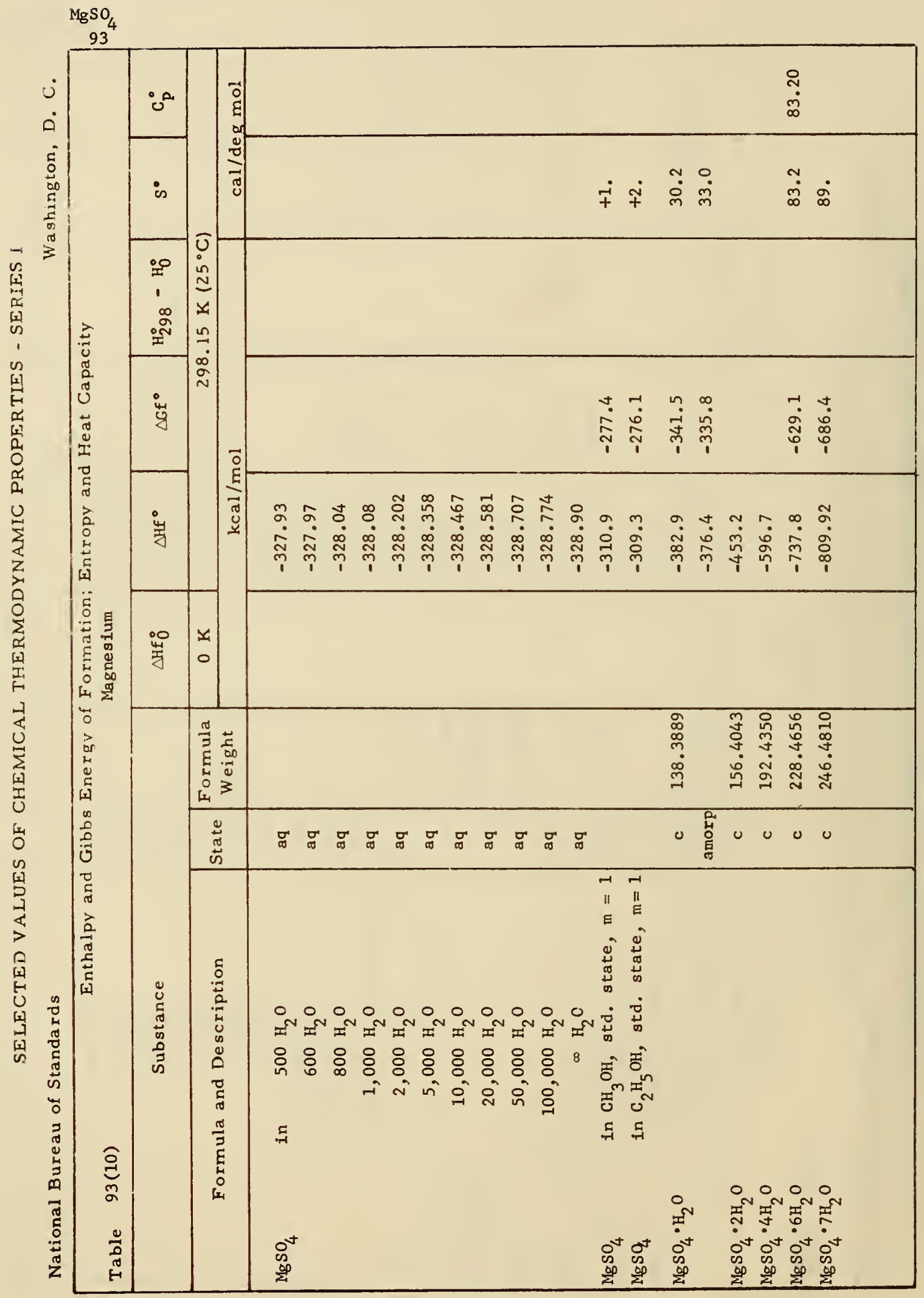




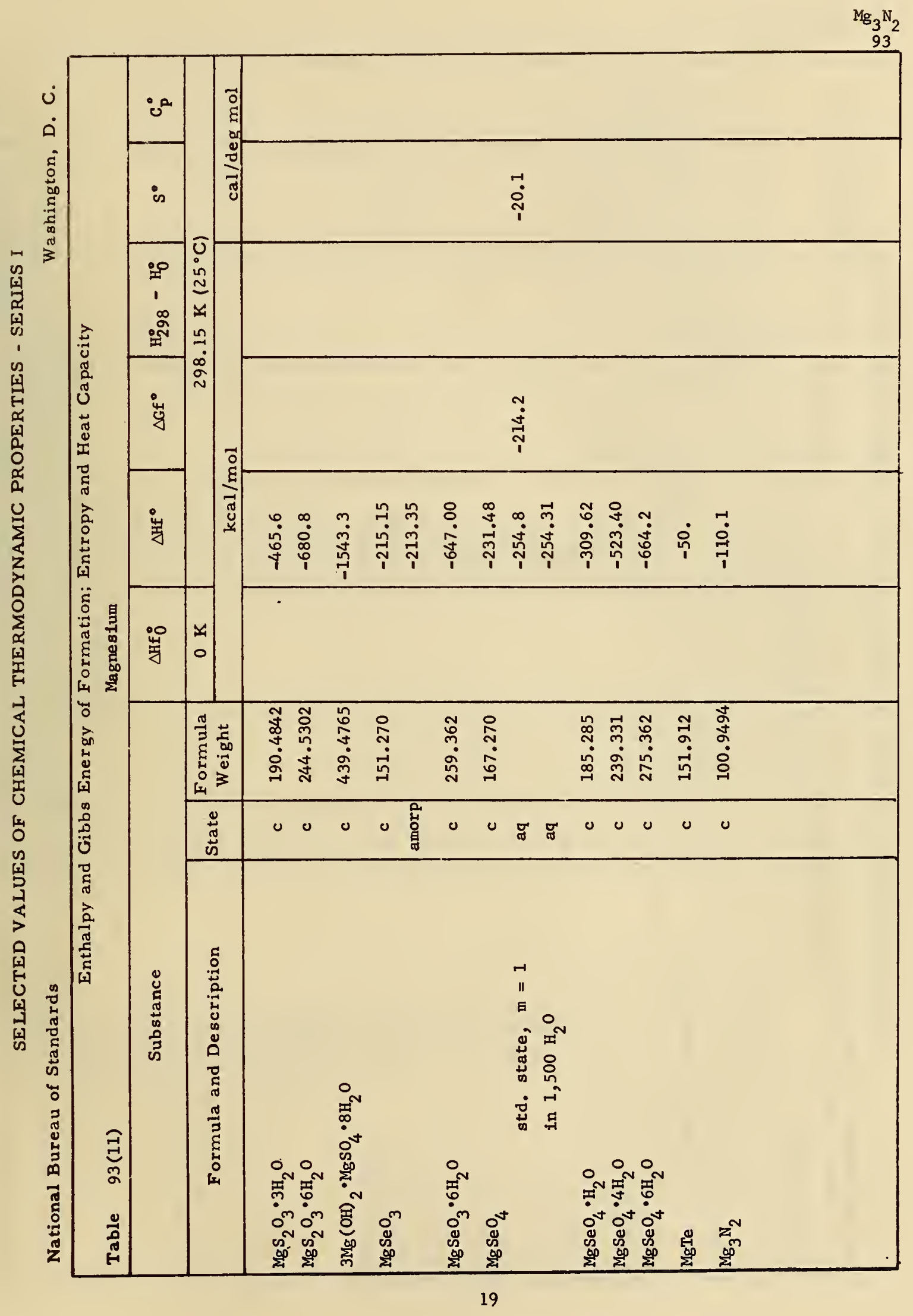




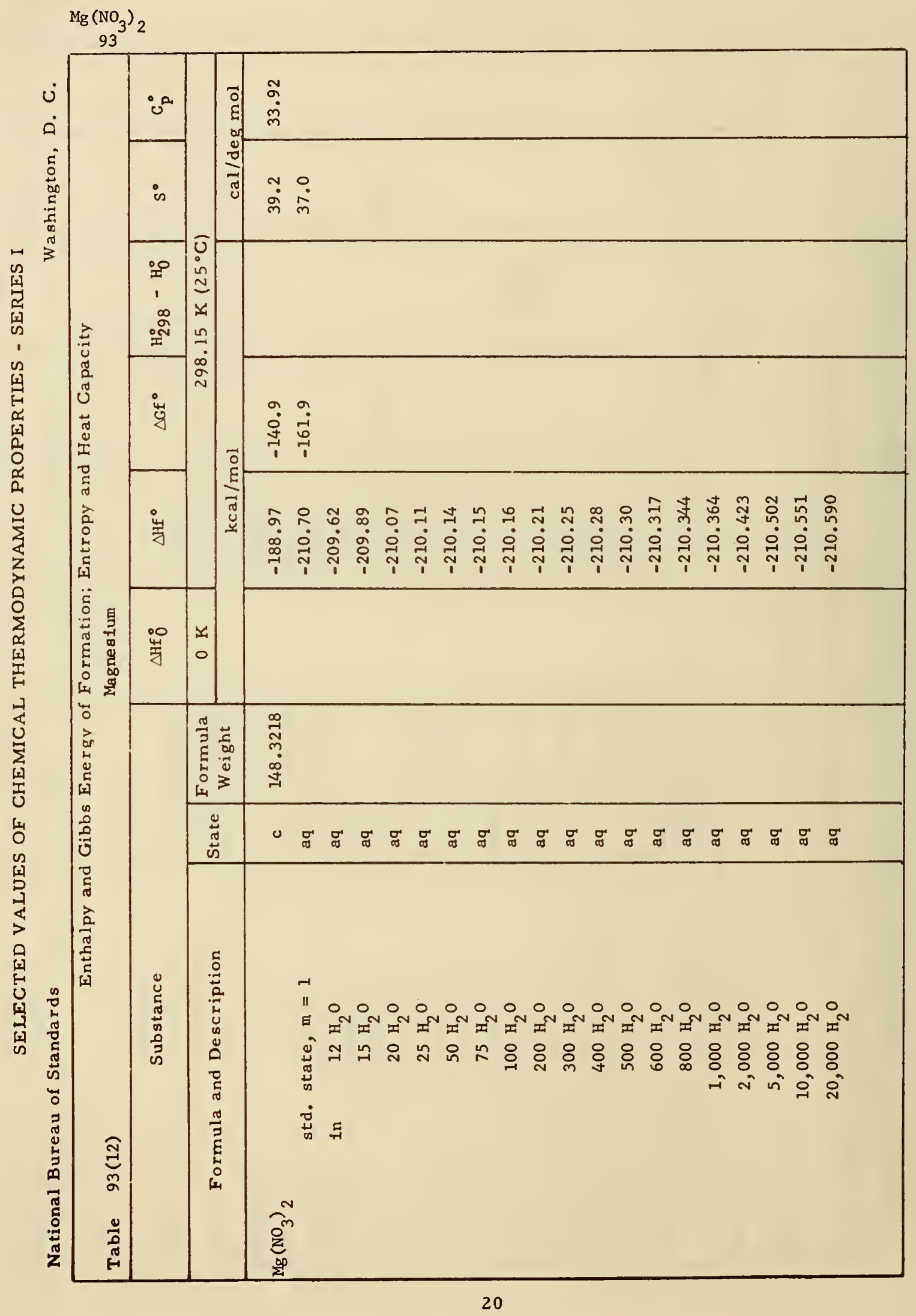


$3 \mathrm{MgSO}_{3} \cdot\left(\mathrm{NH}_{4}\right)_{2} \mathrm{SO}_{3} \cdot 18 \mathrm{H}_{2} \mathrm{O}$

93

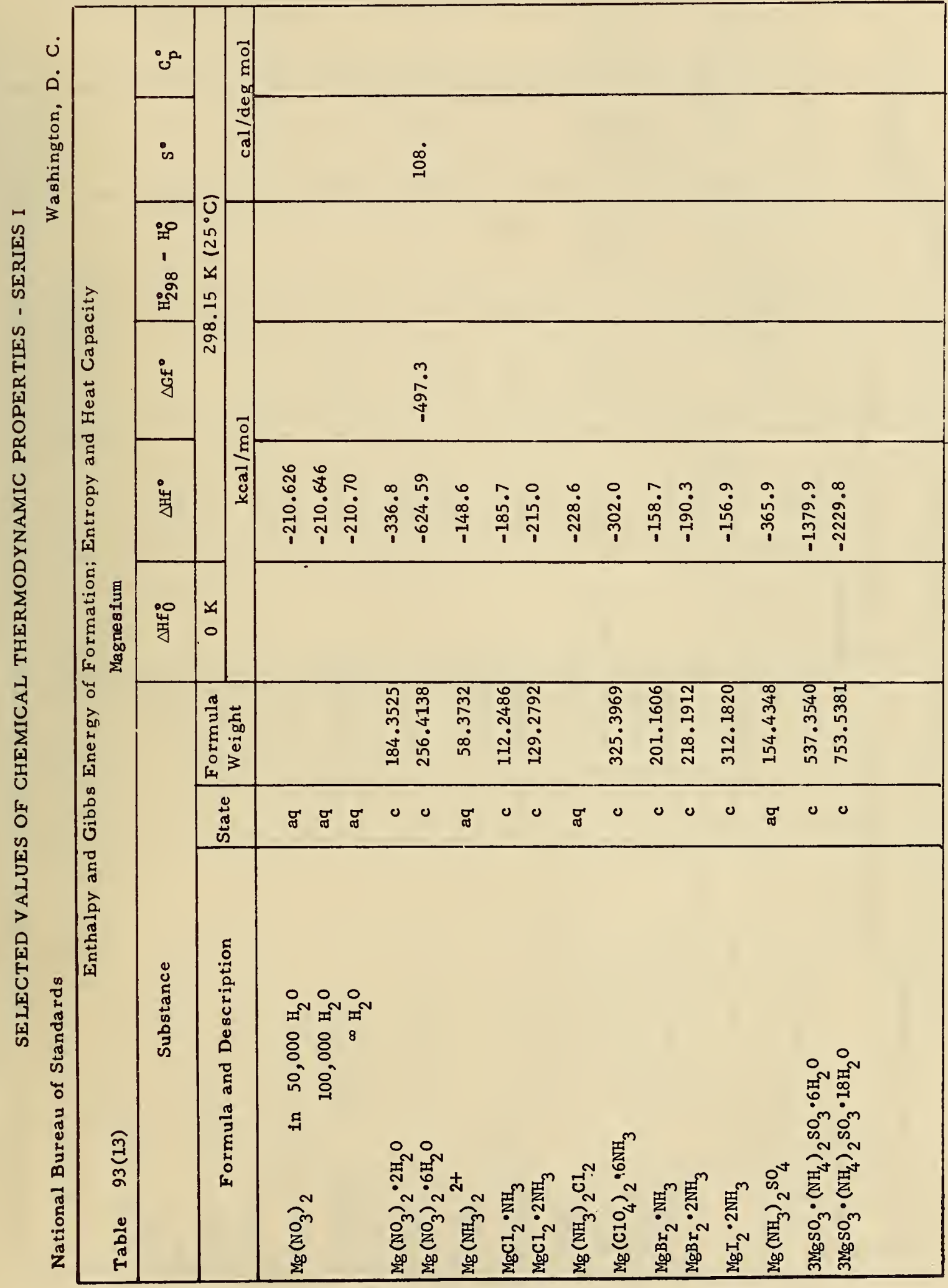




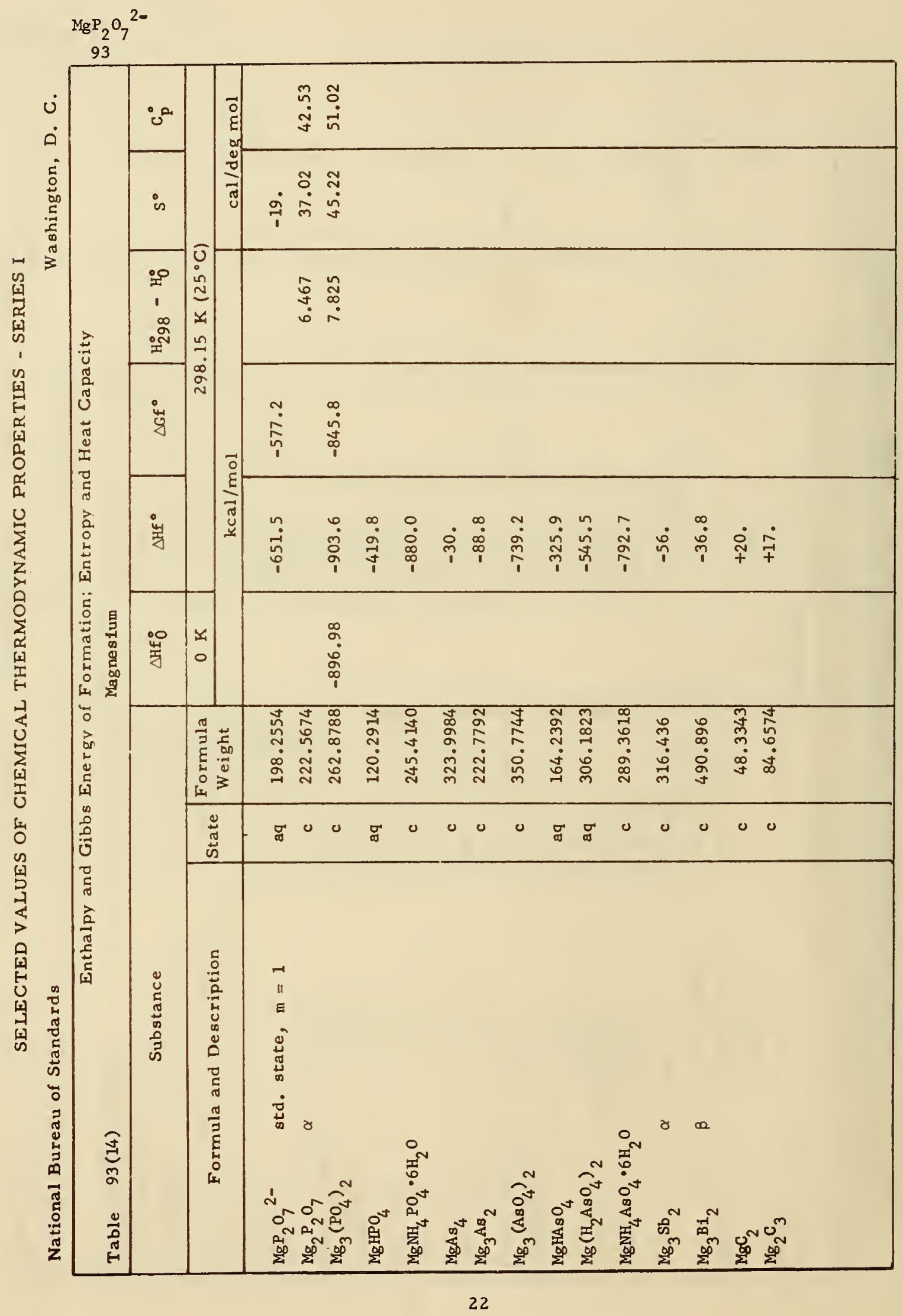




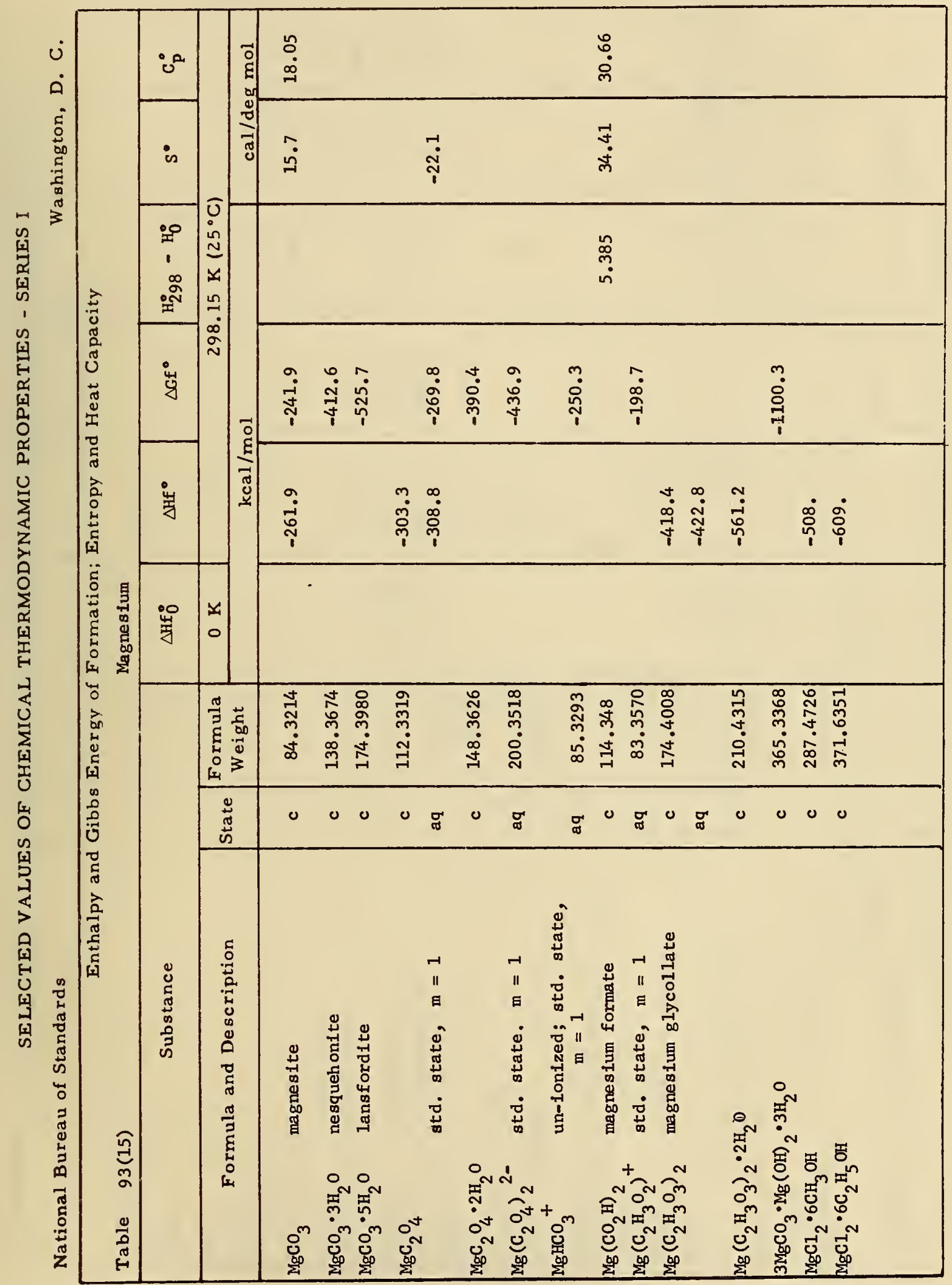




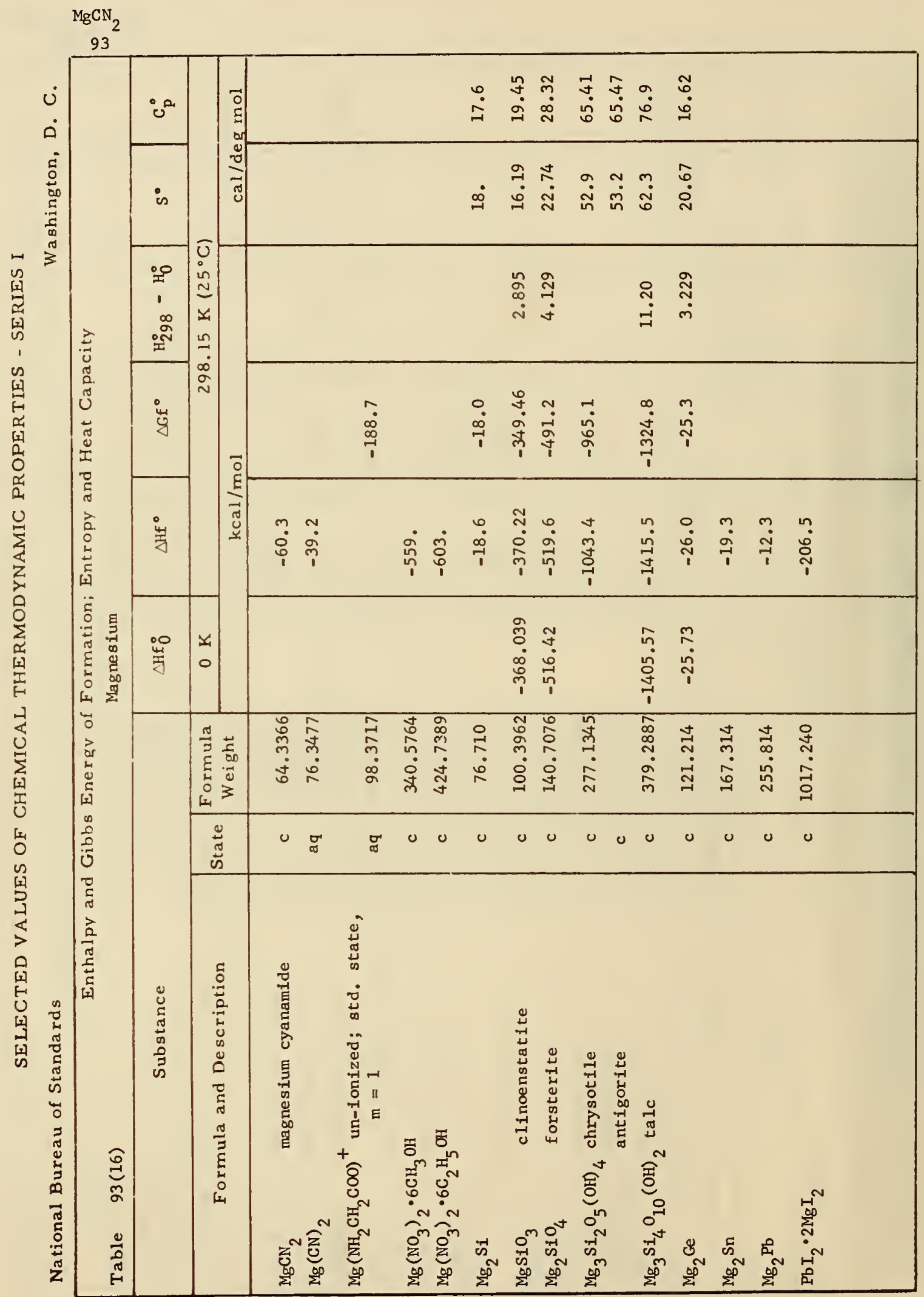




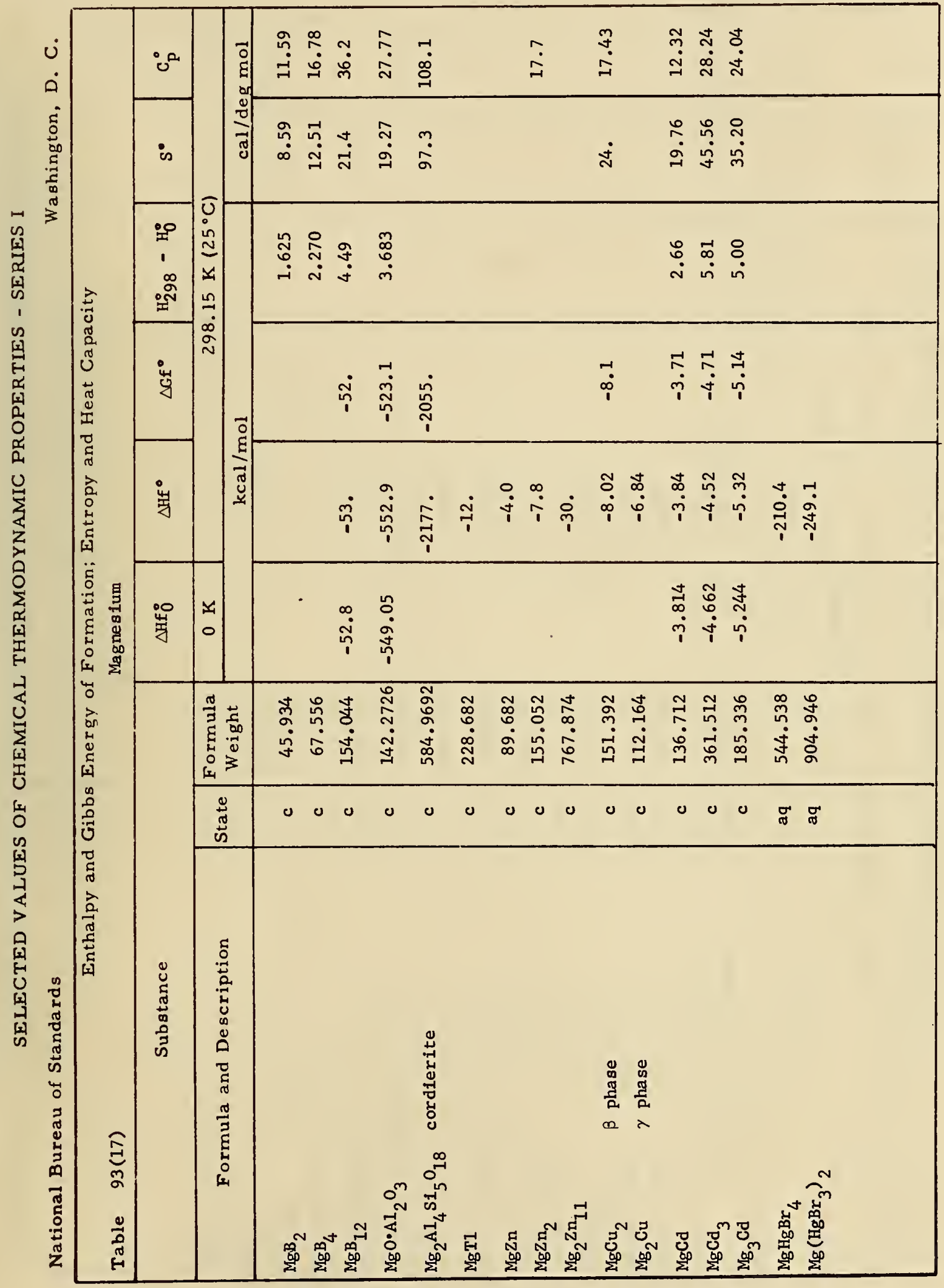




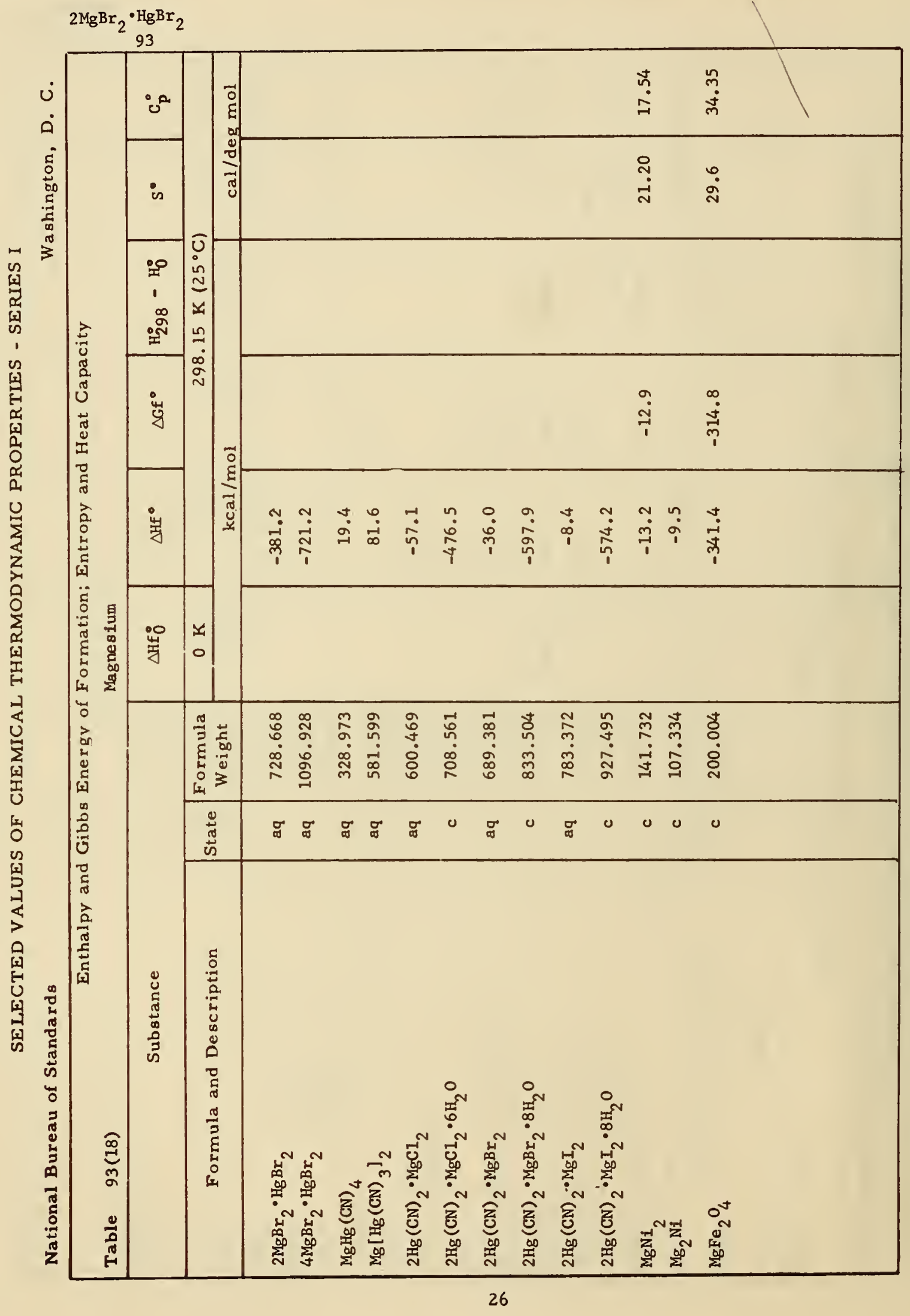




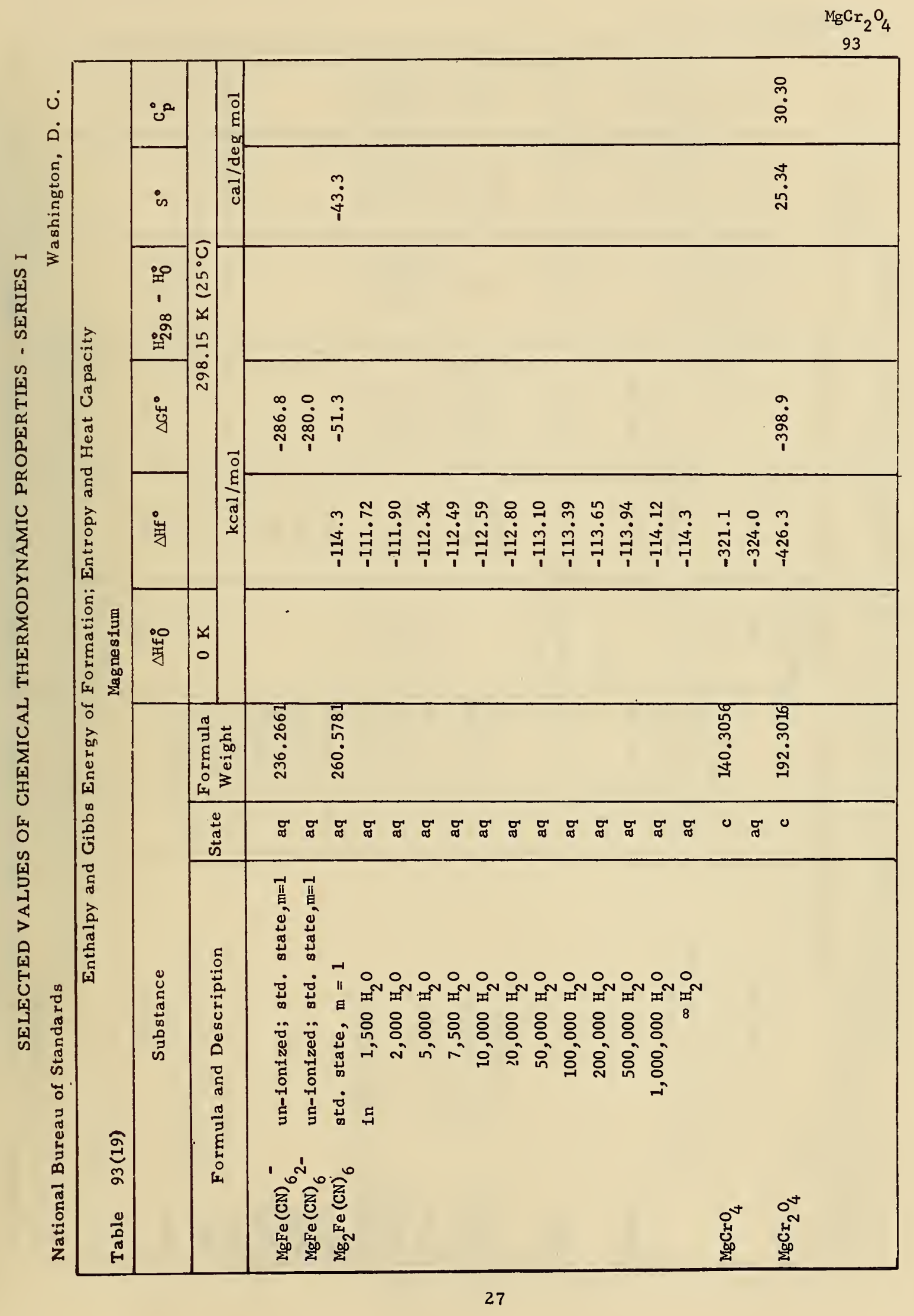




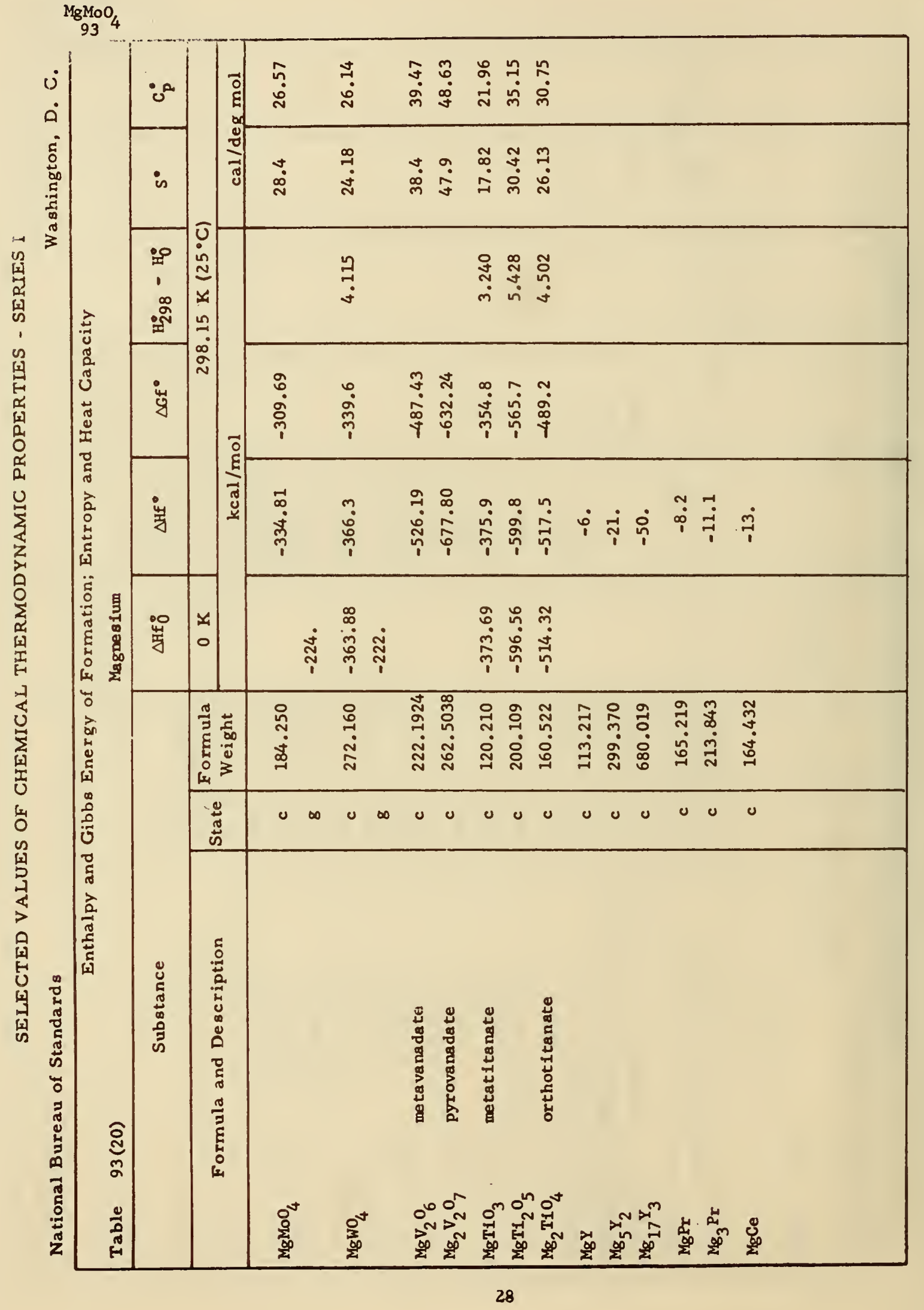




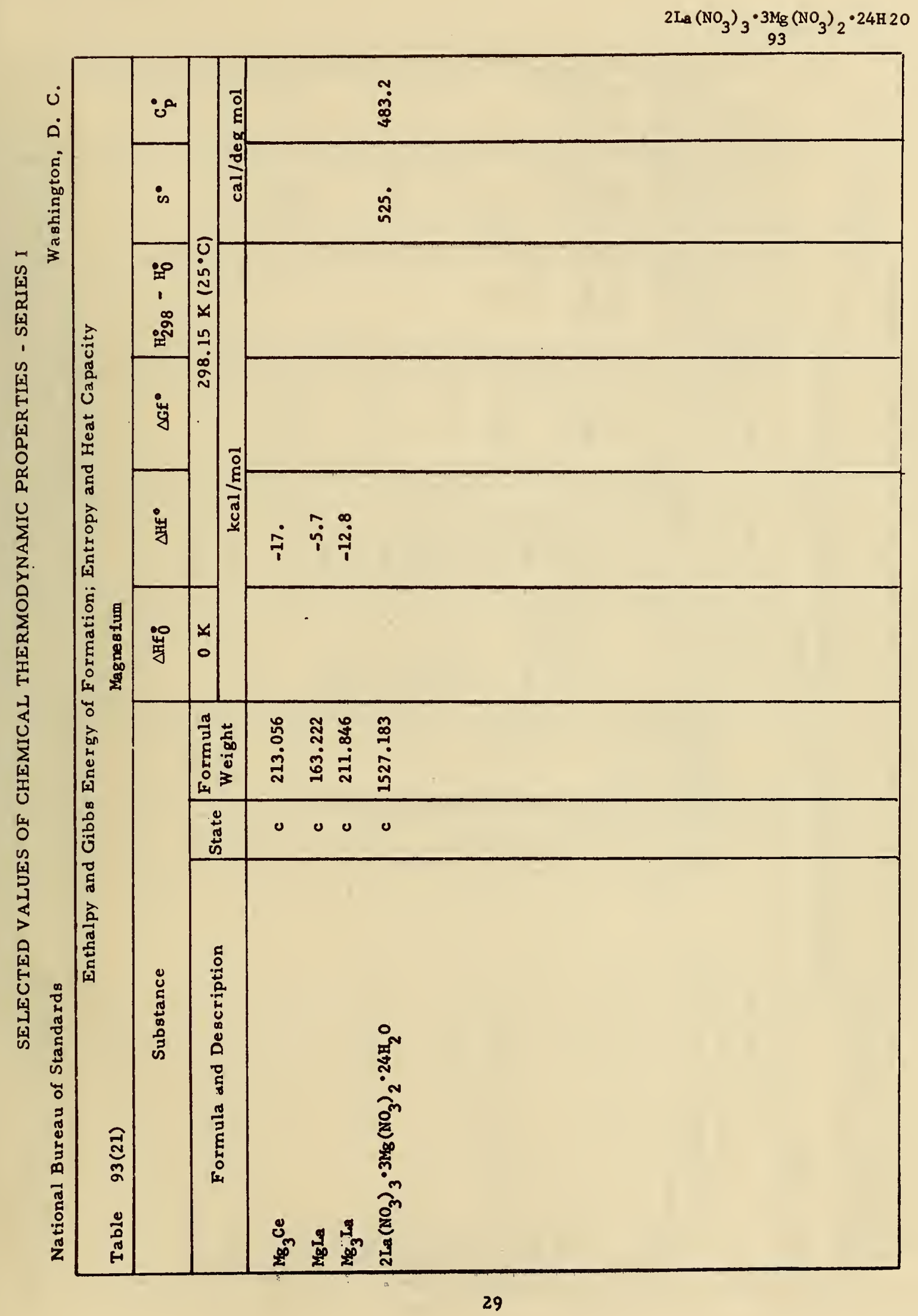




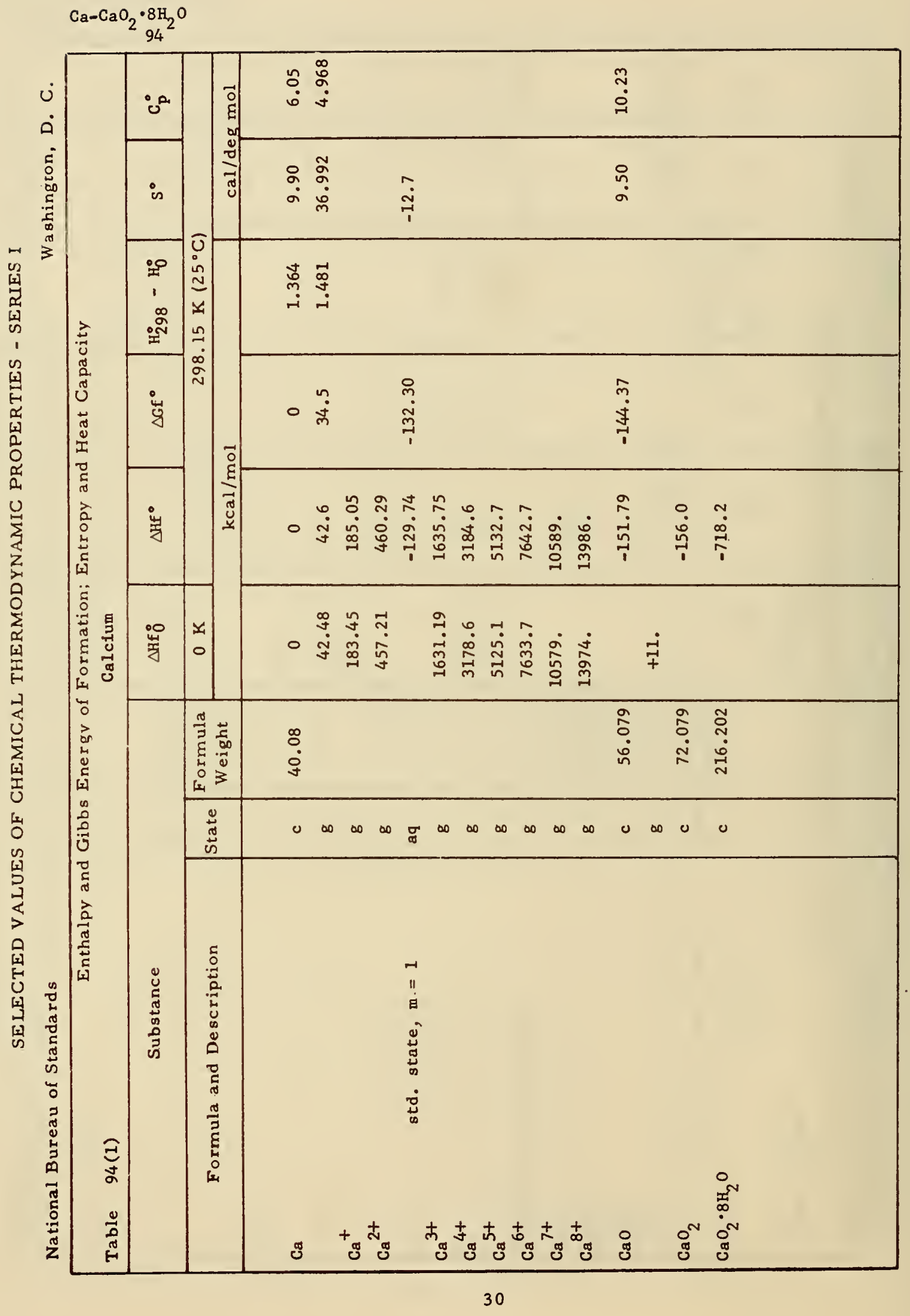




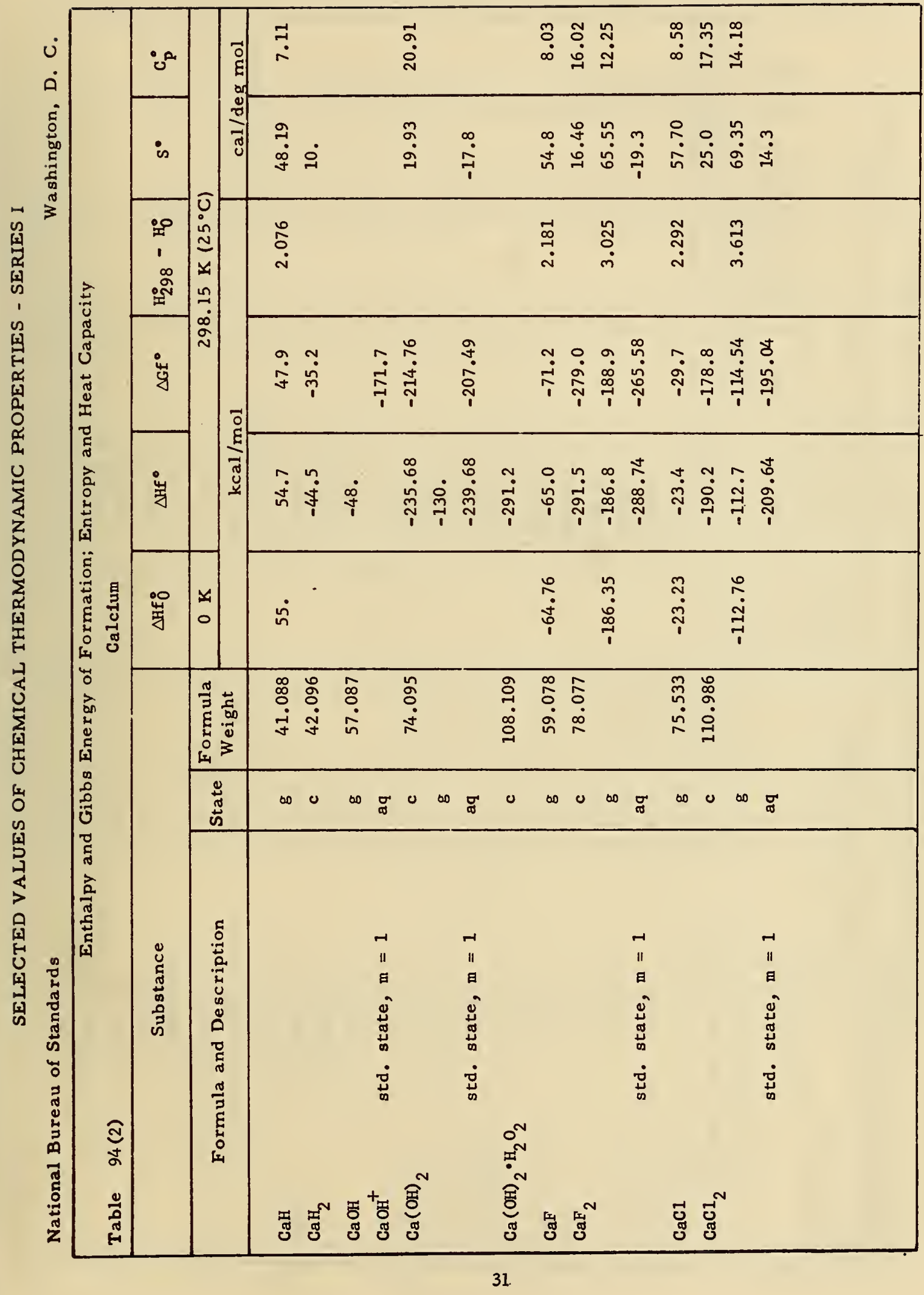




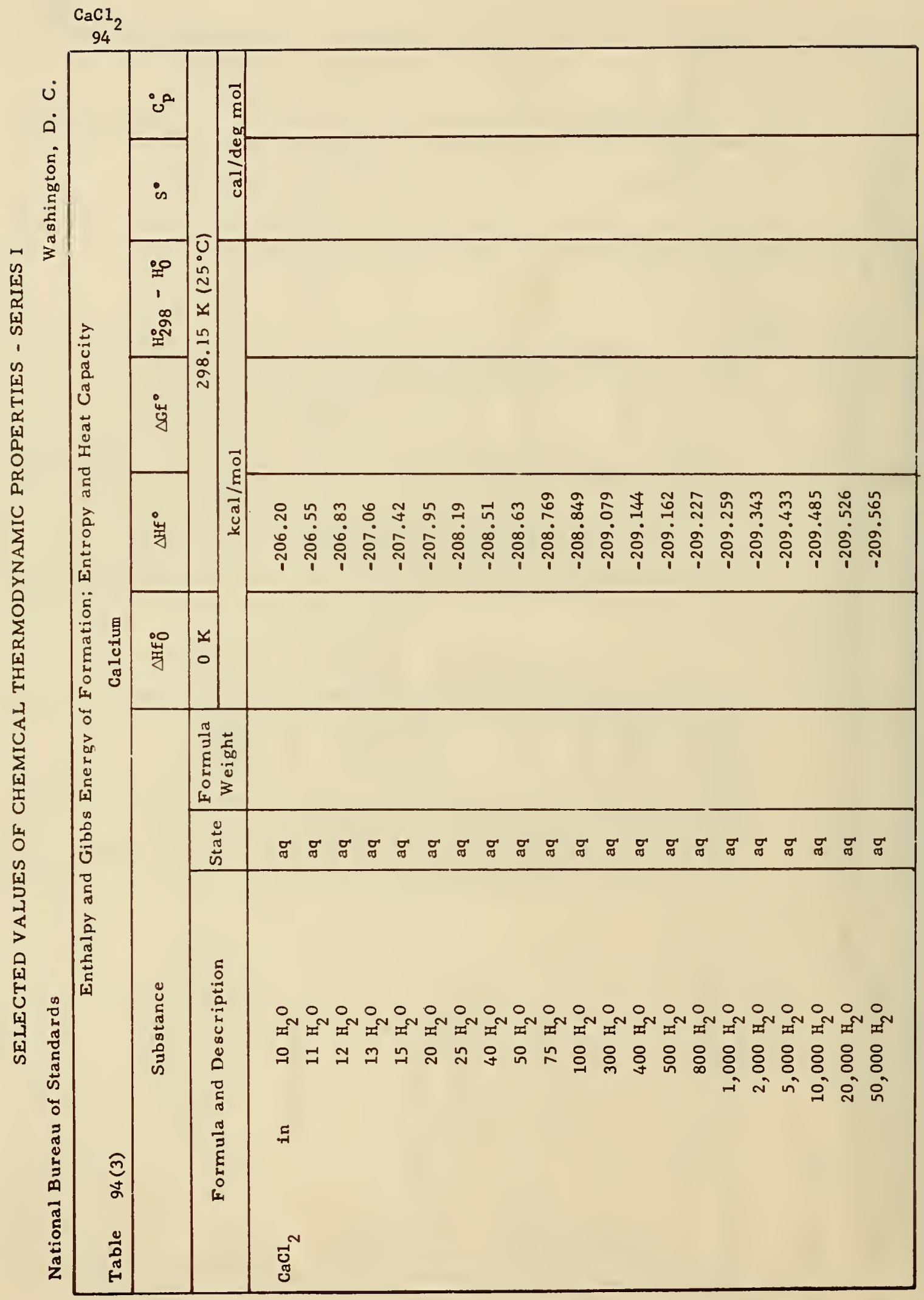




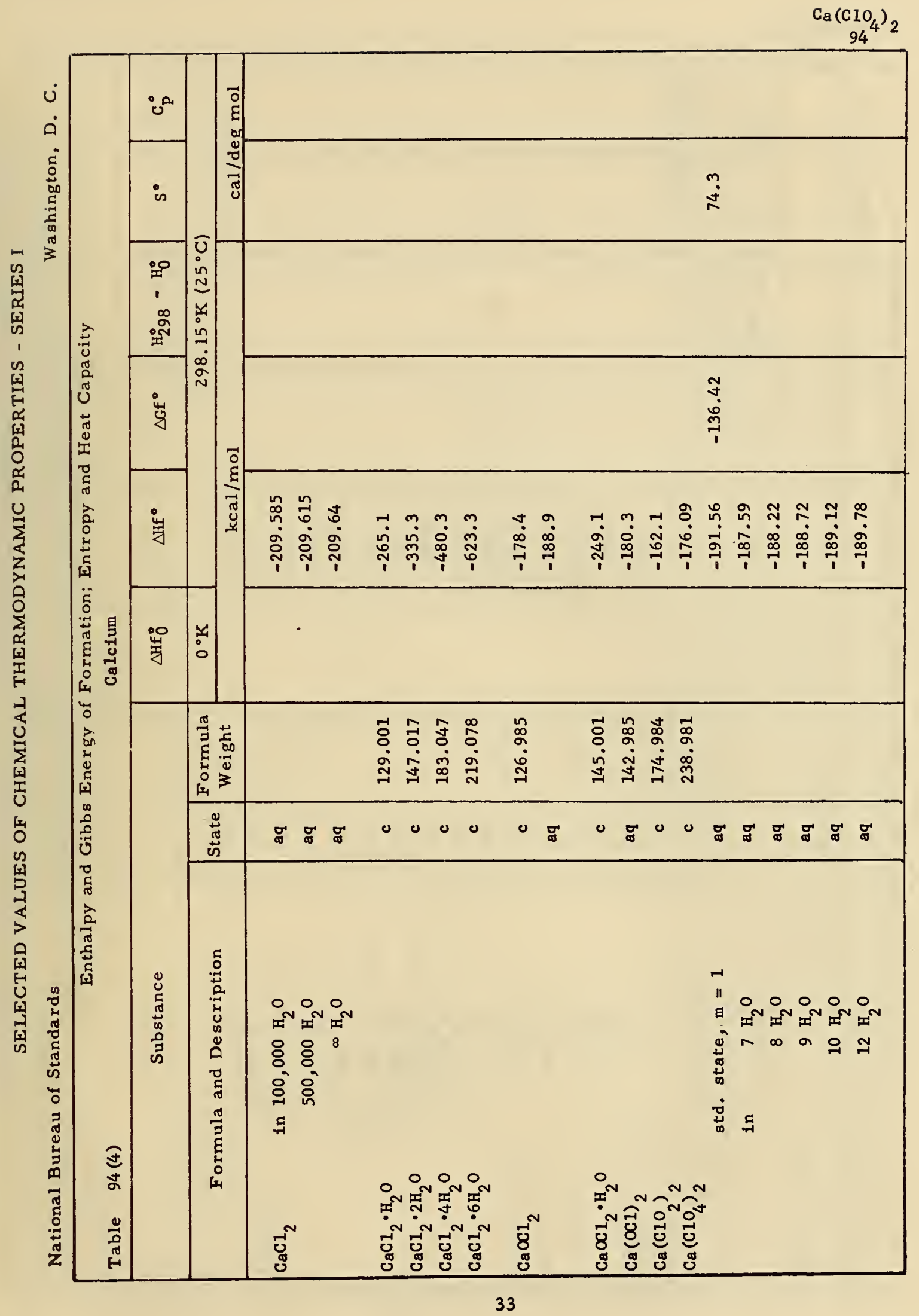




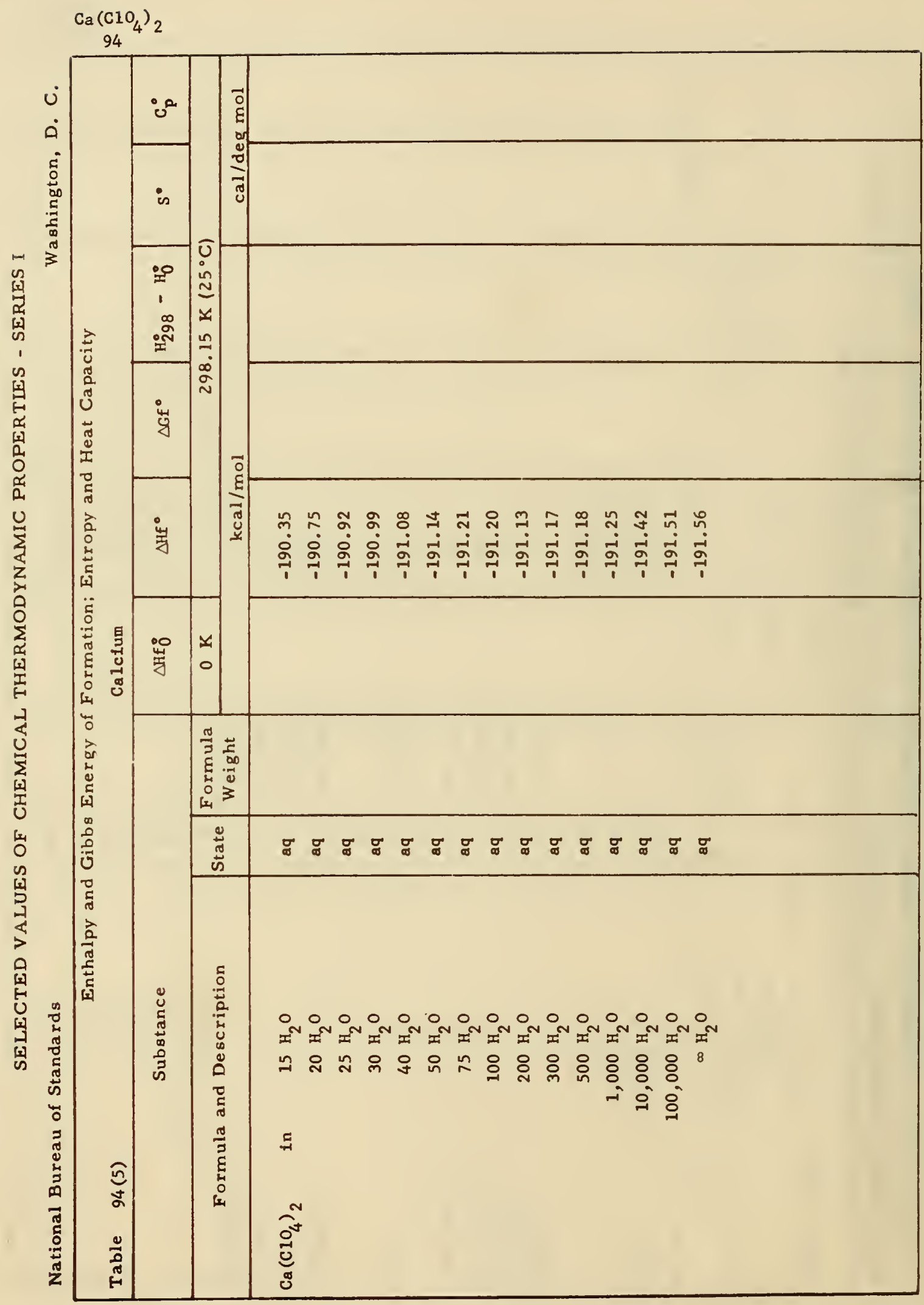




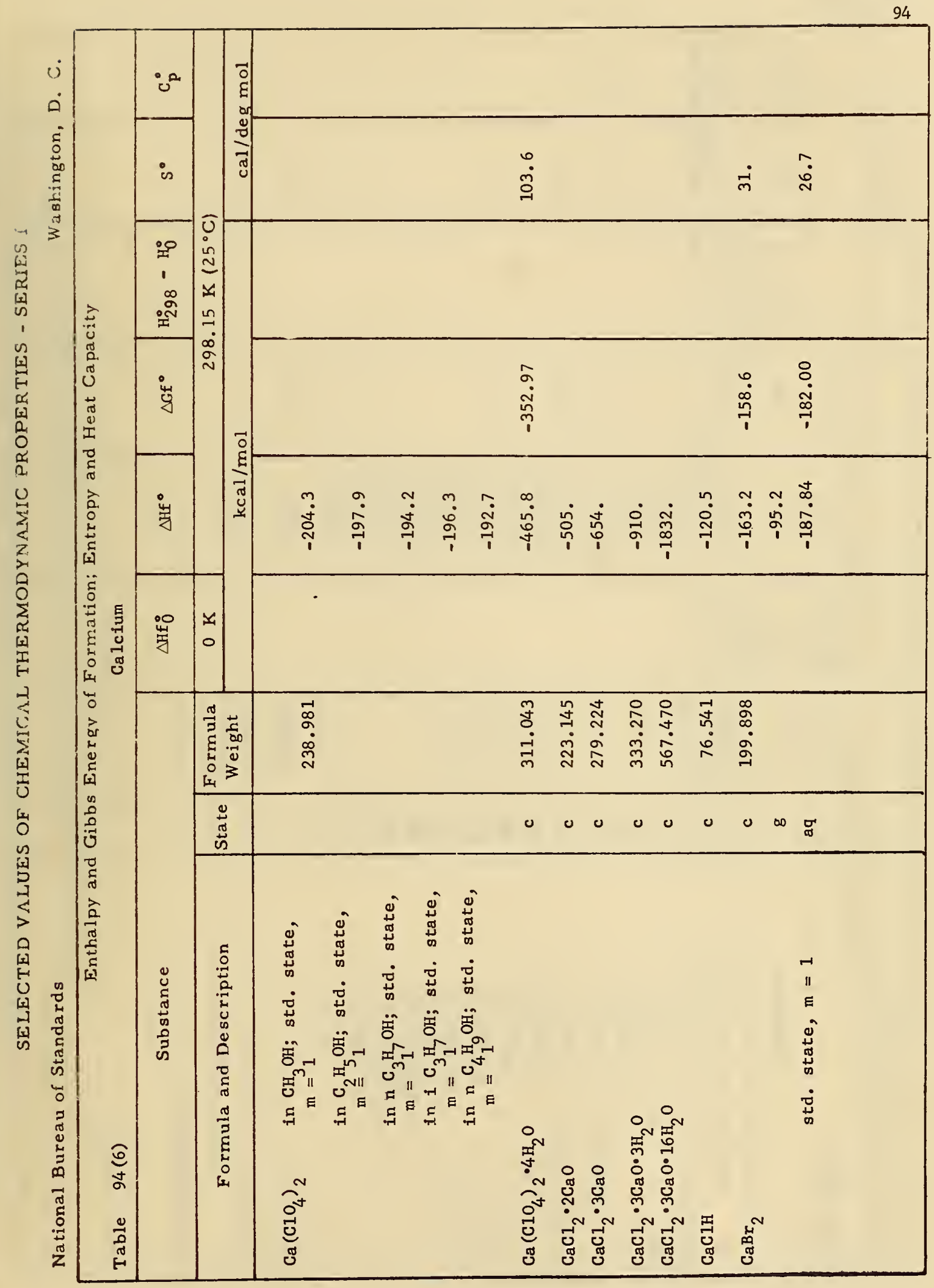




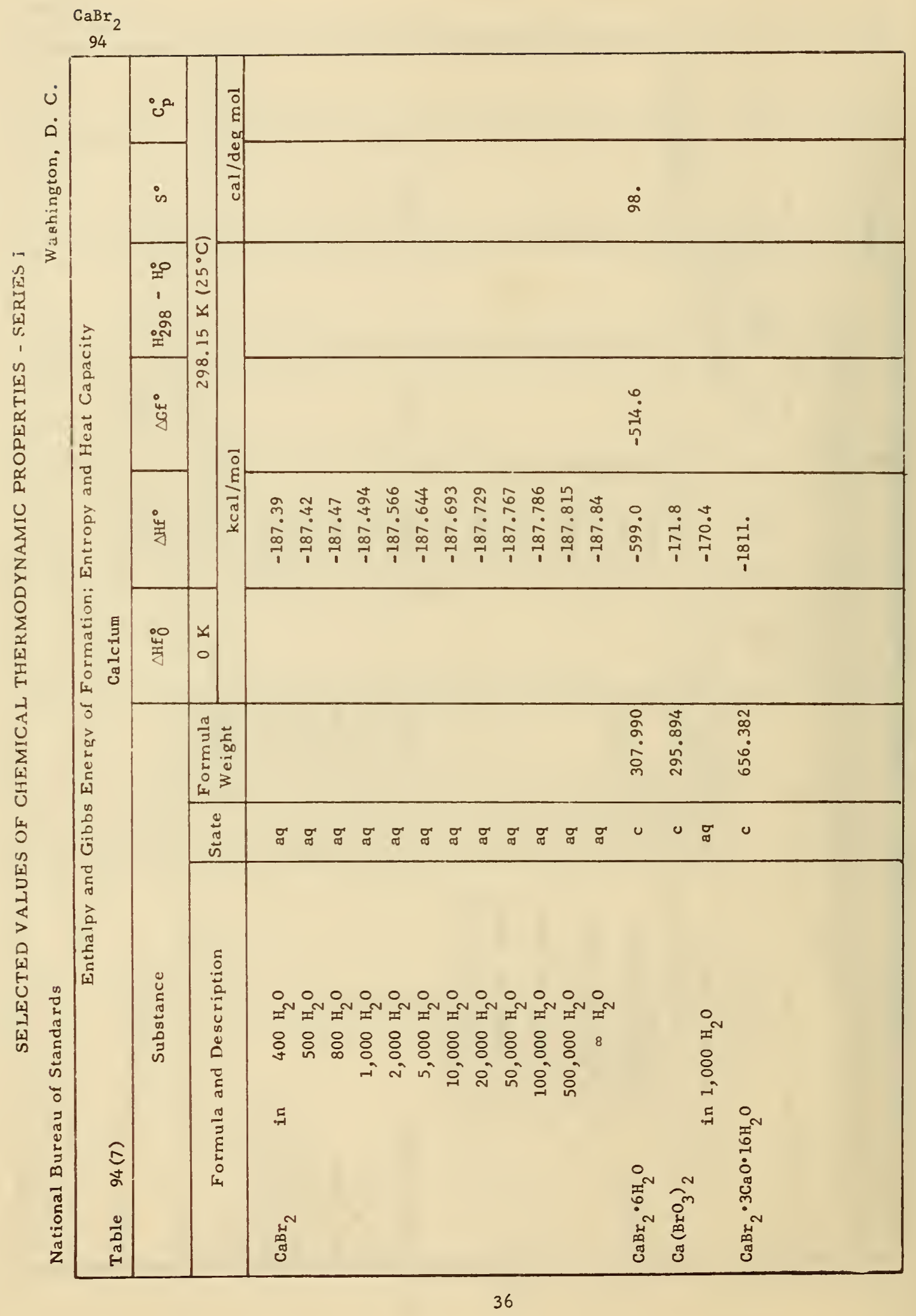




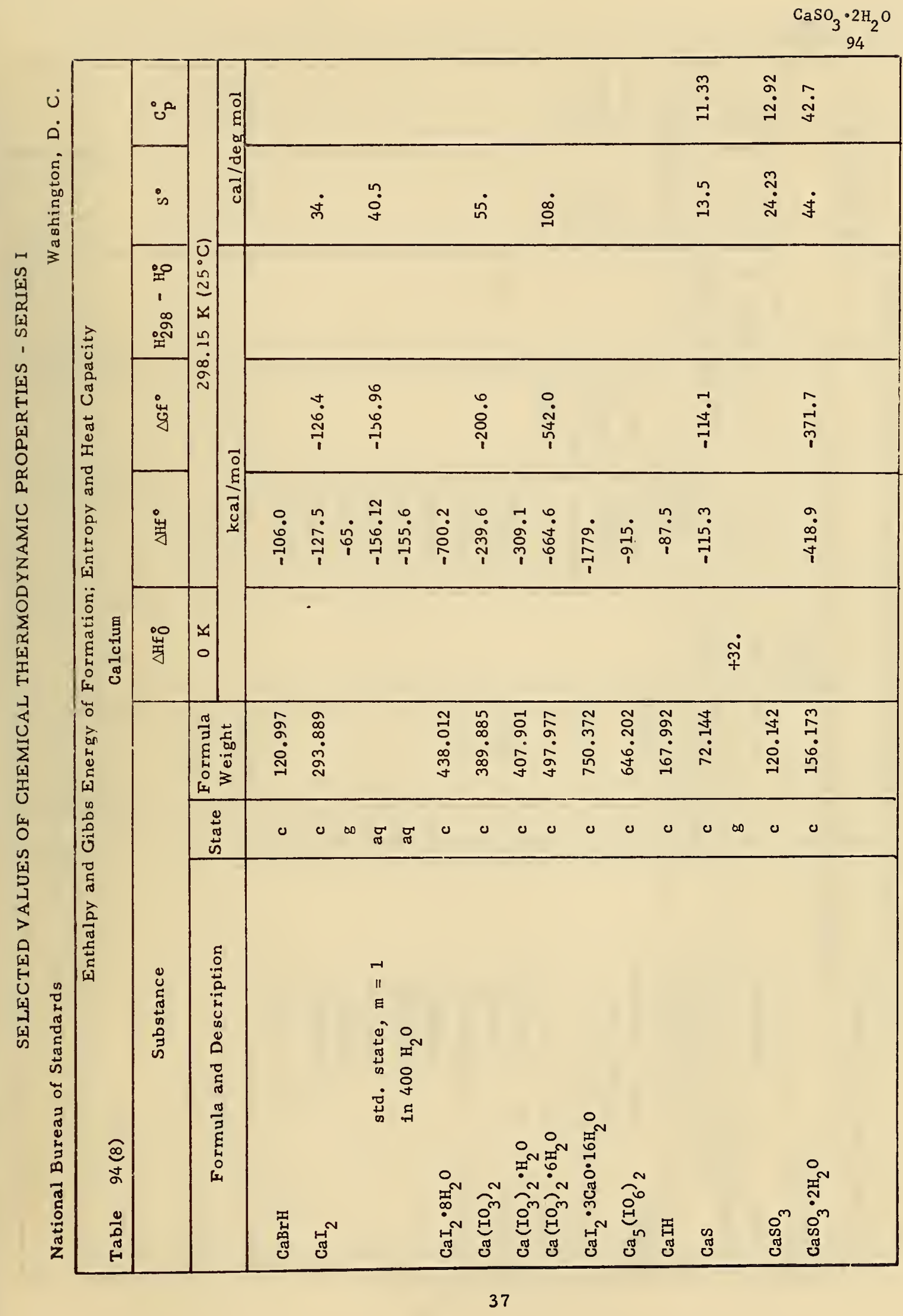




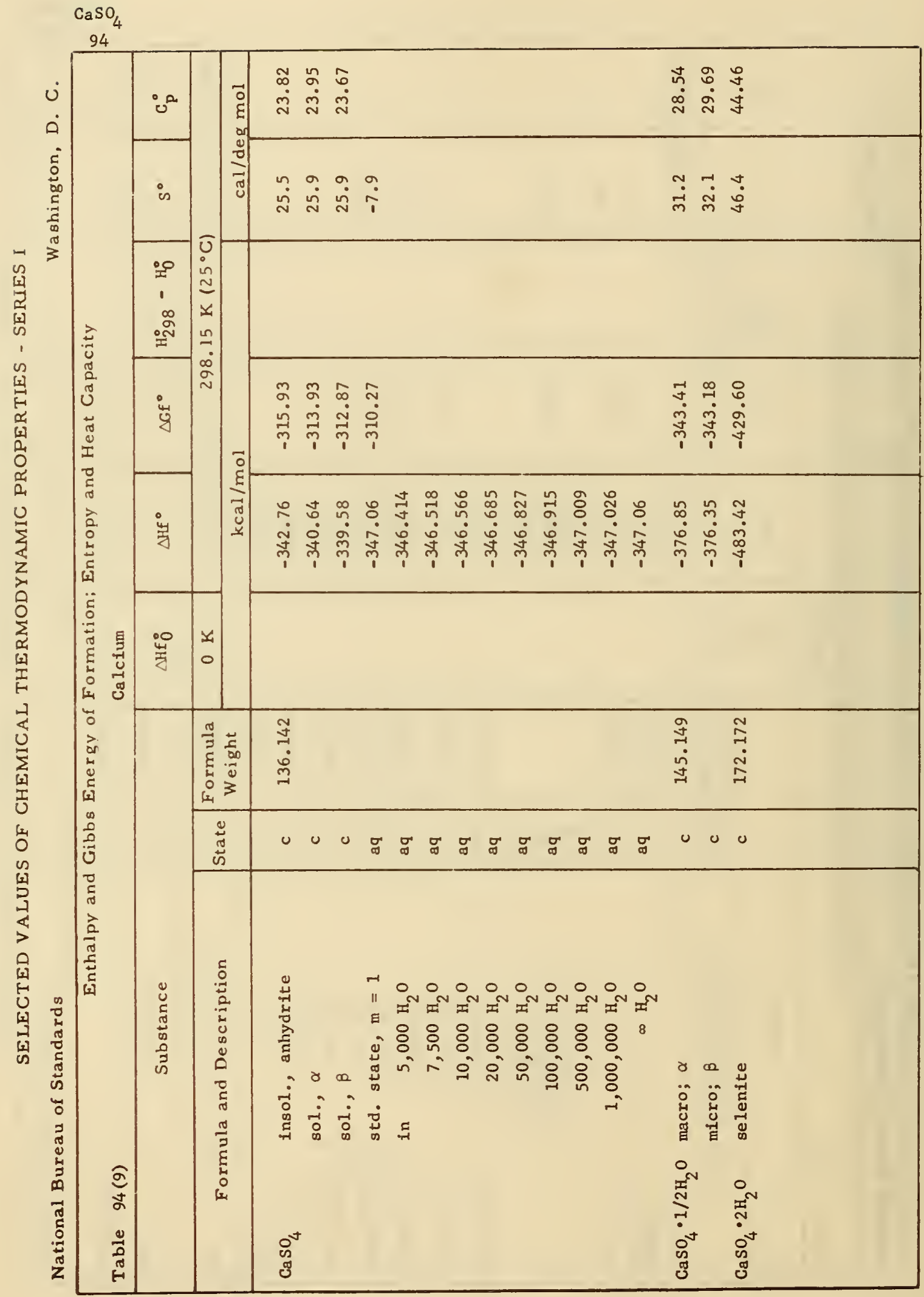




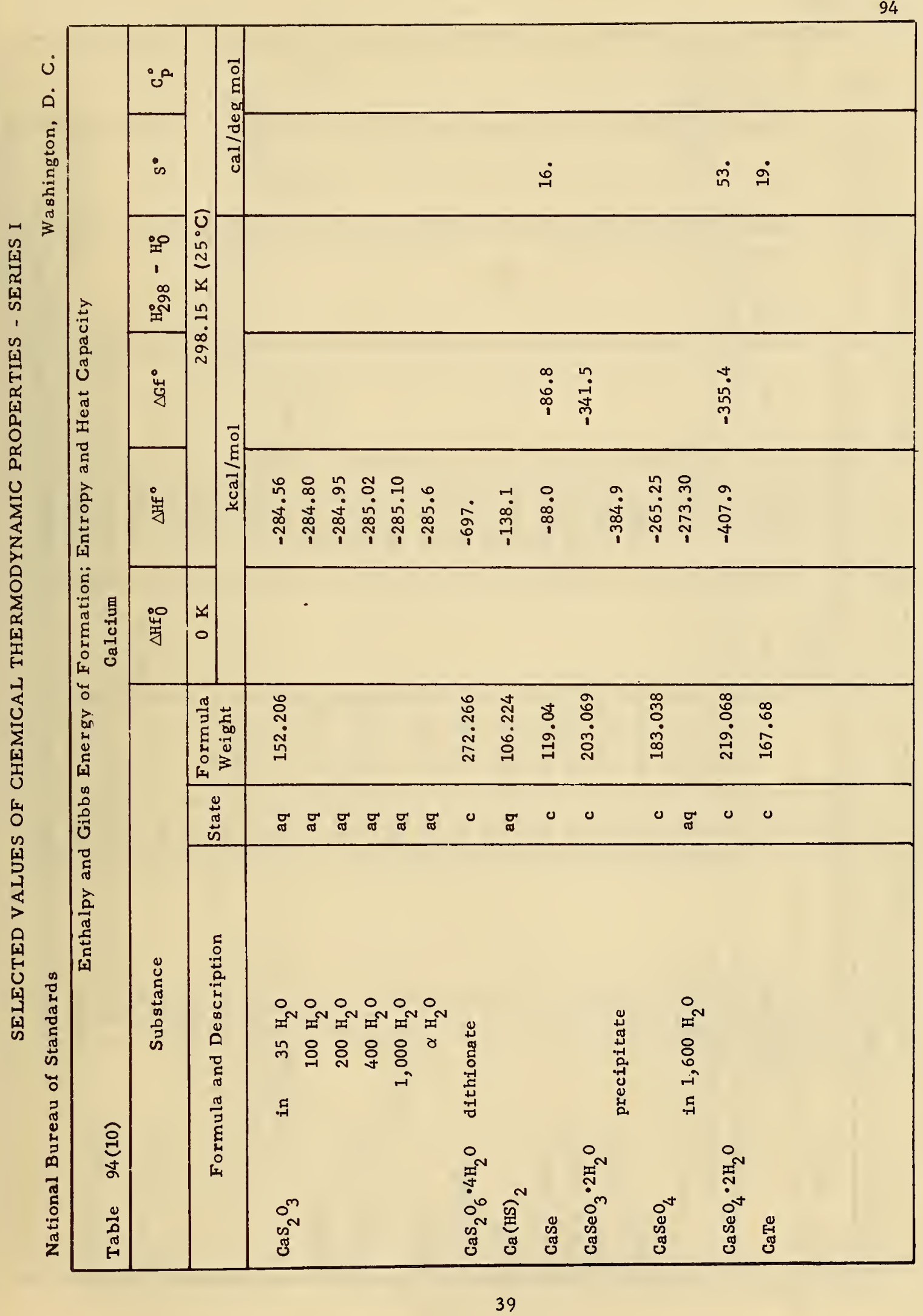




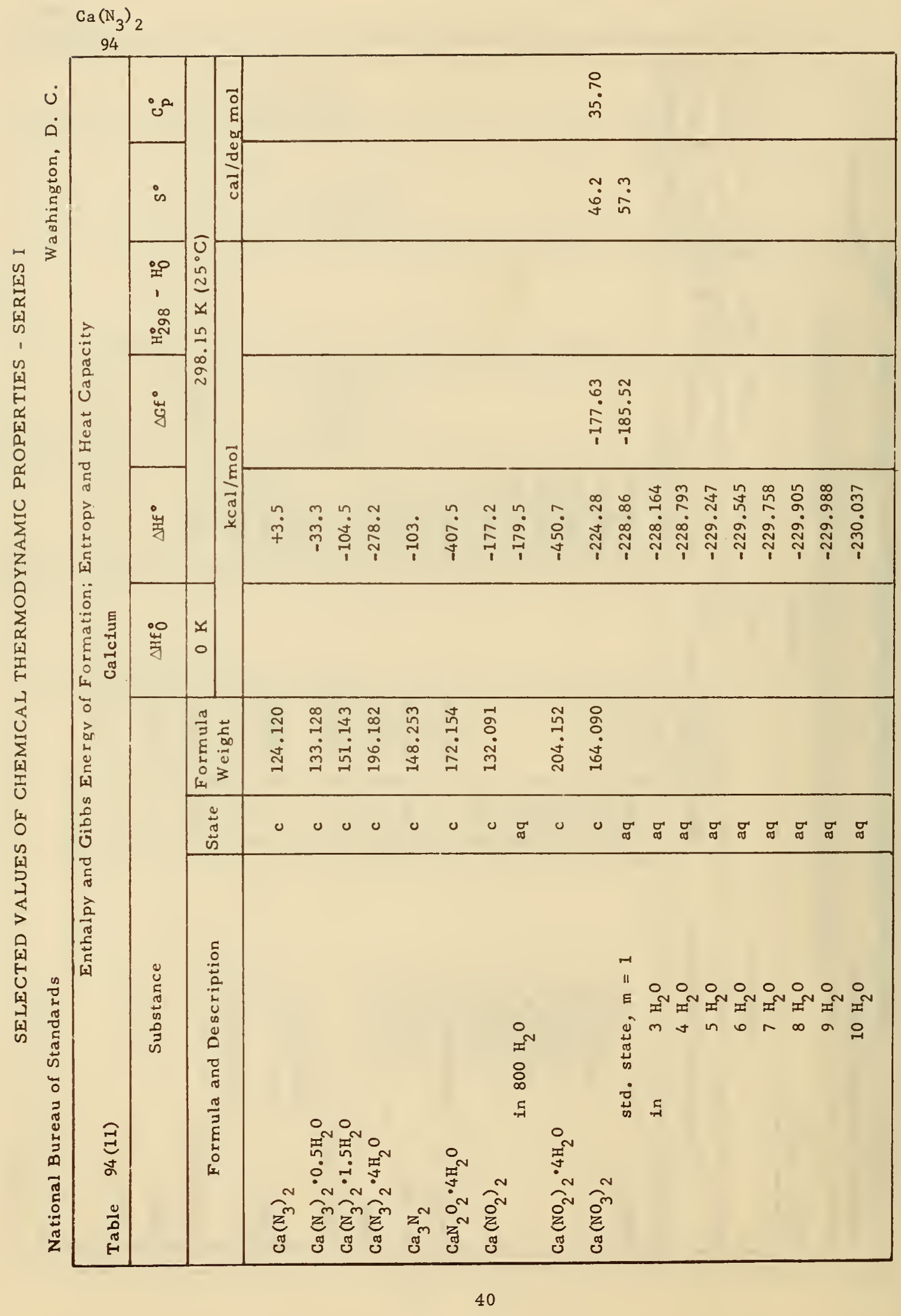




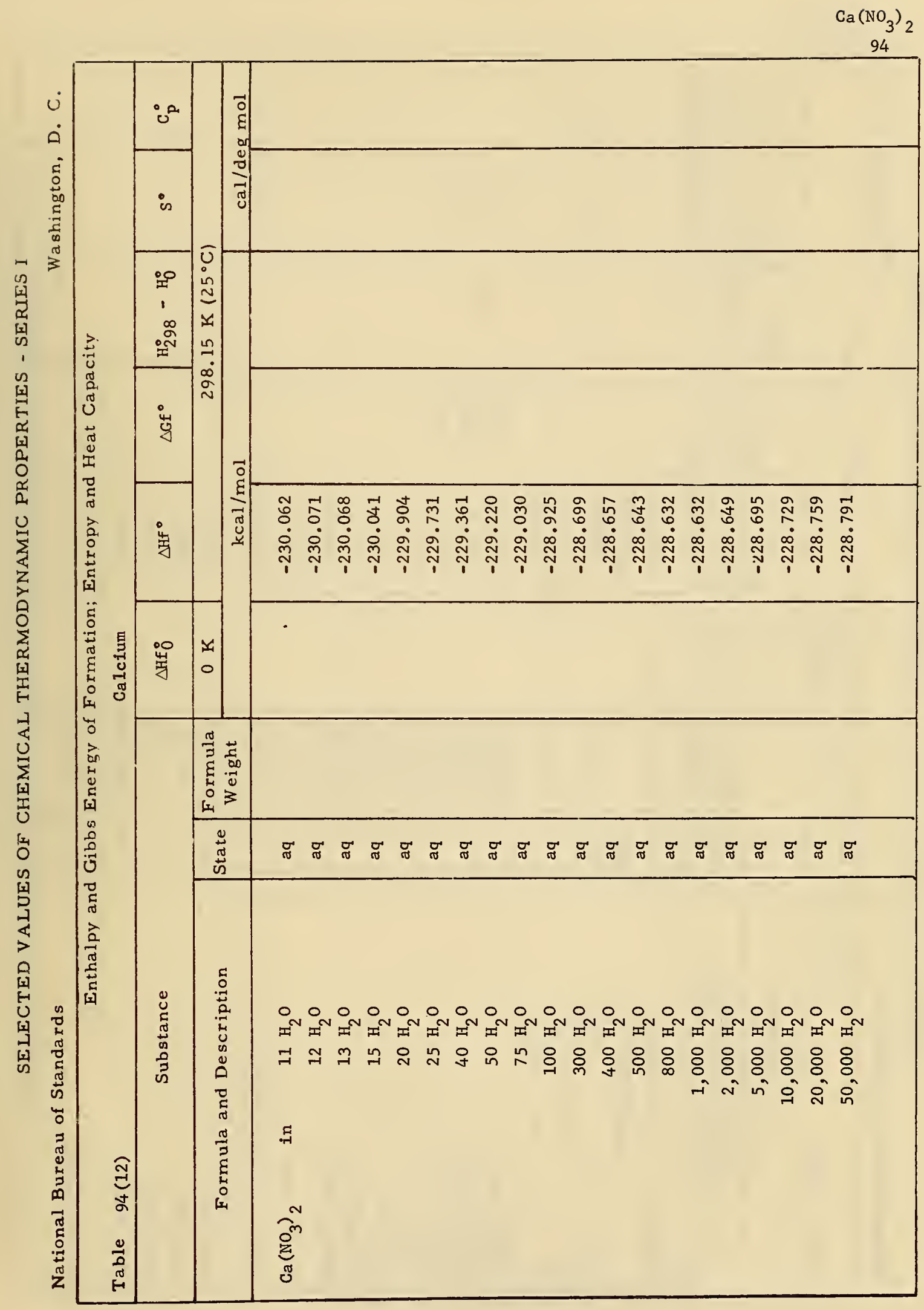




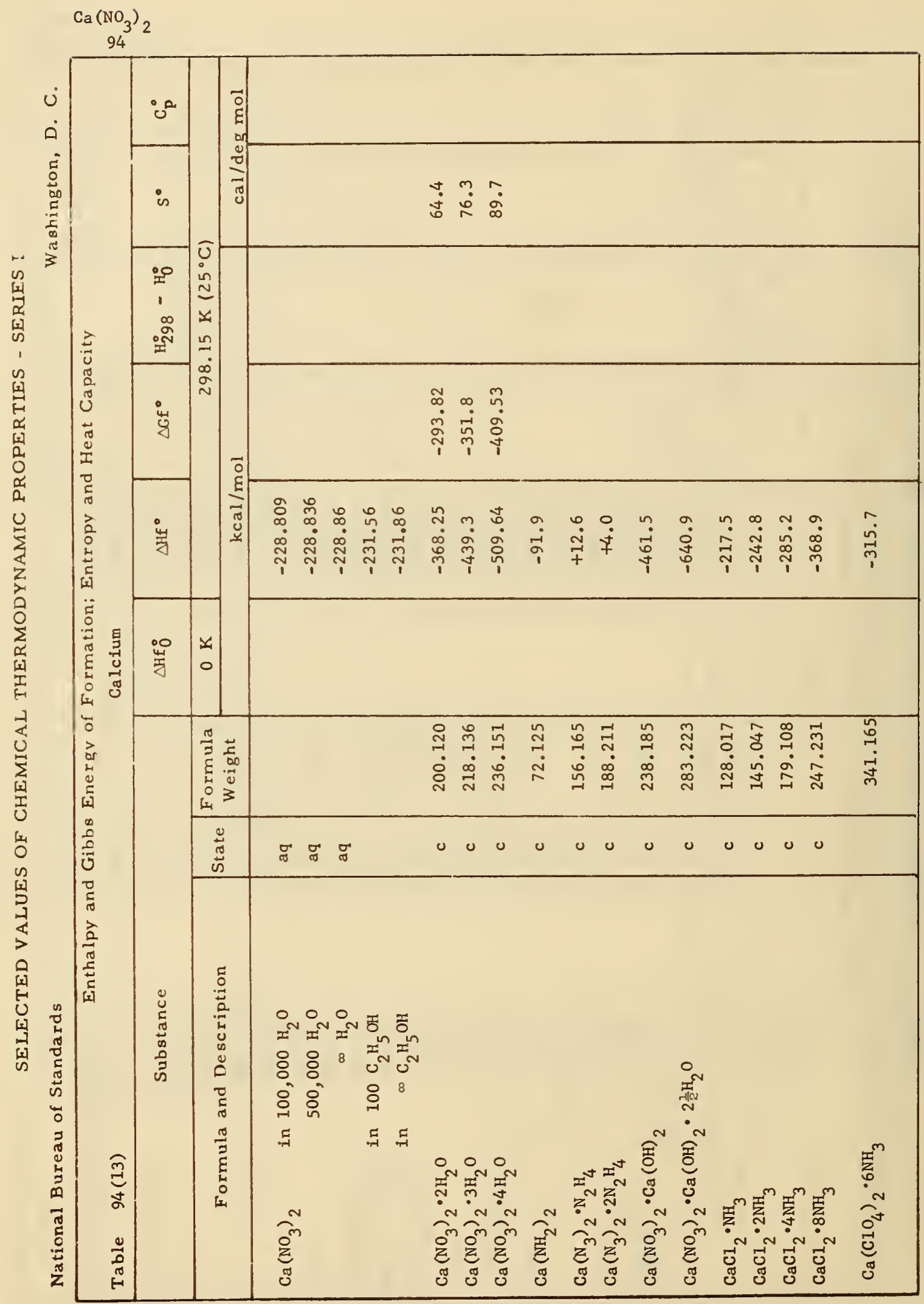


$\underset{94}{\mathrm{Ca}_{3}\left(\mathrm{PO}_{4}\right)_{2}}$

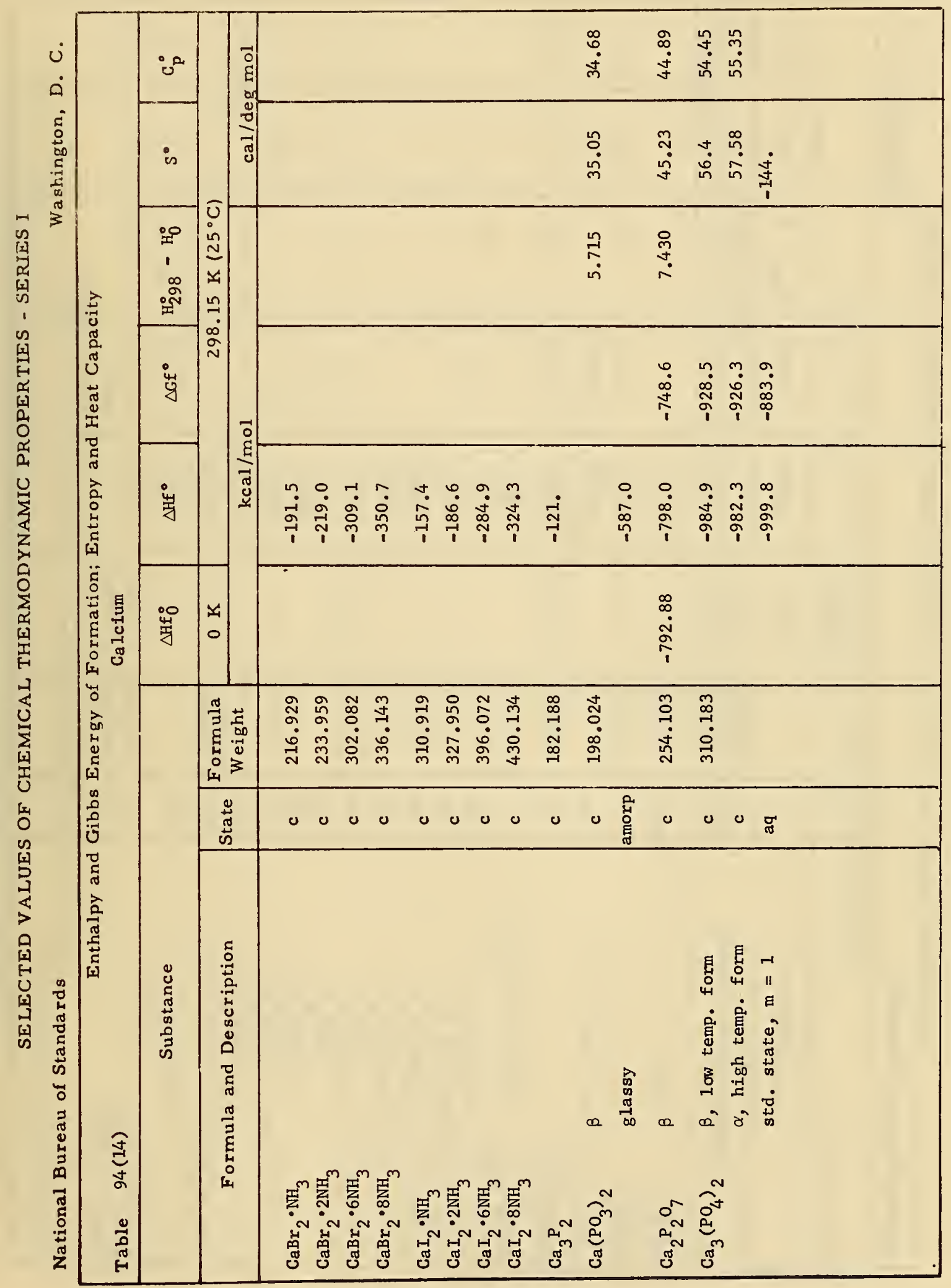




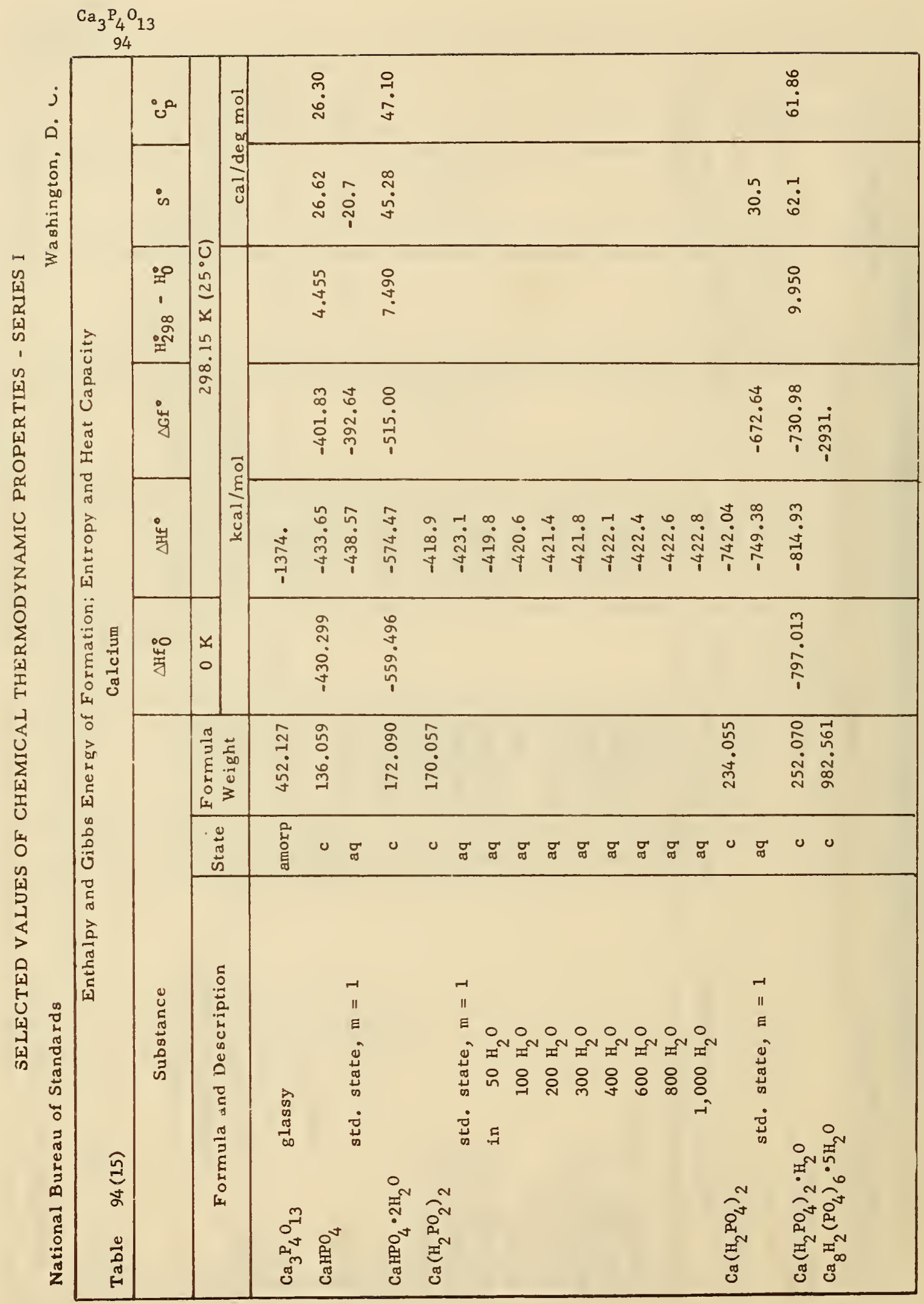




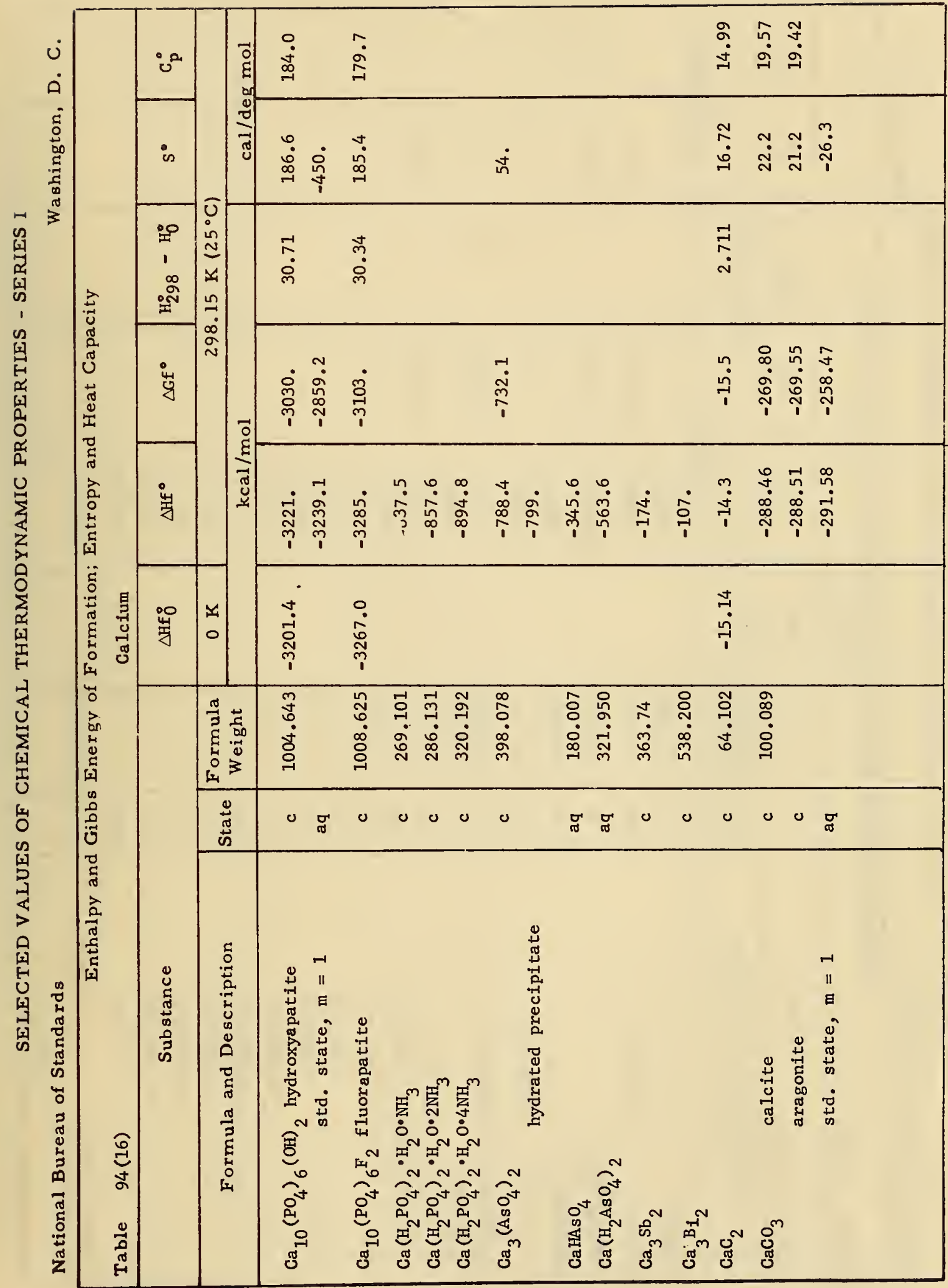




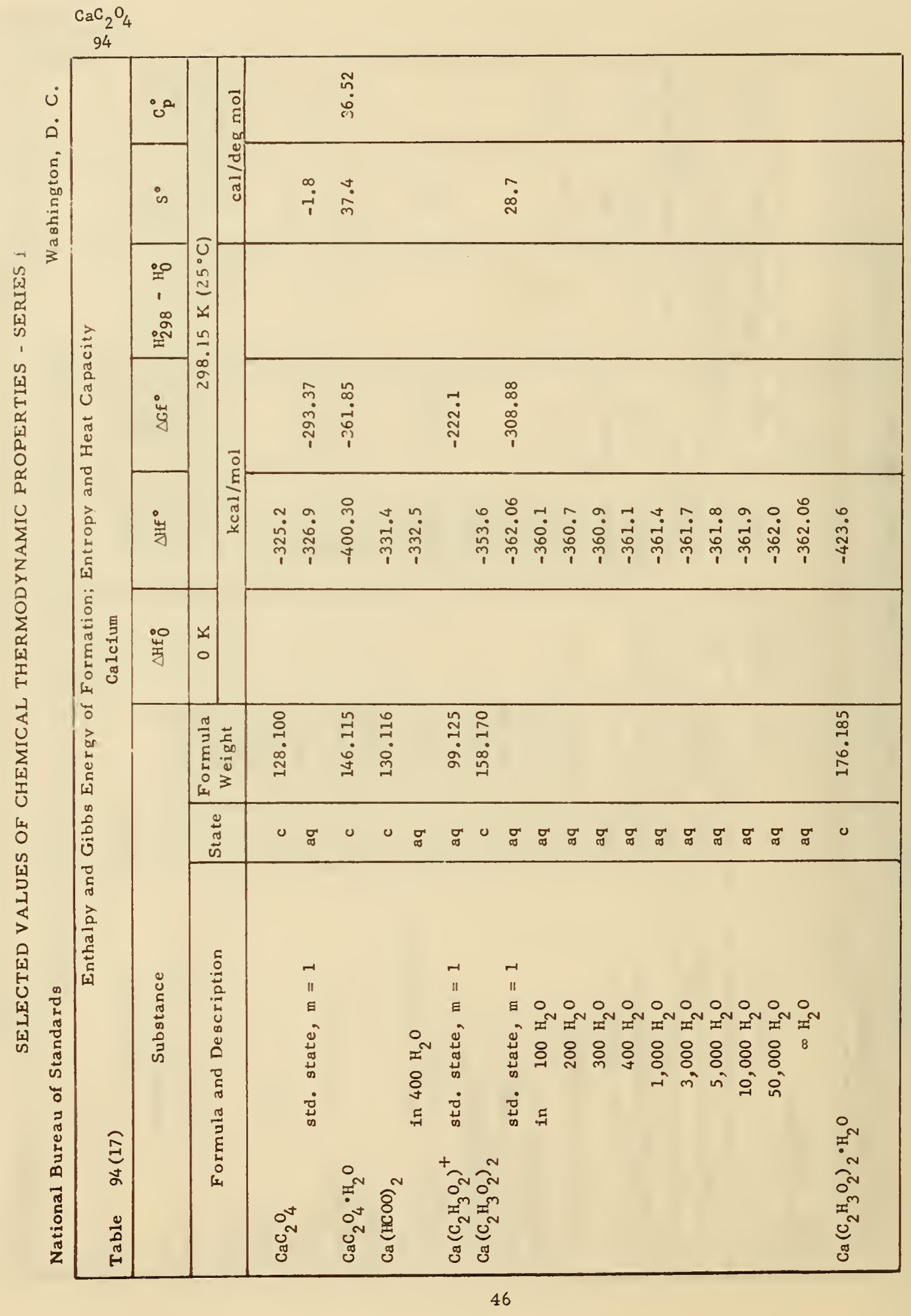


$\mathrm{Ca}\left(\mathrm{NO}_{3}\right)_{2} \cdot 2 \mathrm{CH}_{3} \mathrm{OH}$

94

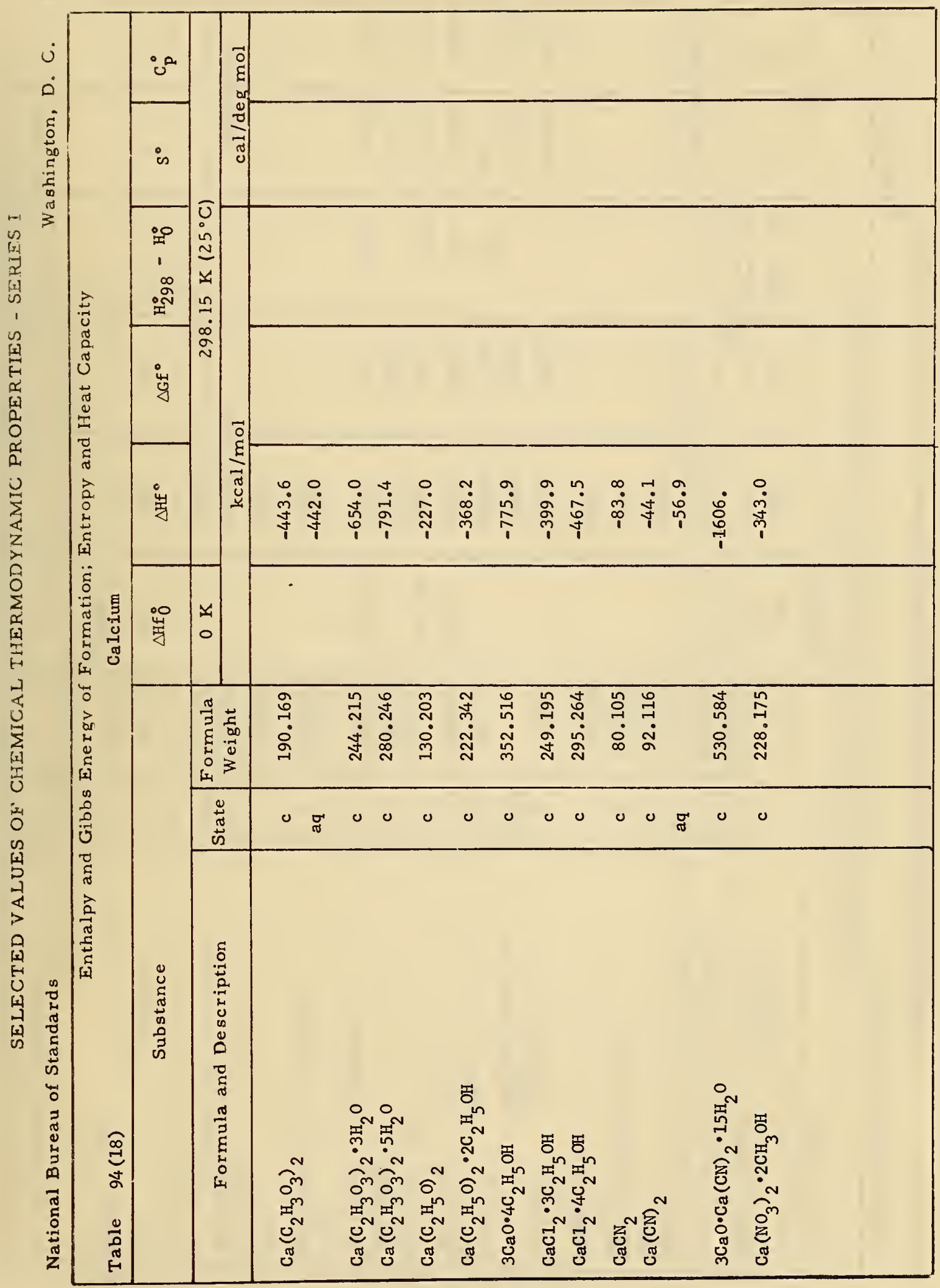




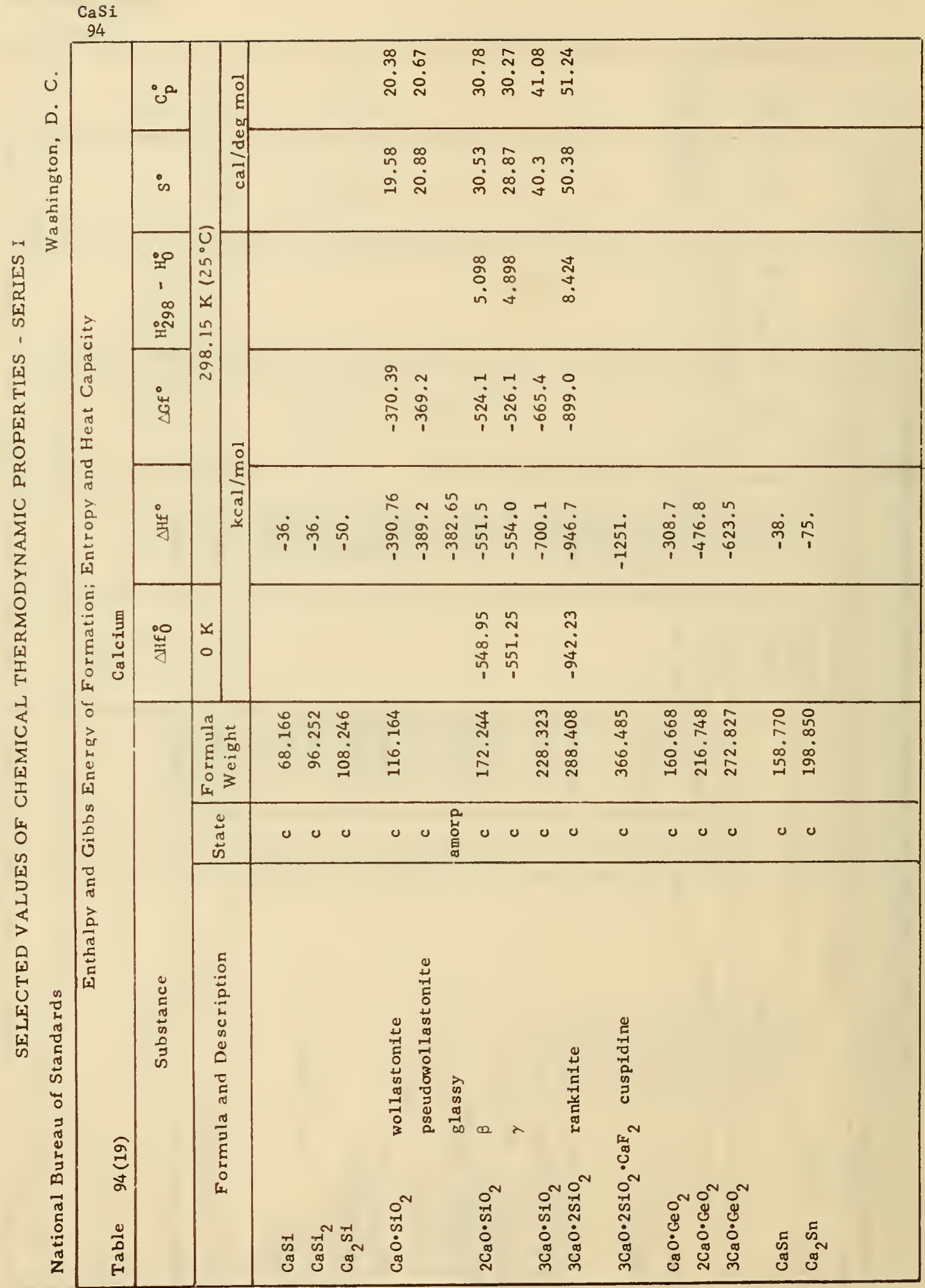




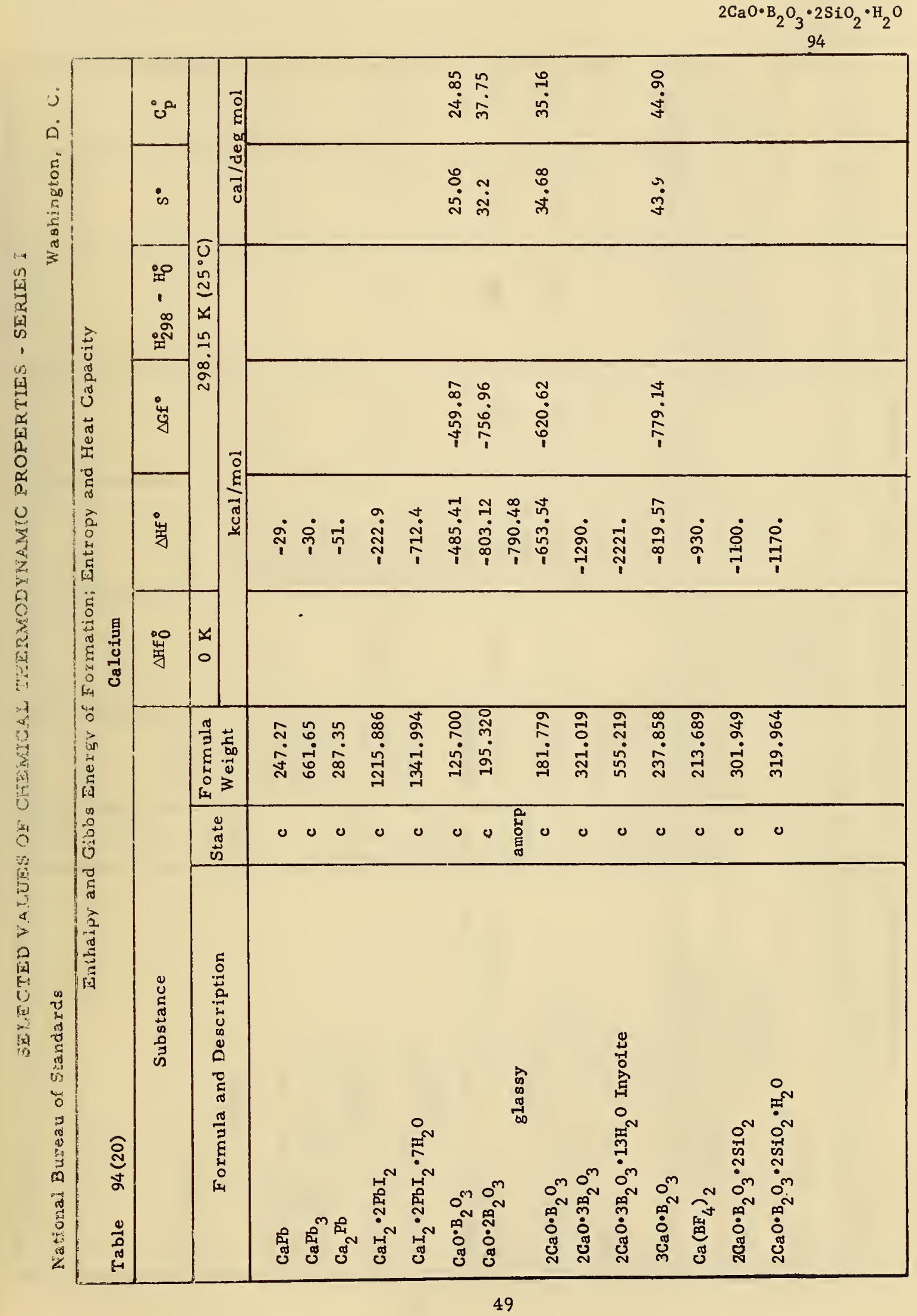




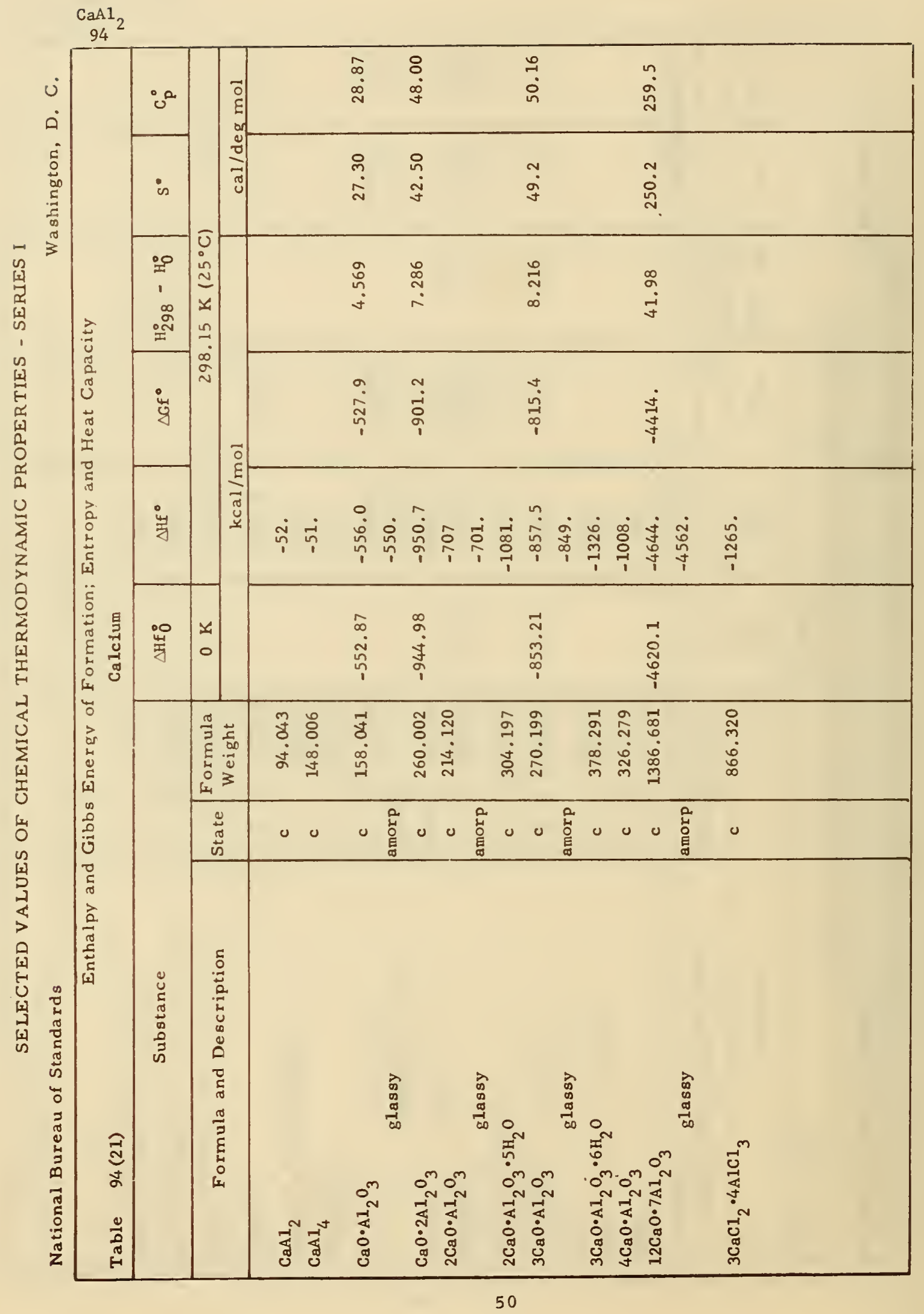


$\mathrm{CaAlGaSi}_{2} \mathrm{O}_{8}$

94

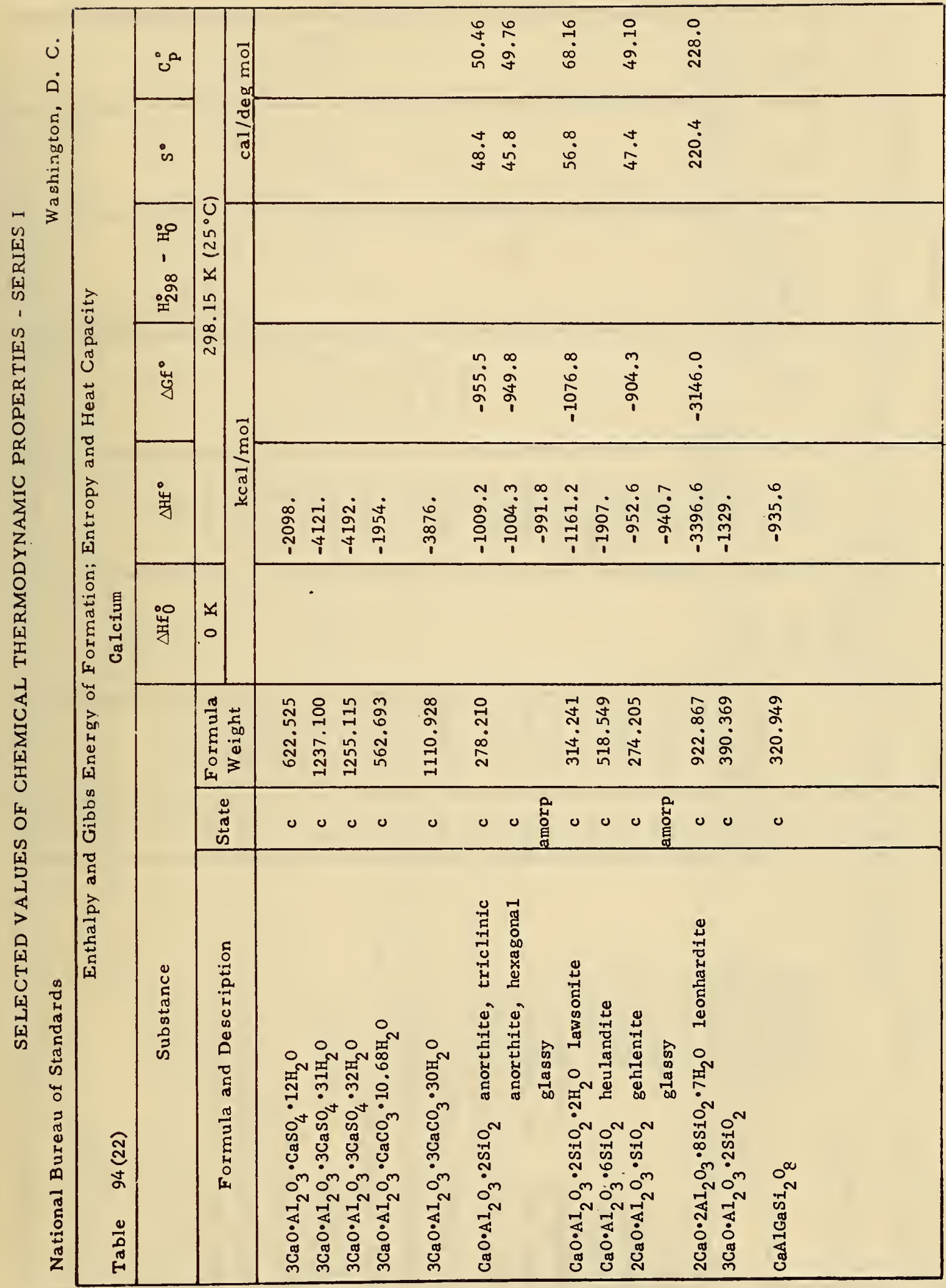




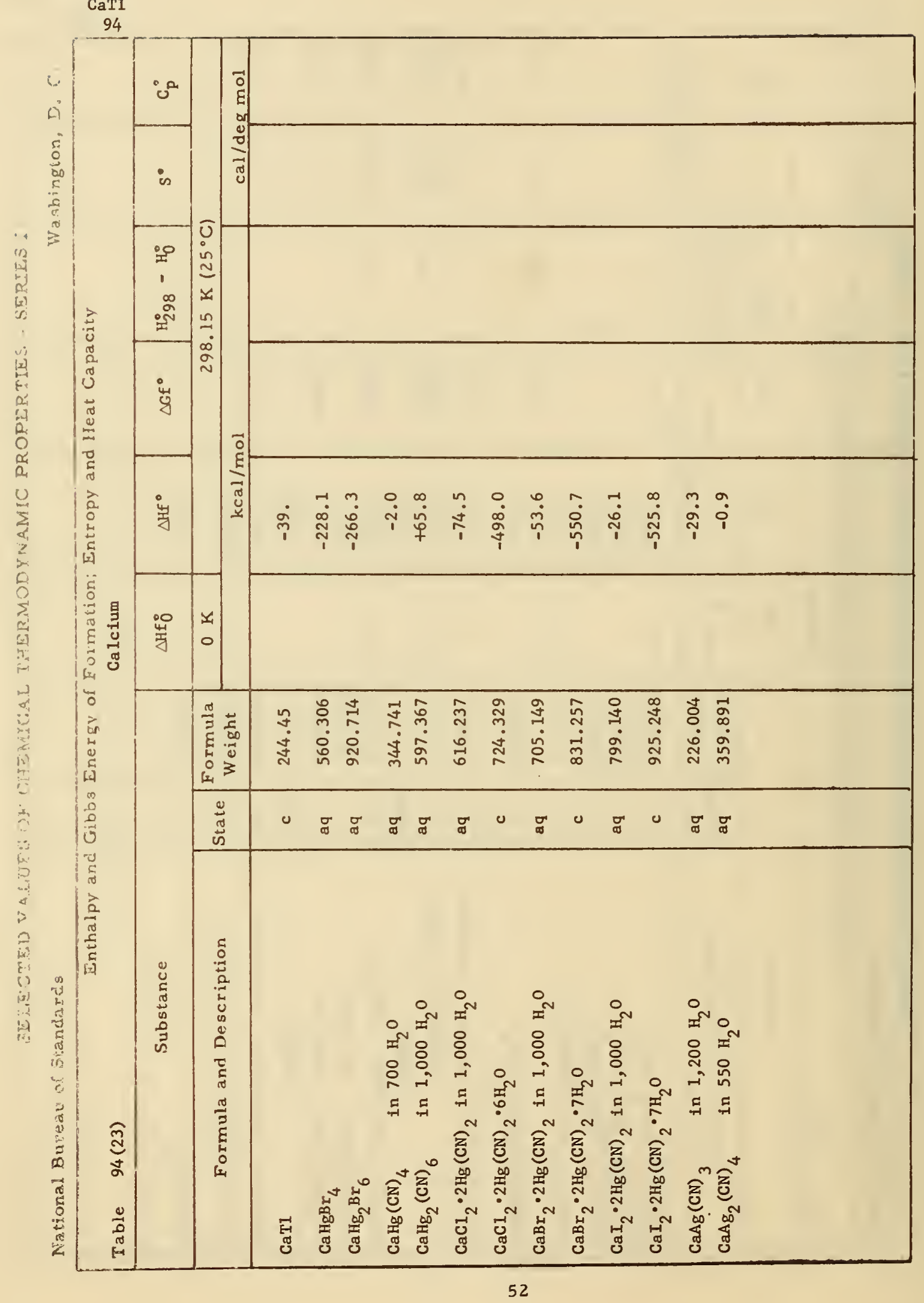




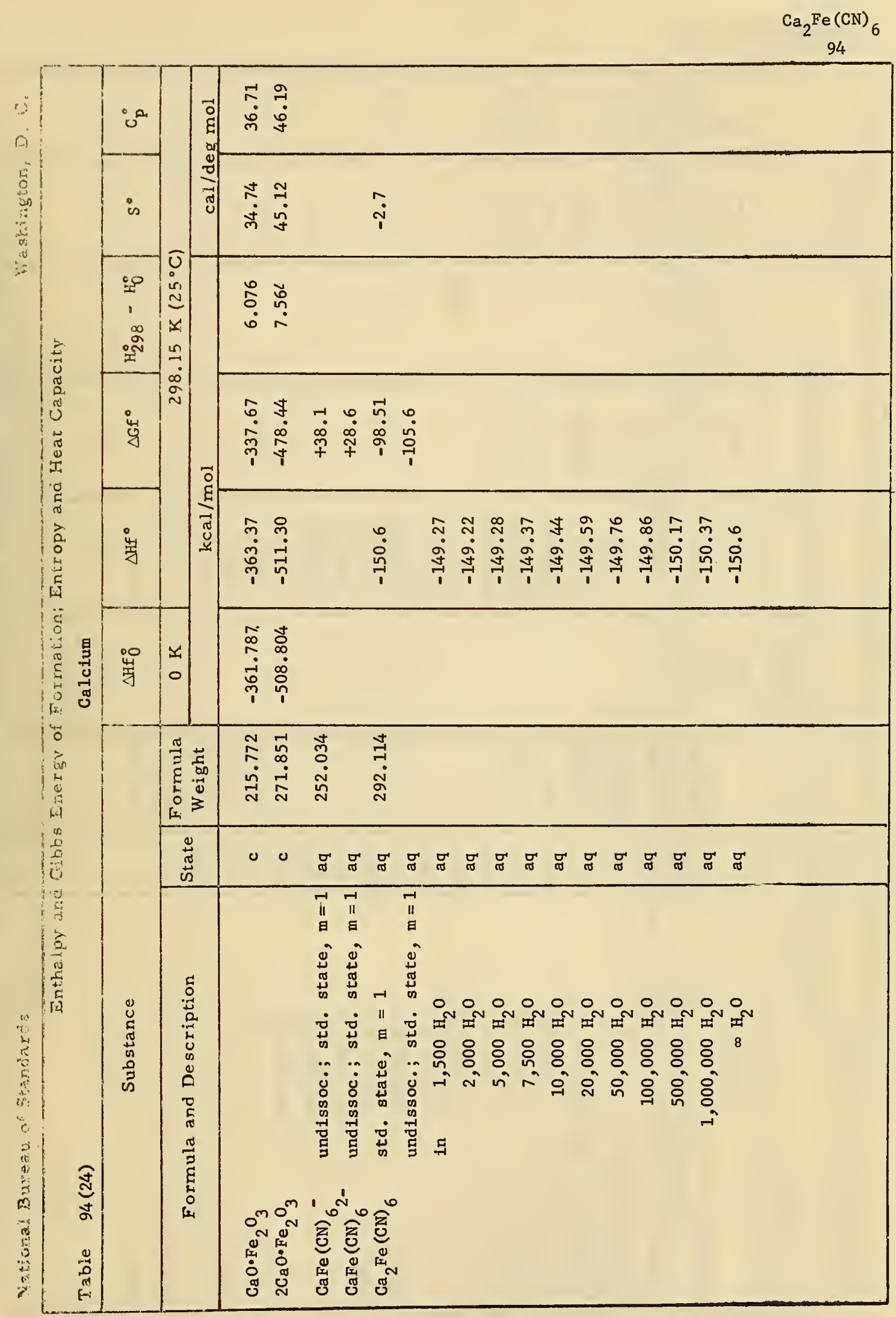


$\mathrm{Ca}_{2} \mathrm{Fe}(\mathrm{CN})_{6} \cdot 11 \mathrm{H}_{2} \mathrm{O}$

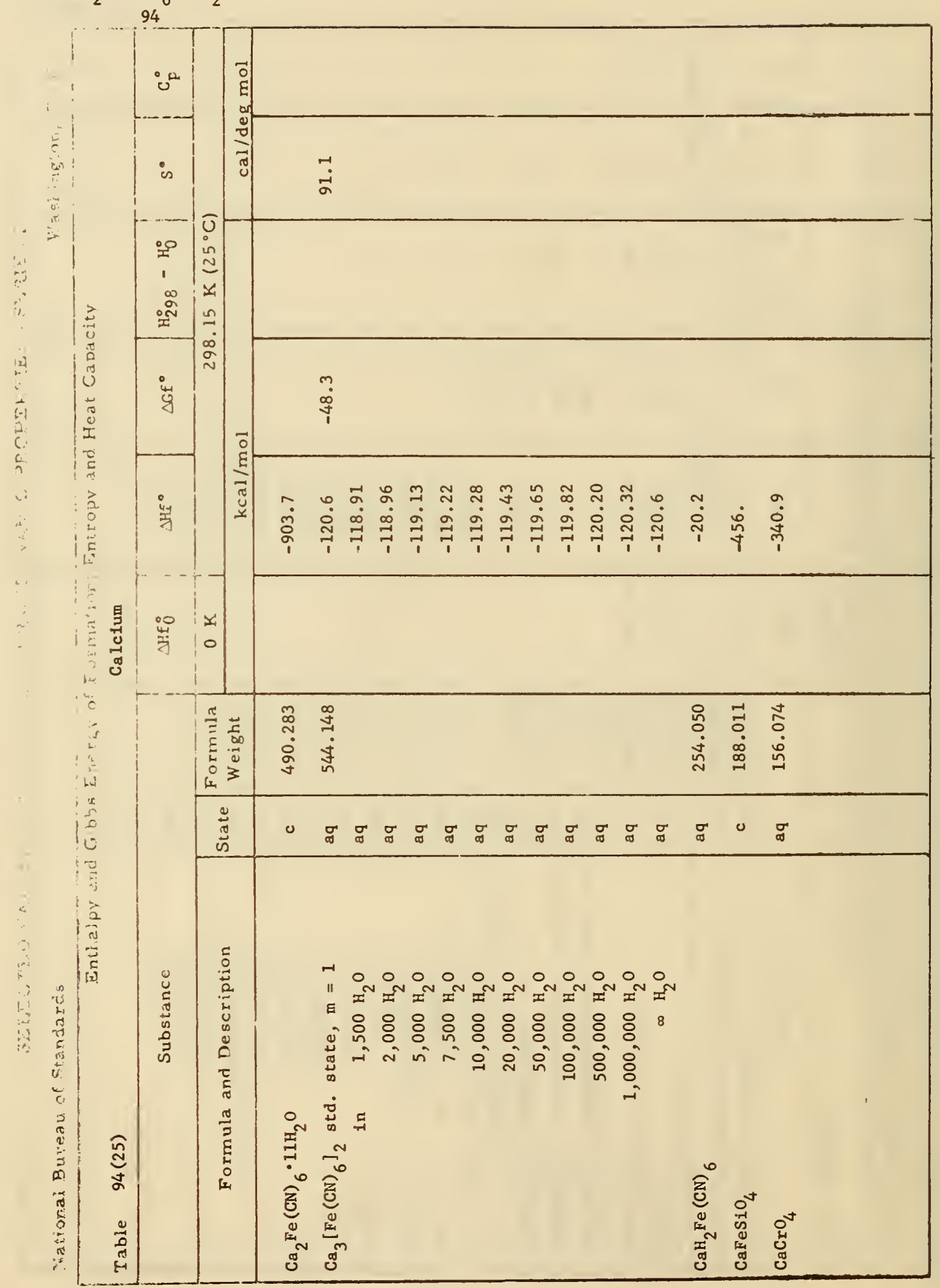




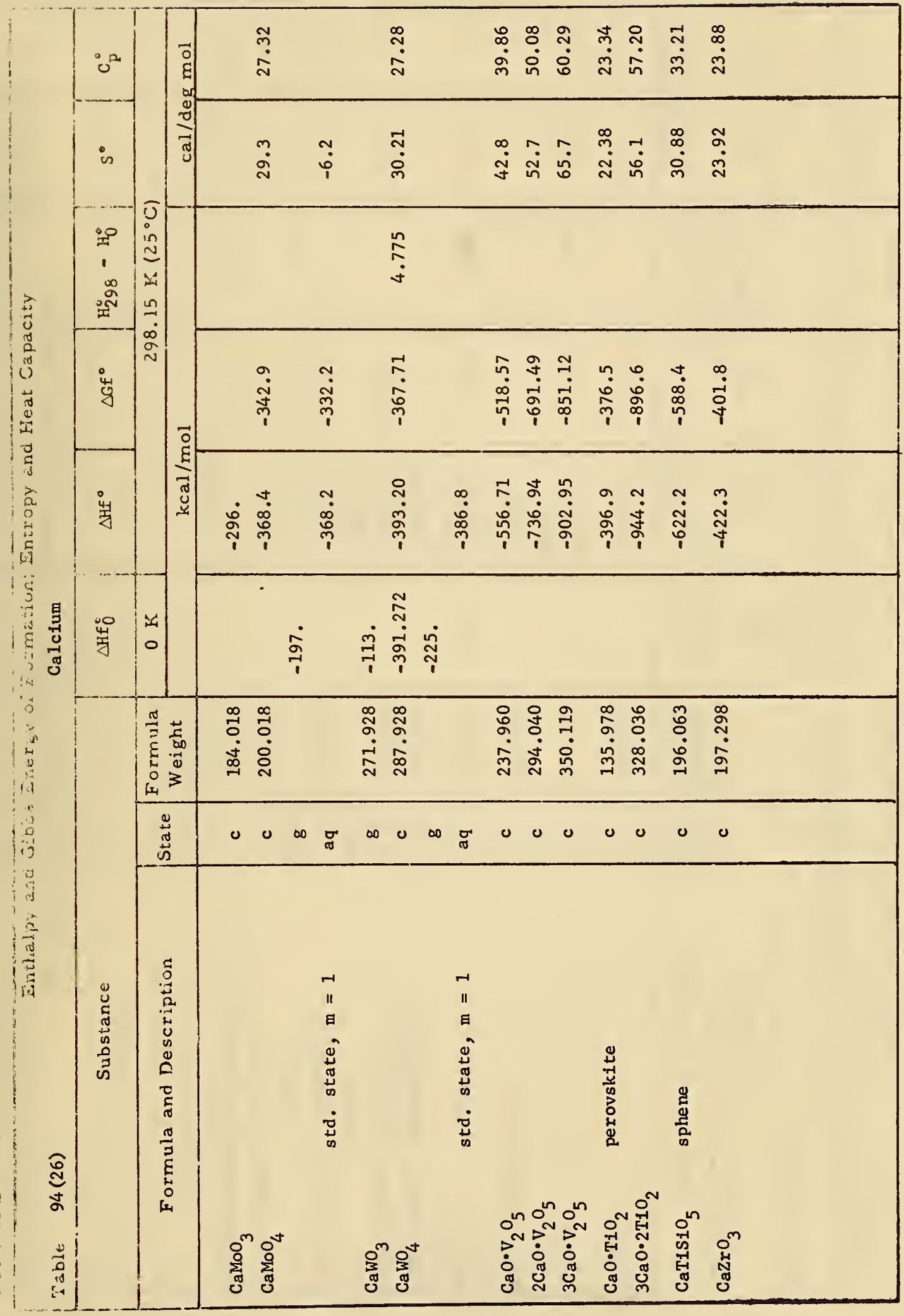


$\mathrm{CaHfO}_{3}$

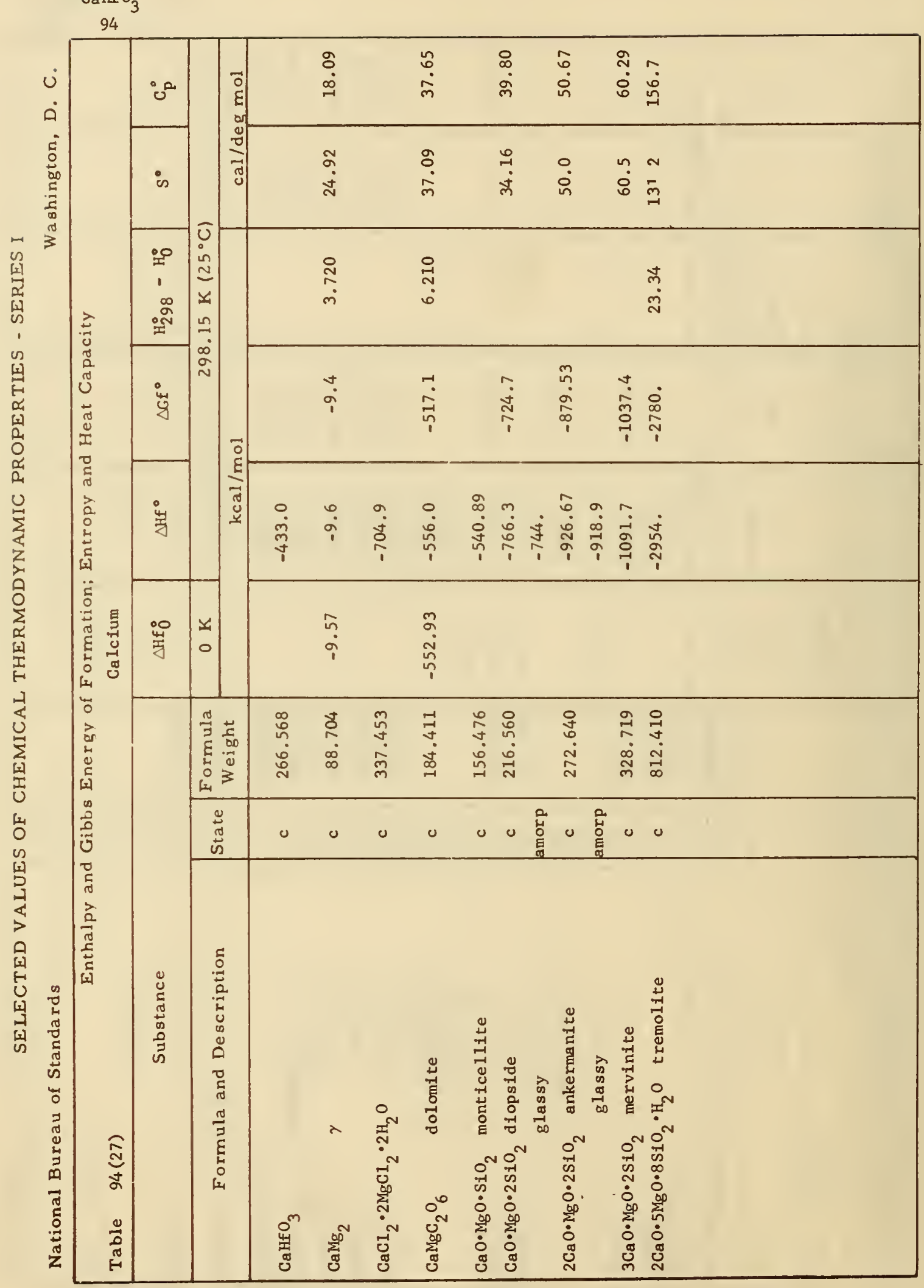




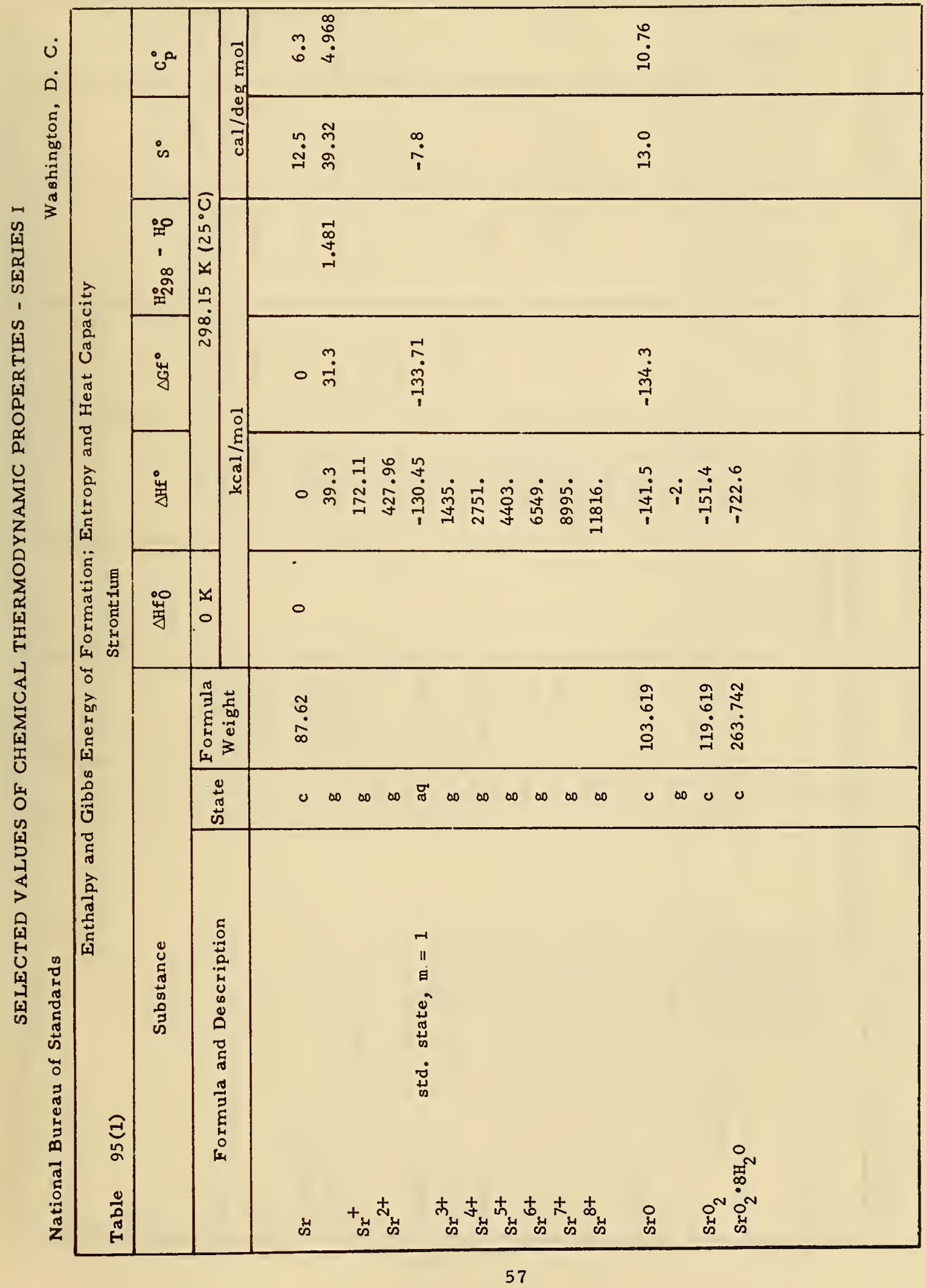




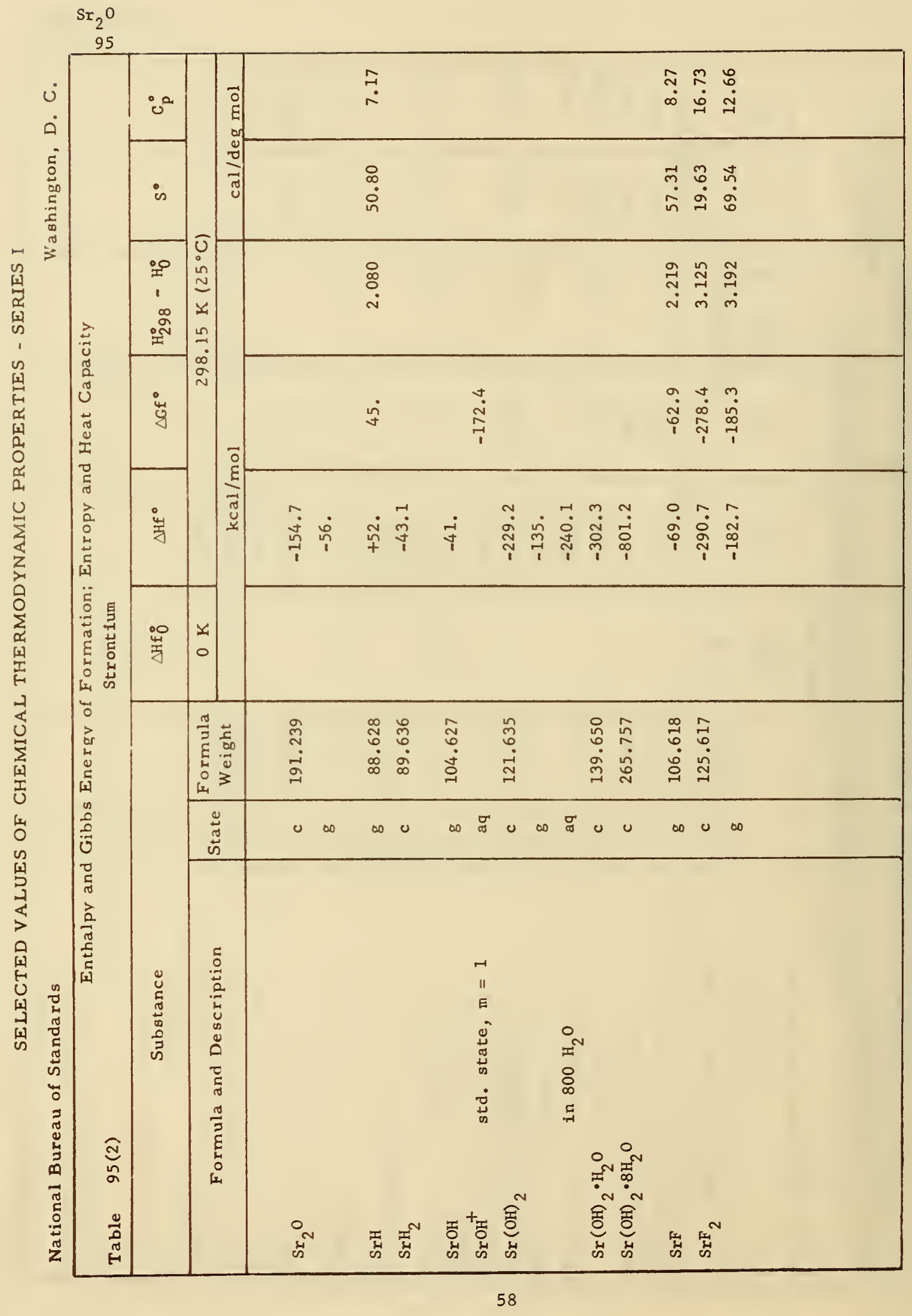




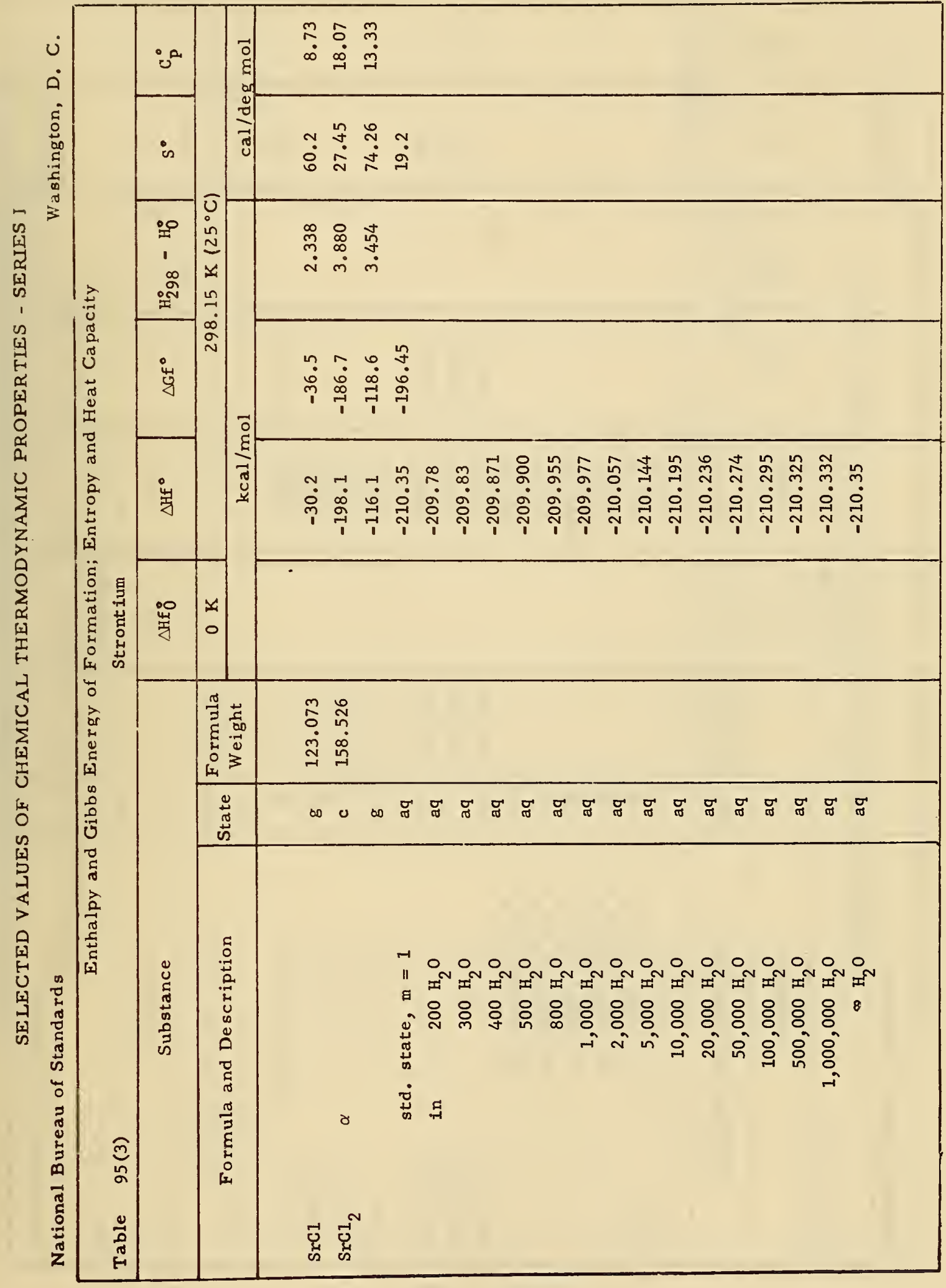




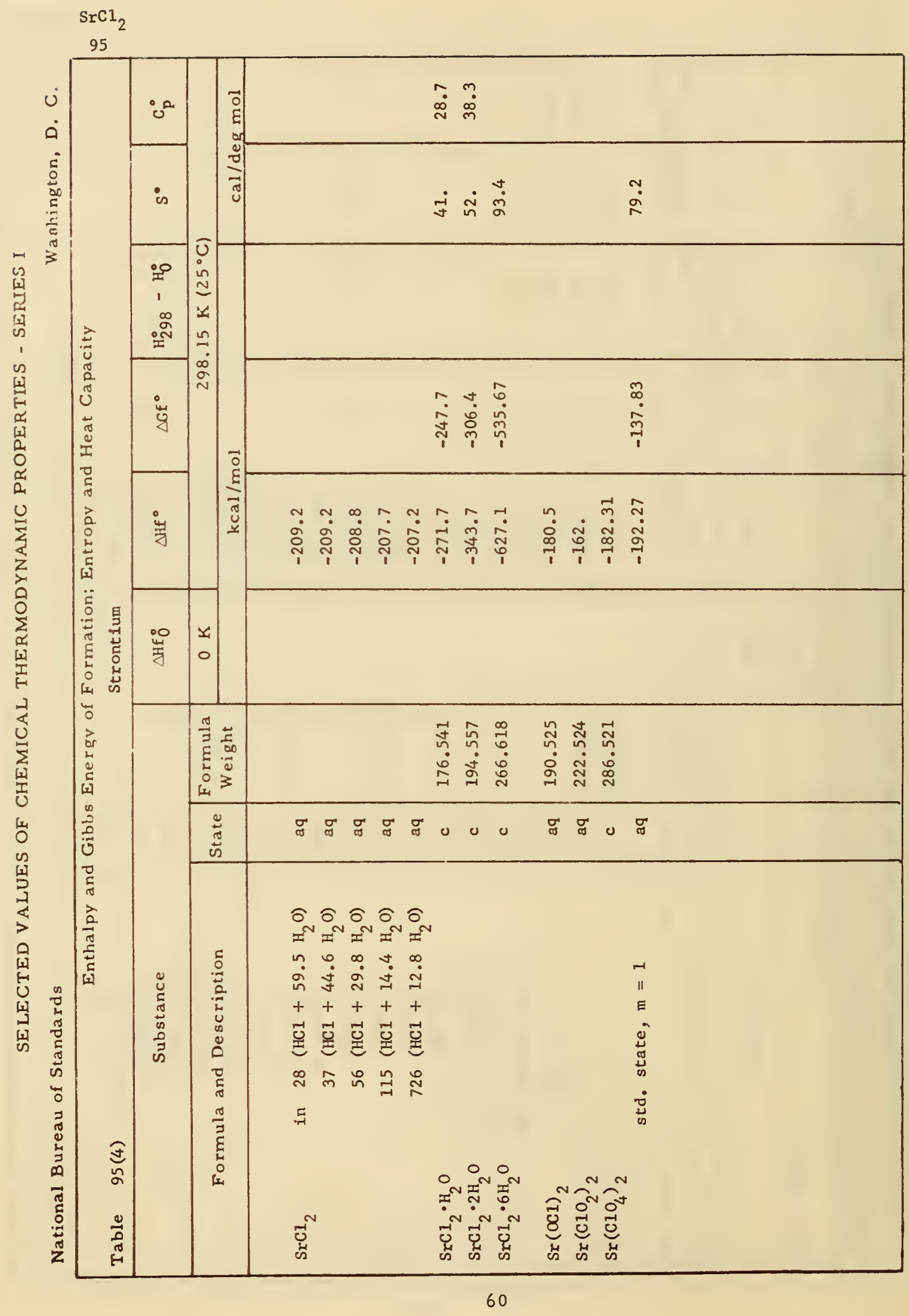


$\mathrm{Sr}\left(\mathrm{ClO}_{4}\right)_{2}$

95

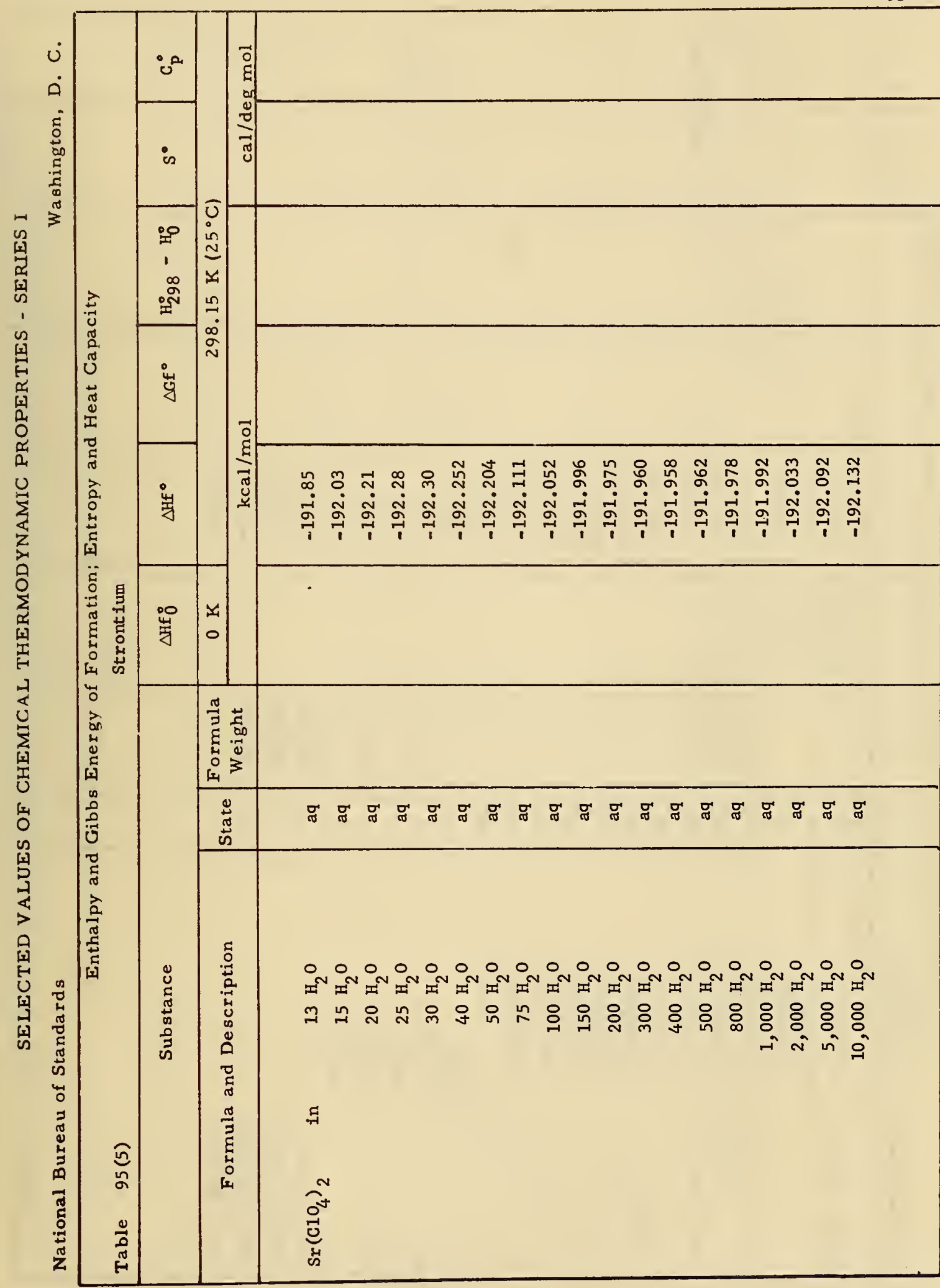




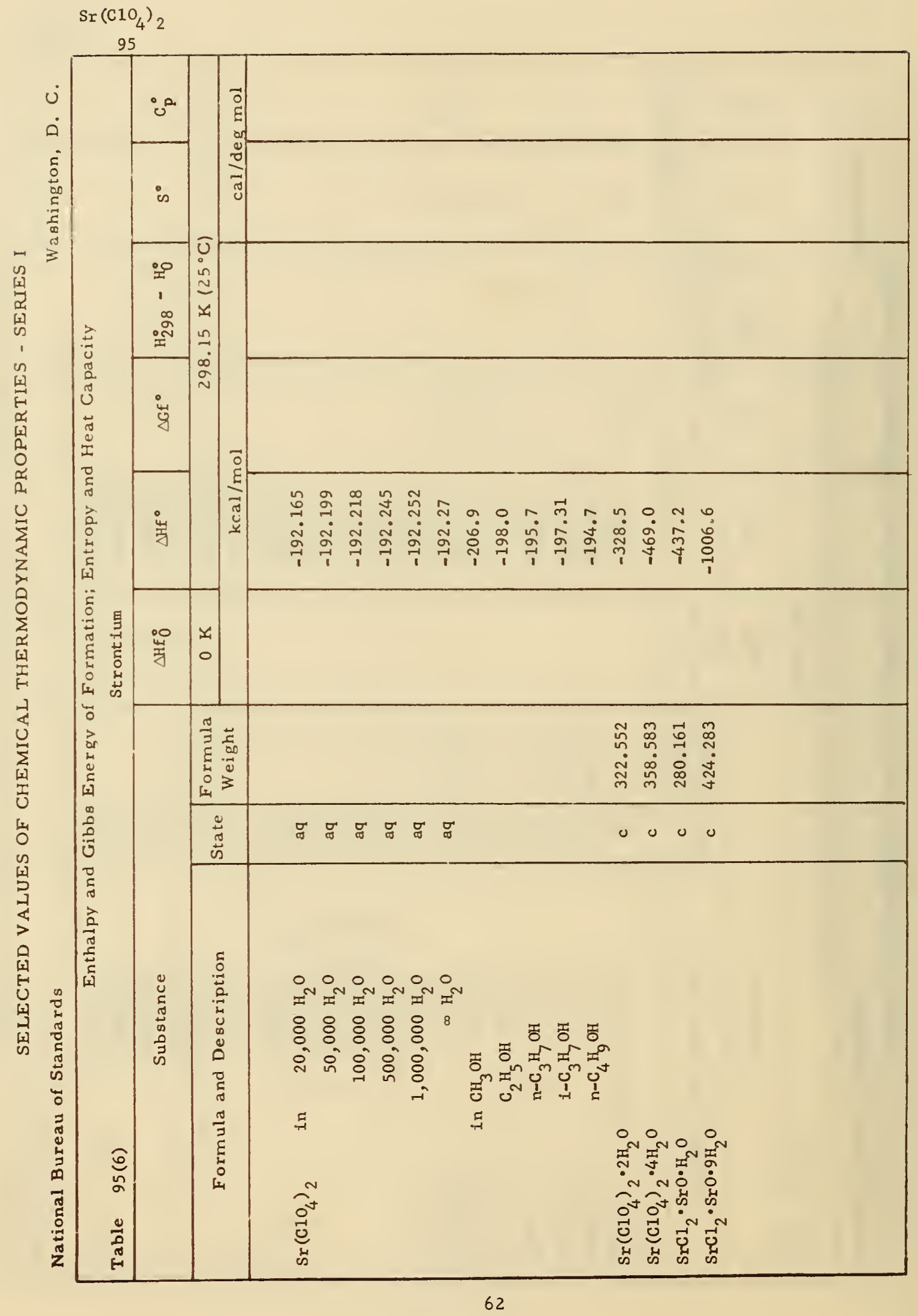




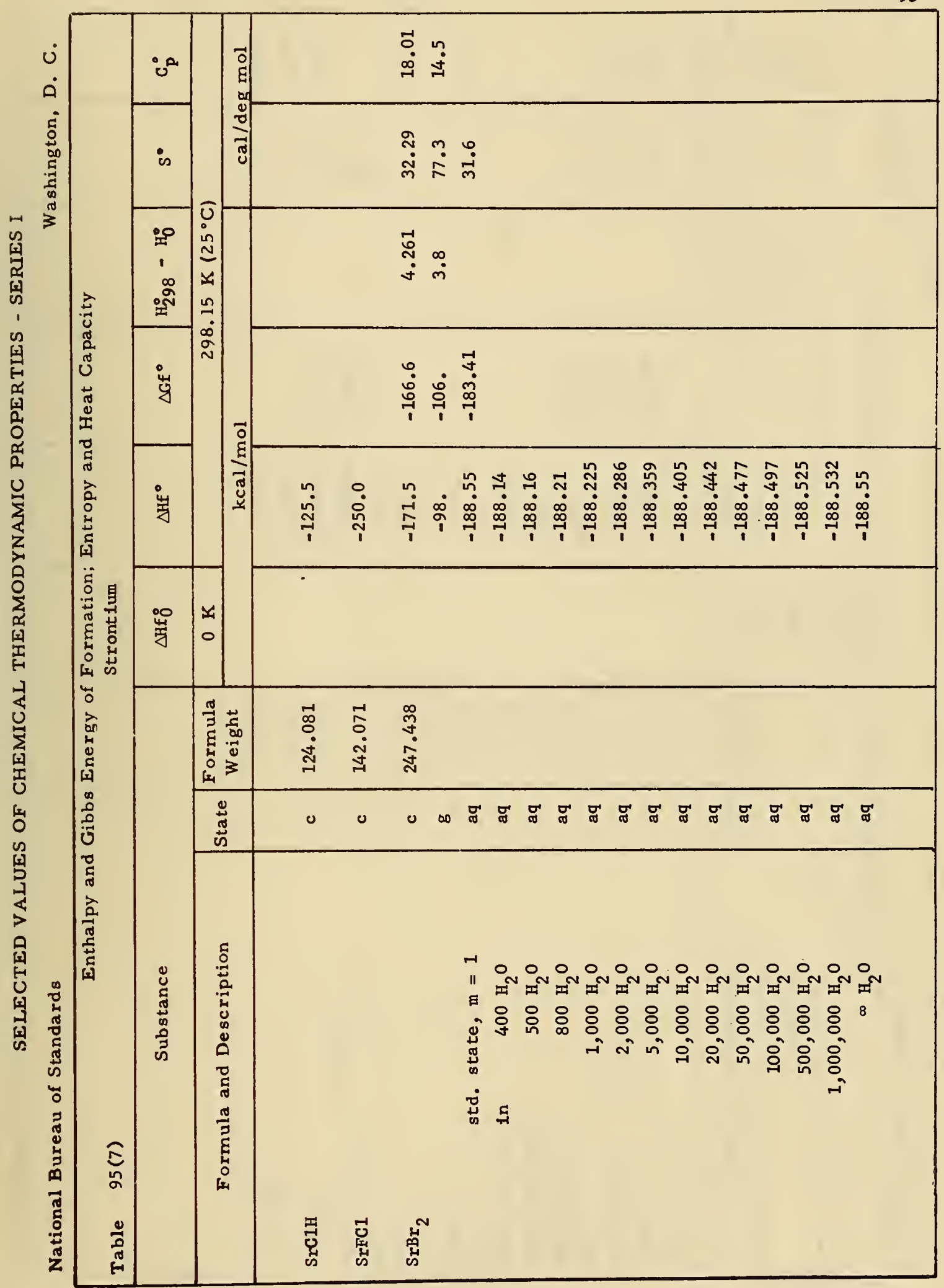




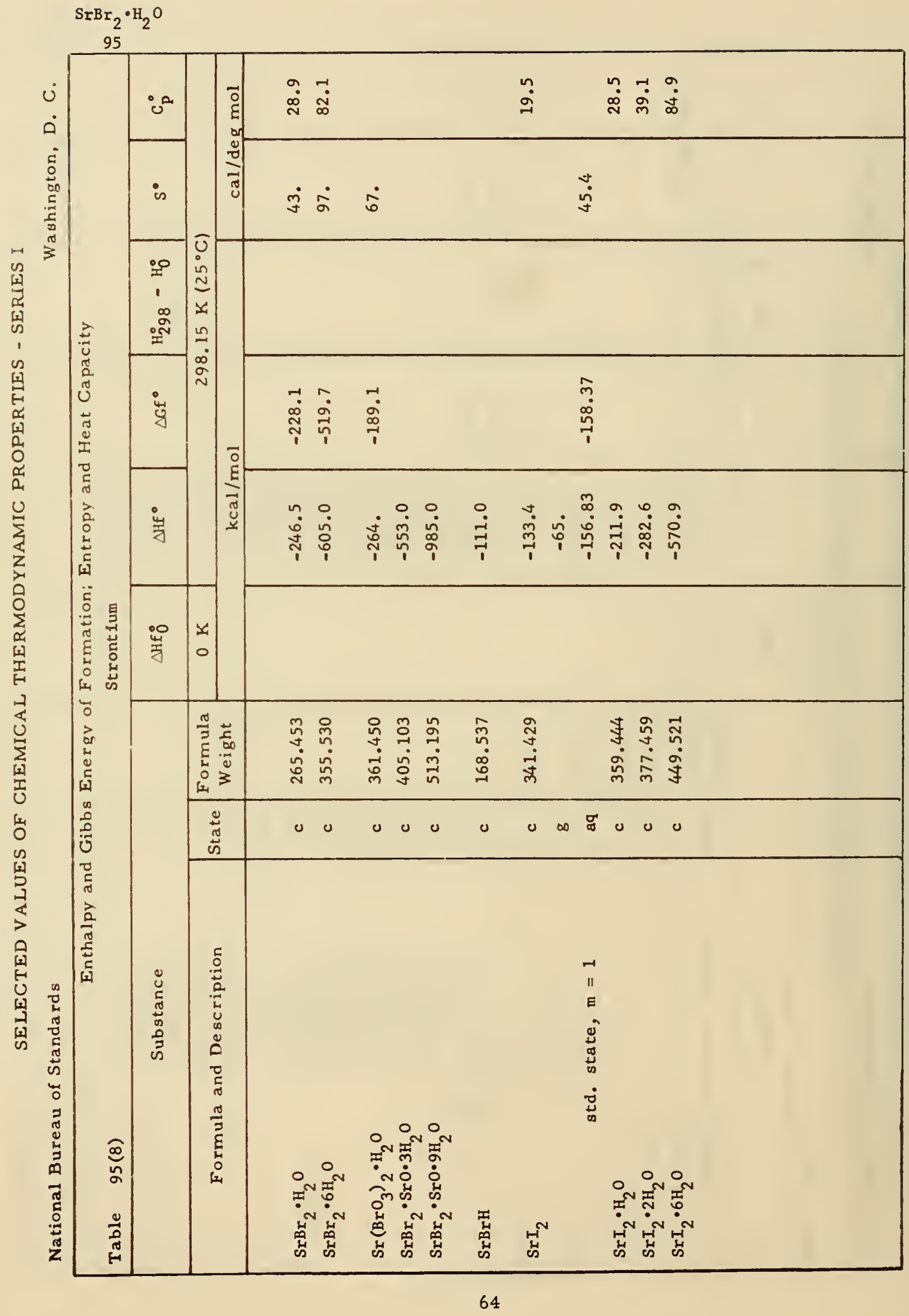




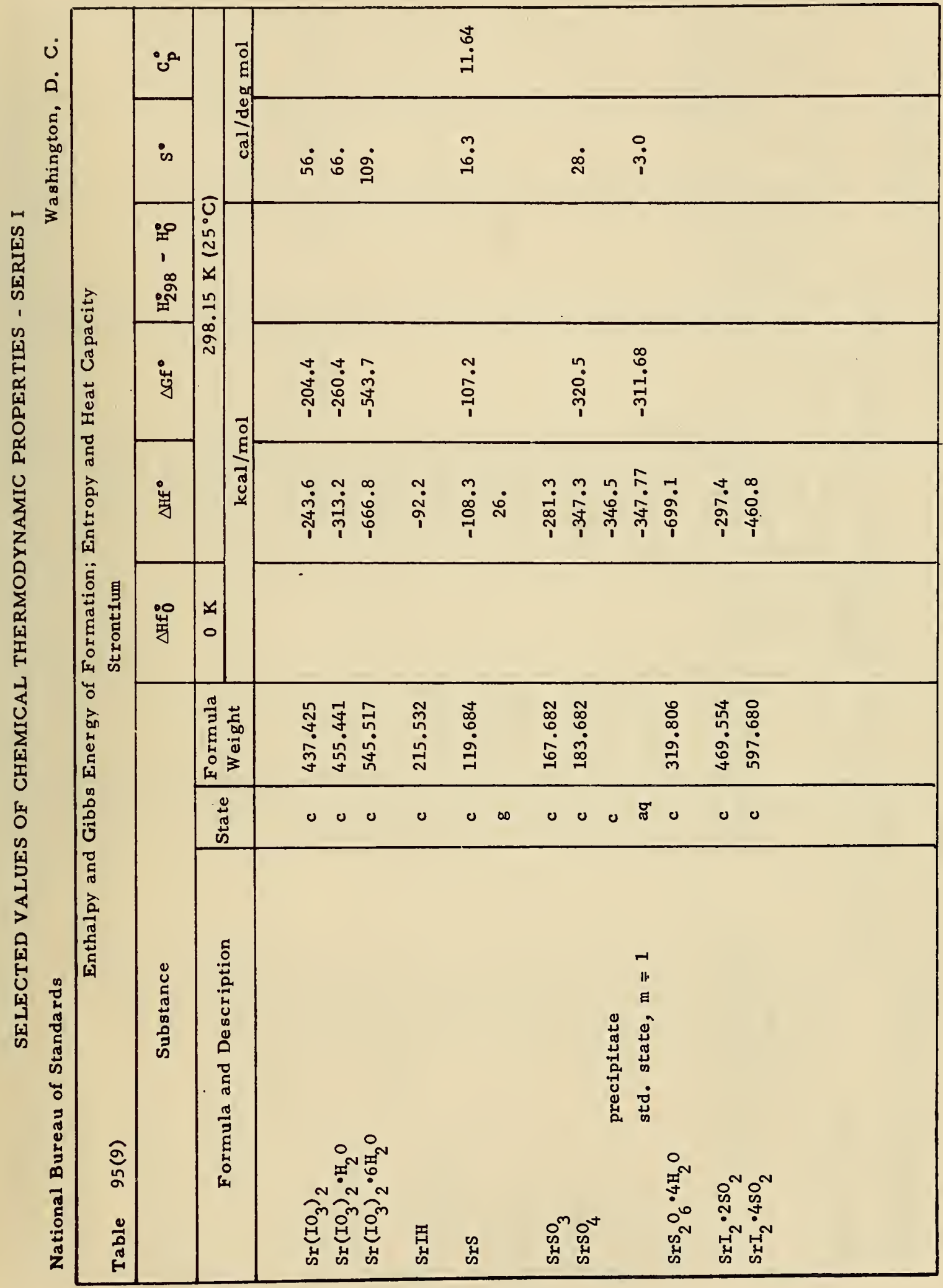




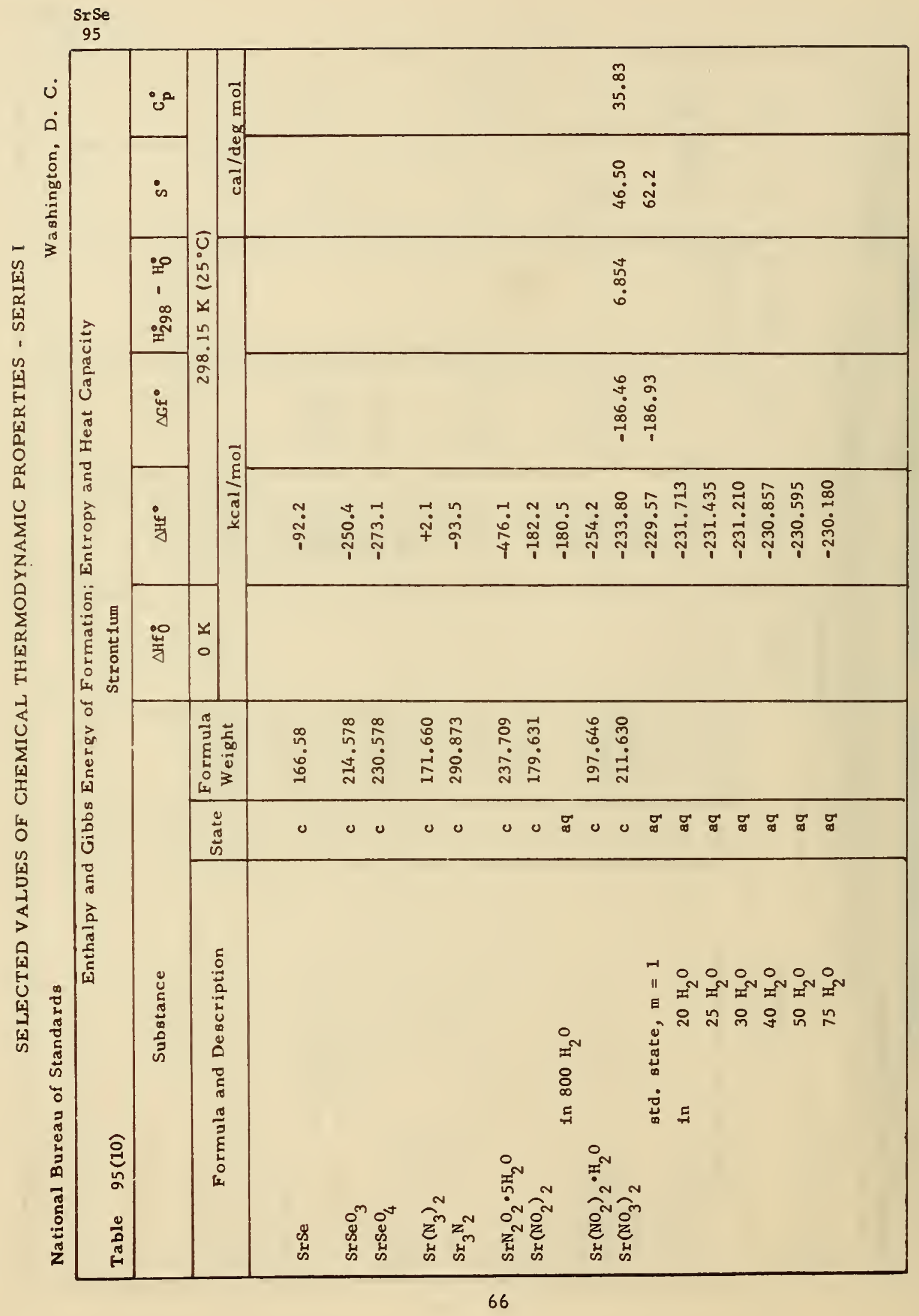




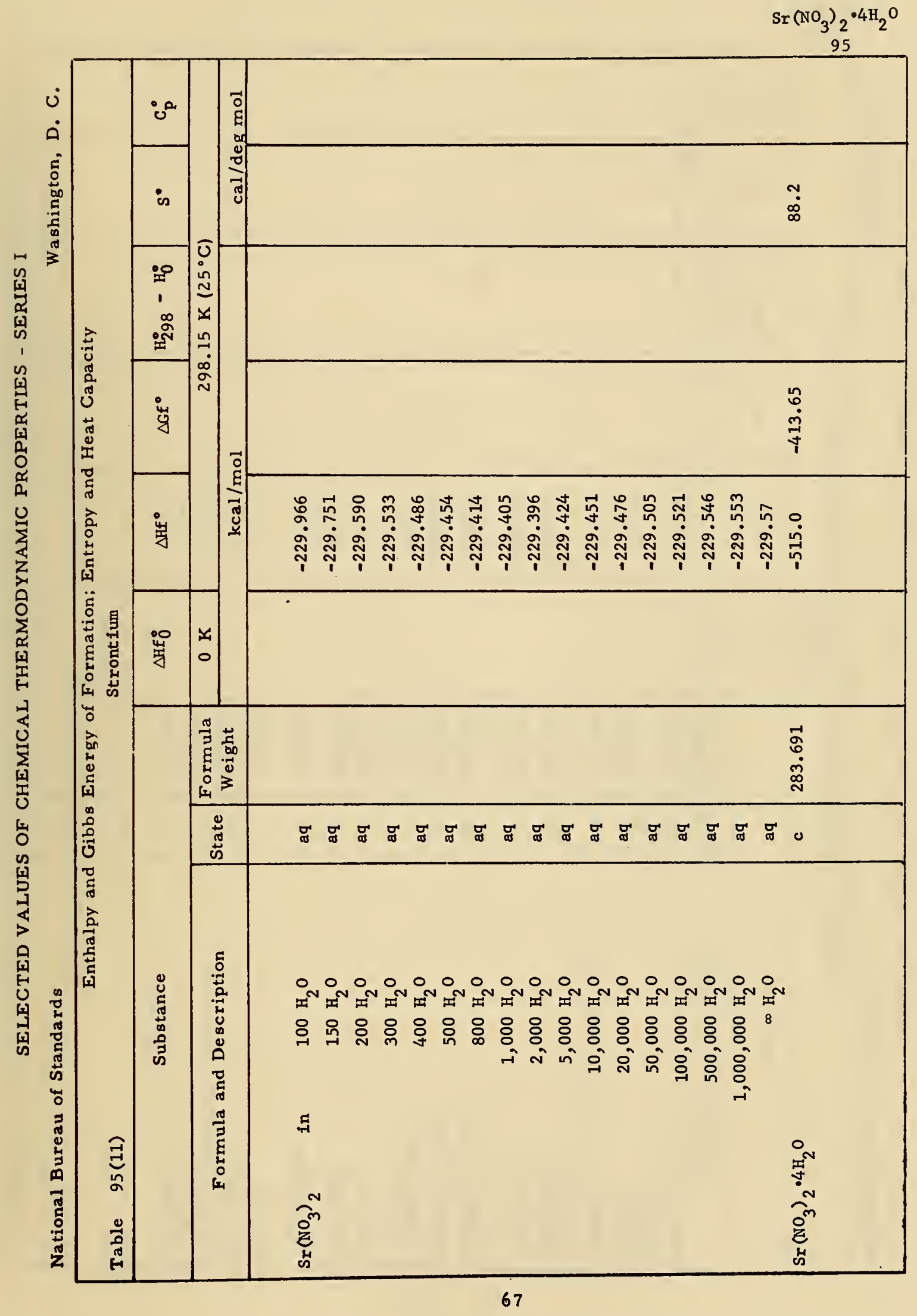




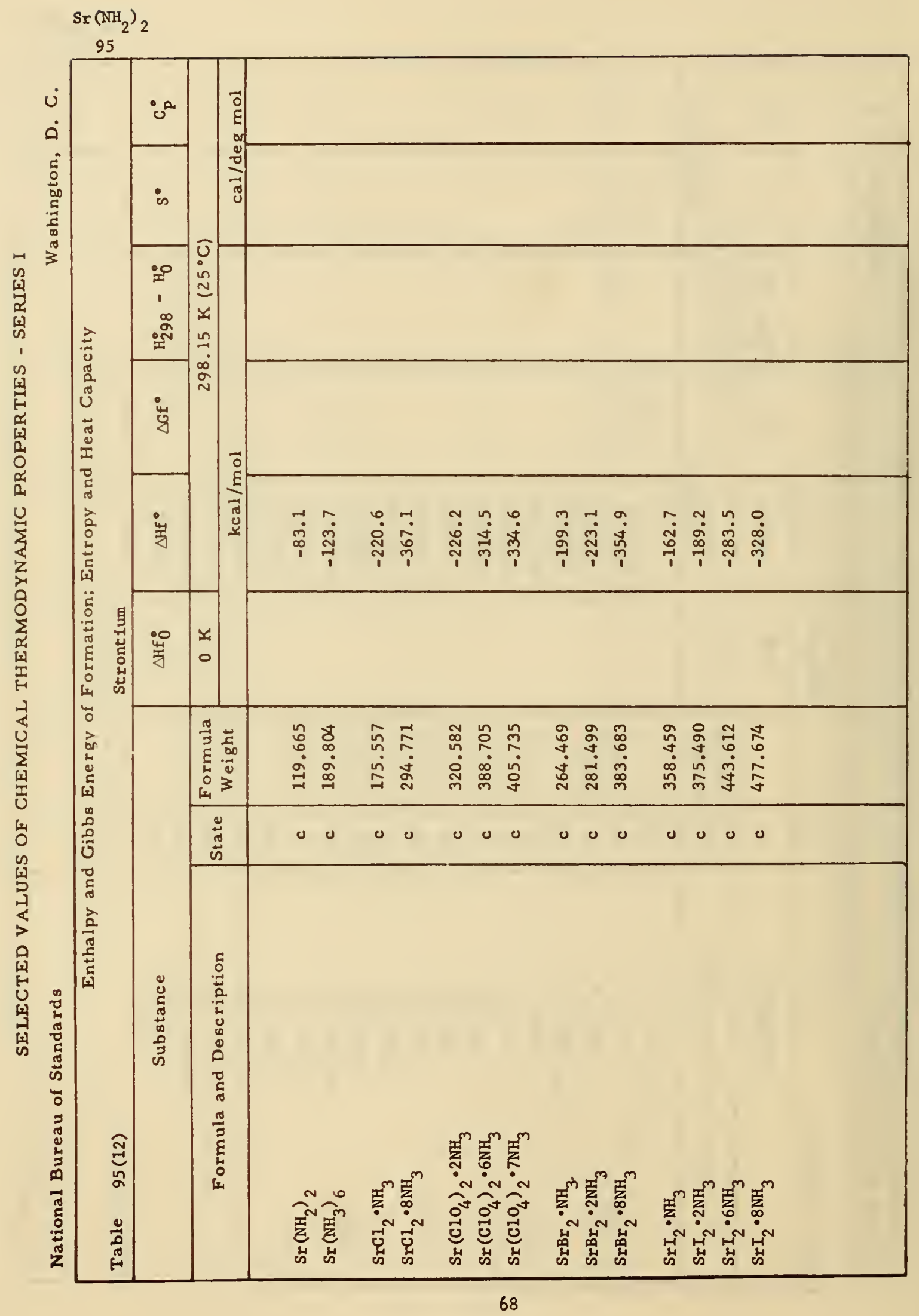




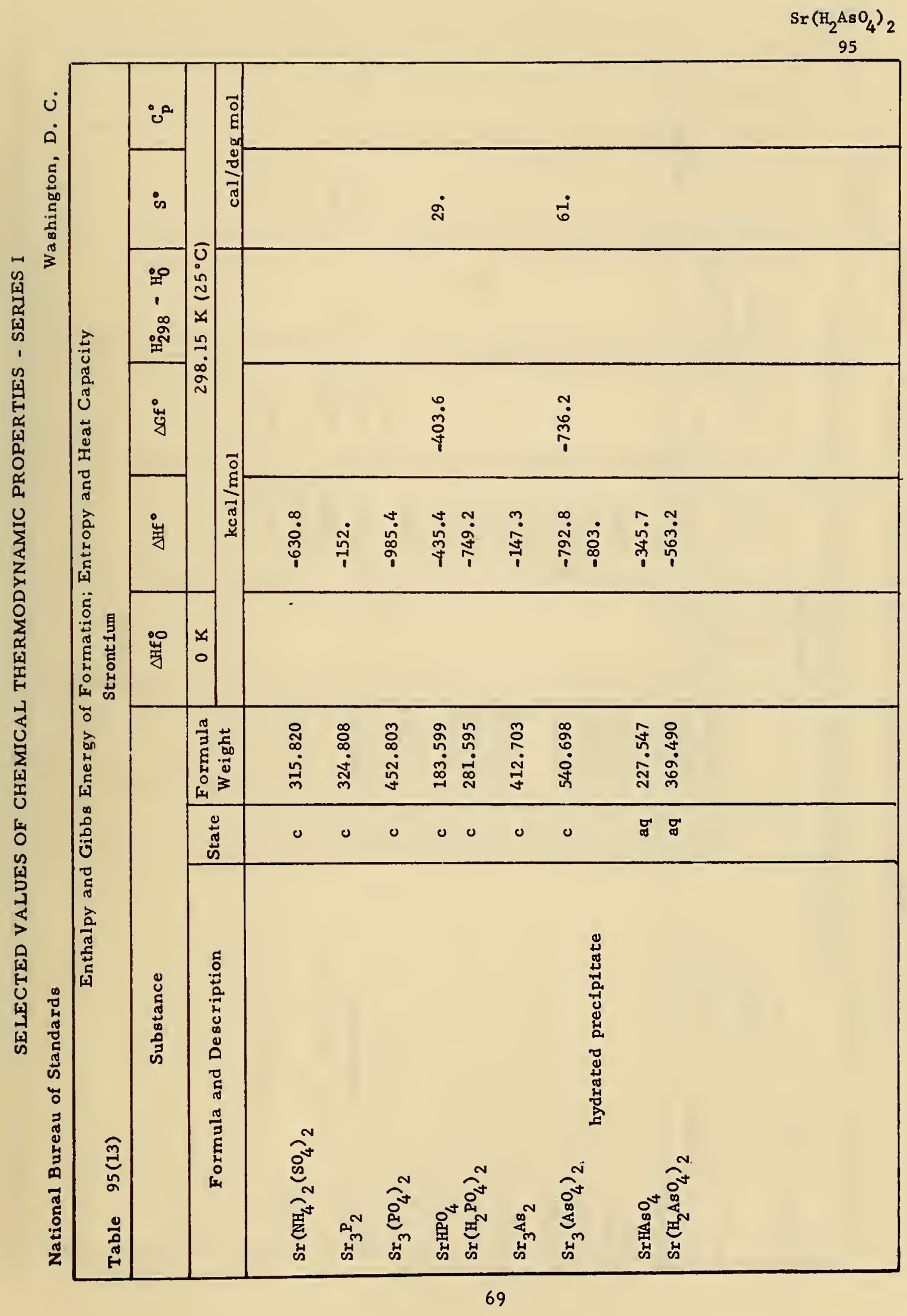




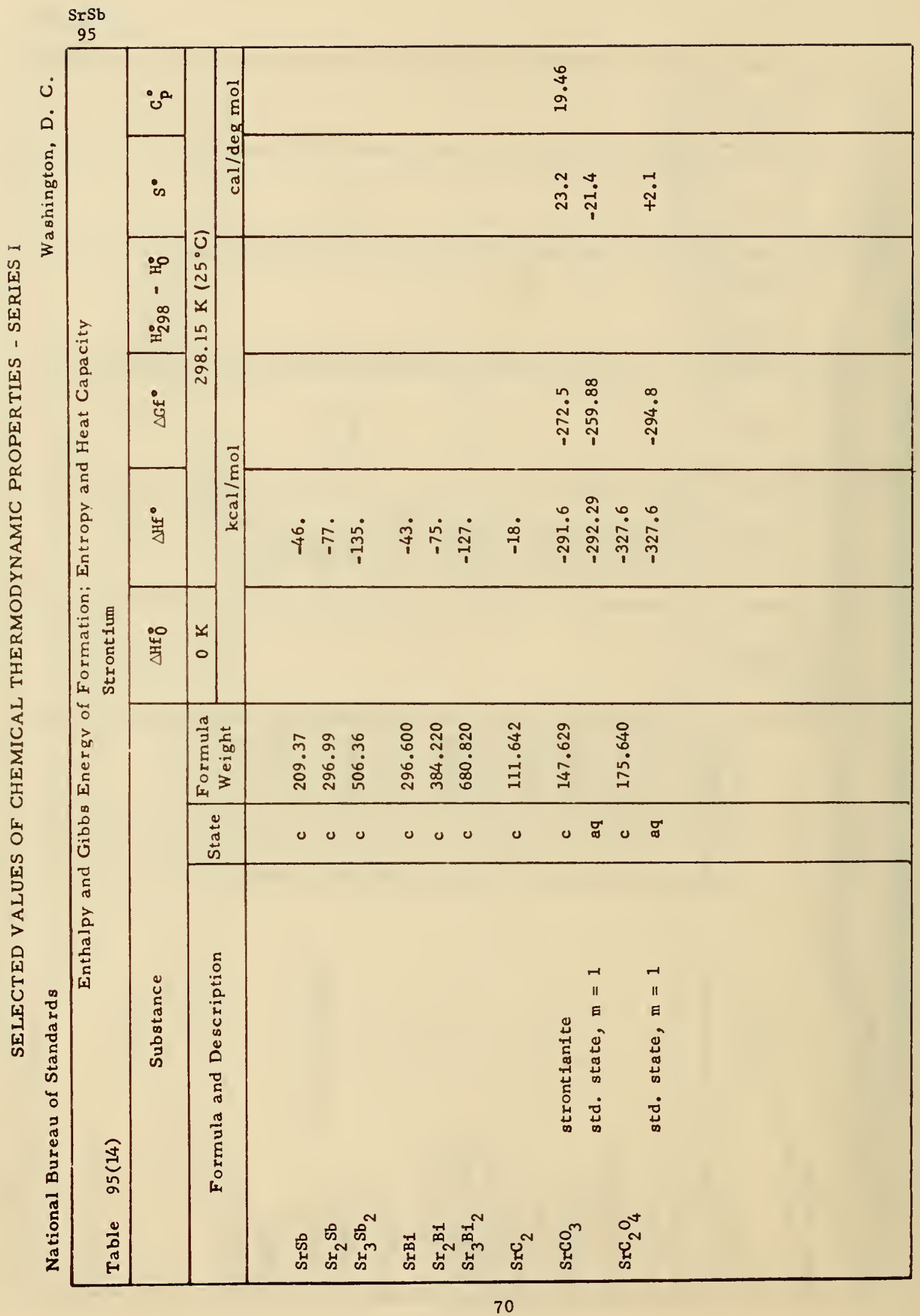




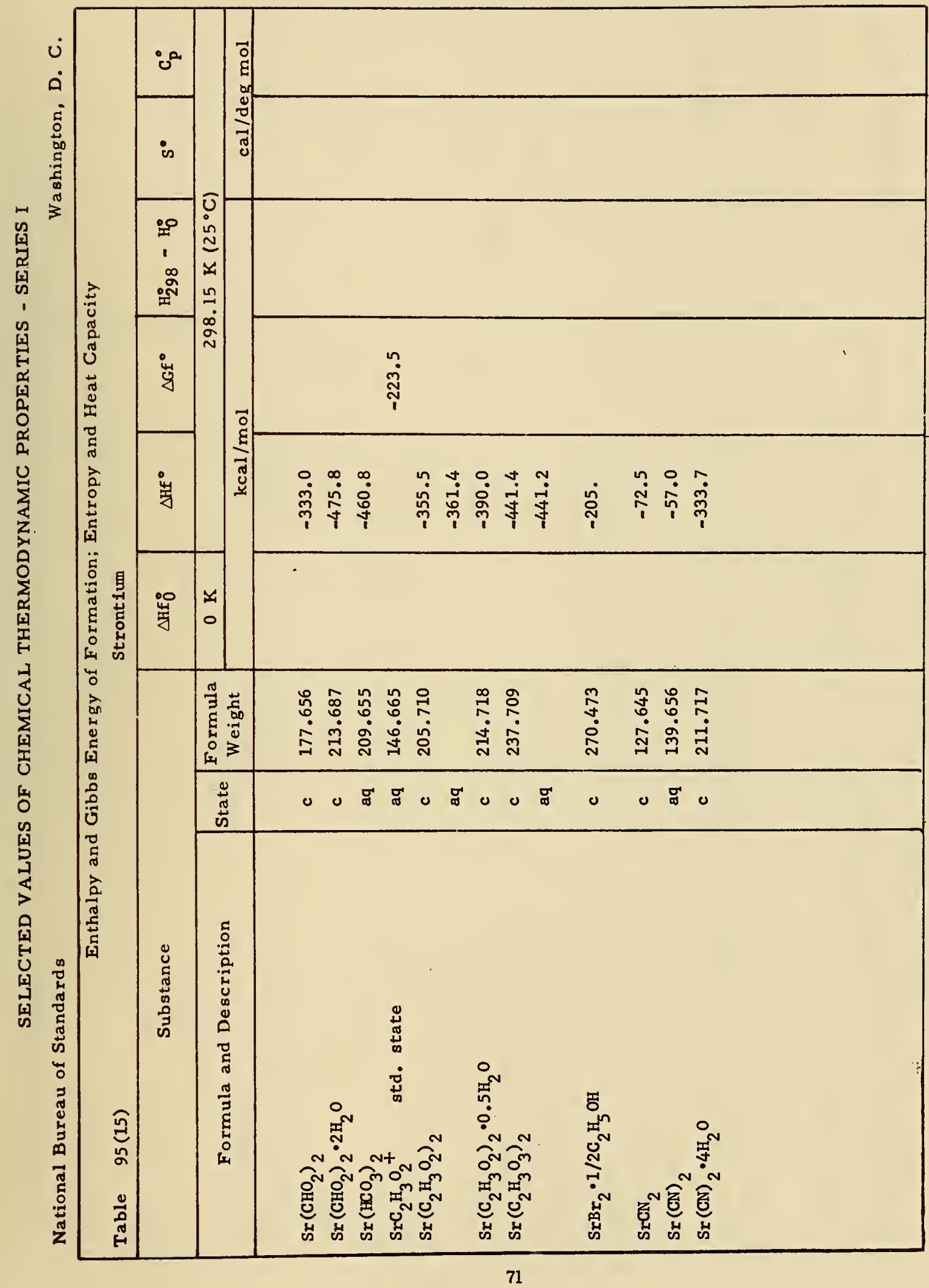




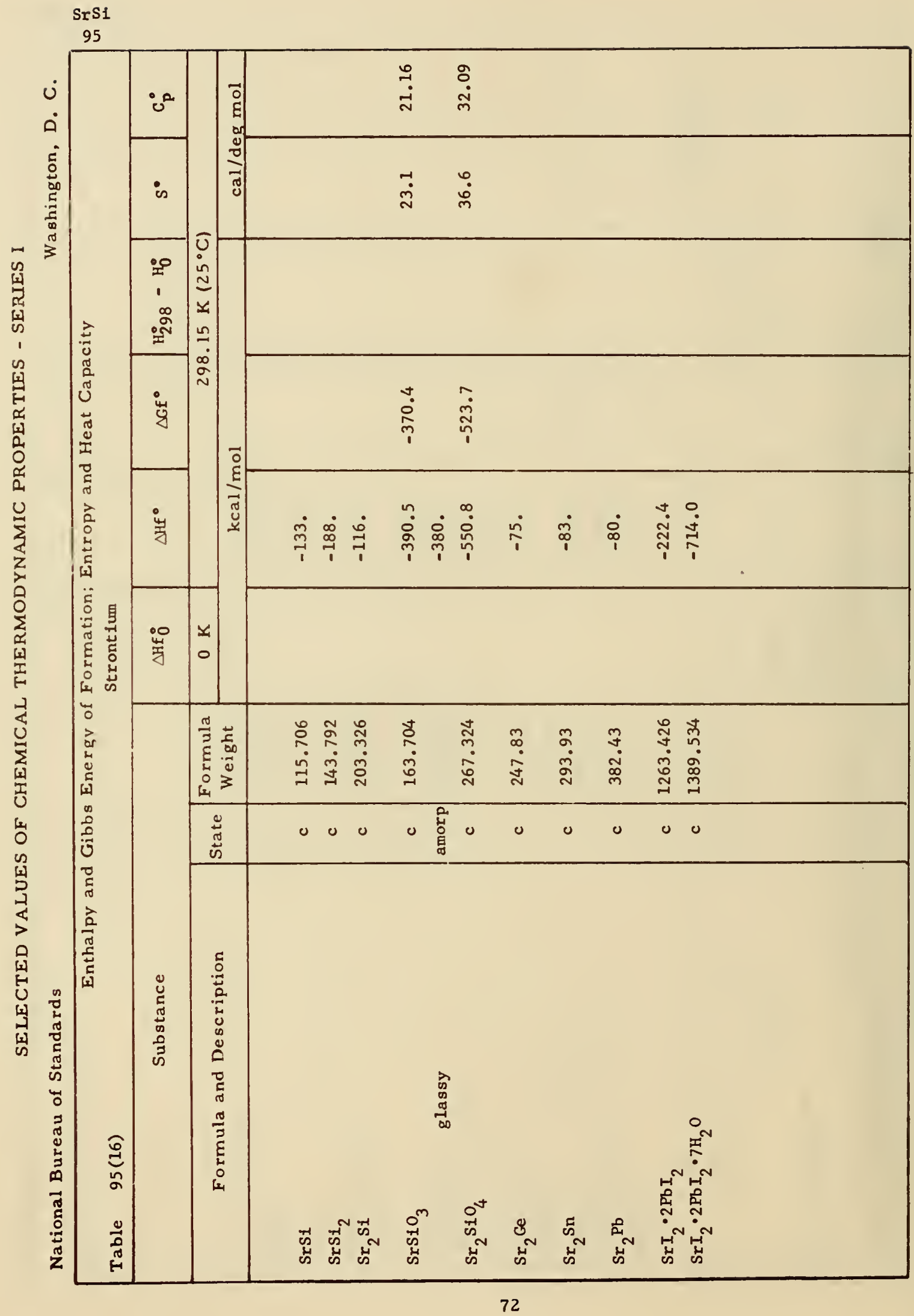


$\mathrm{Sr}\left[\mathrm{Hg}(\mathrm{CN})_{3}\right]_{2}$

95

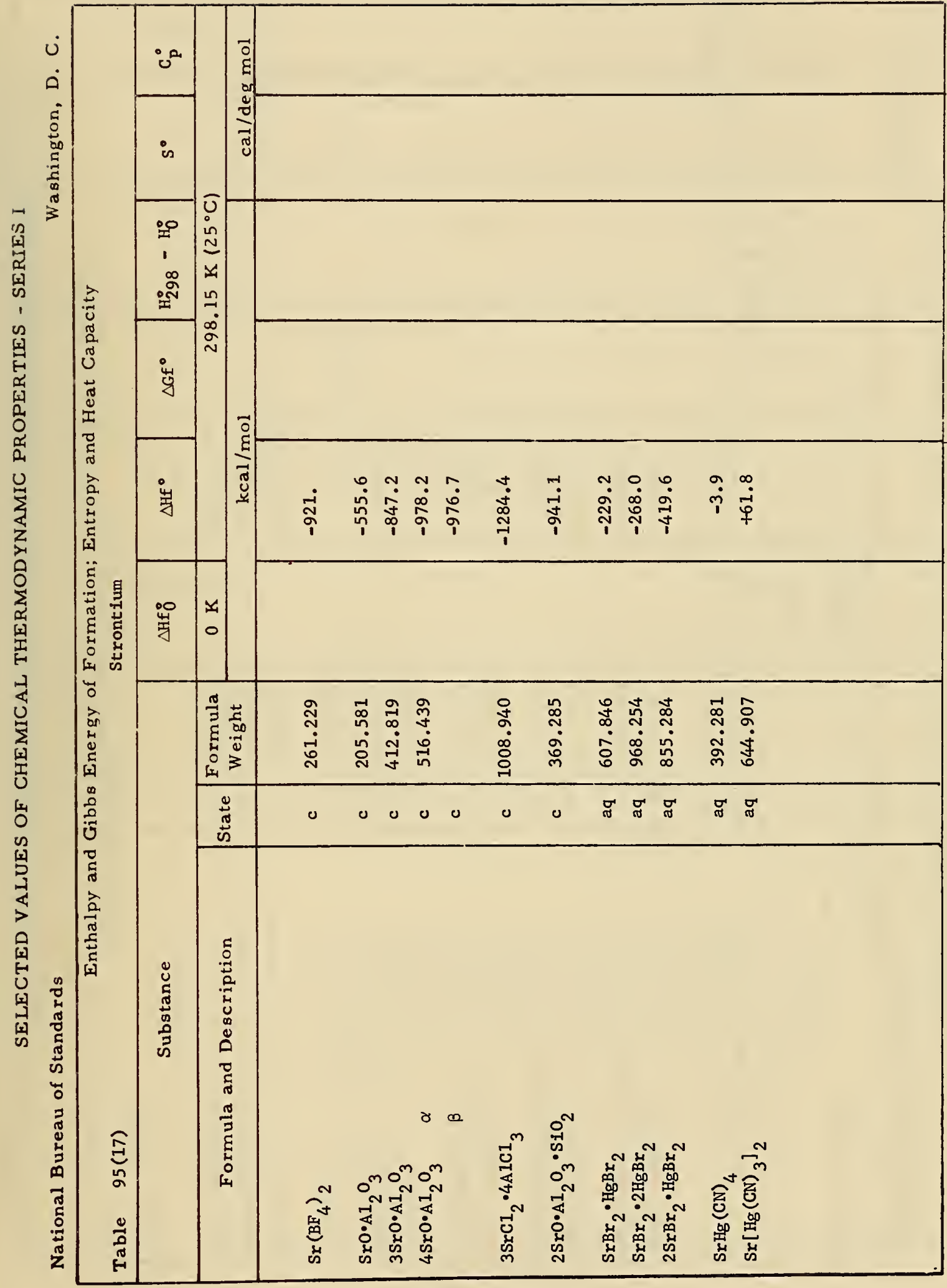




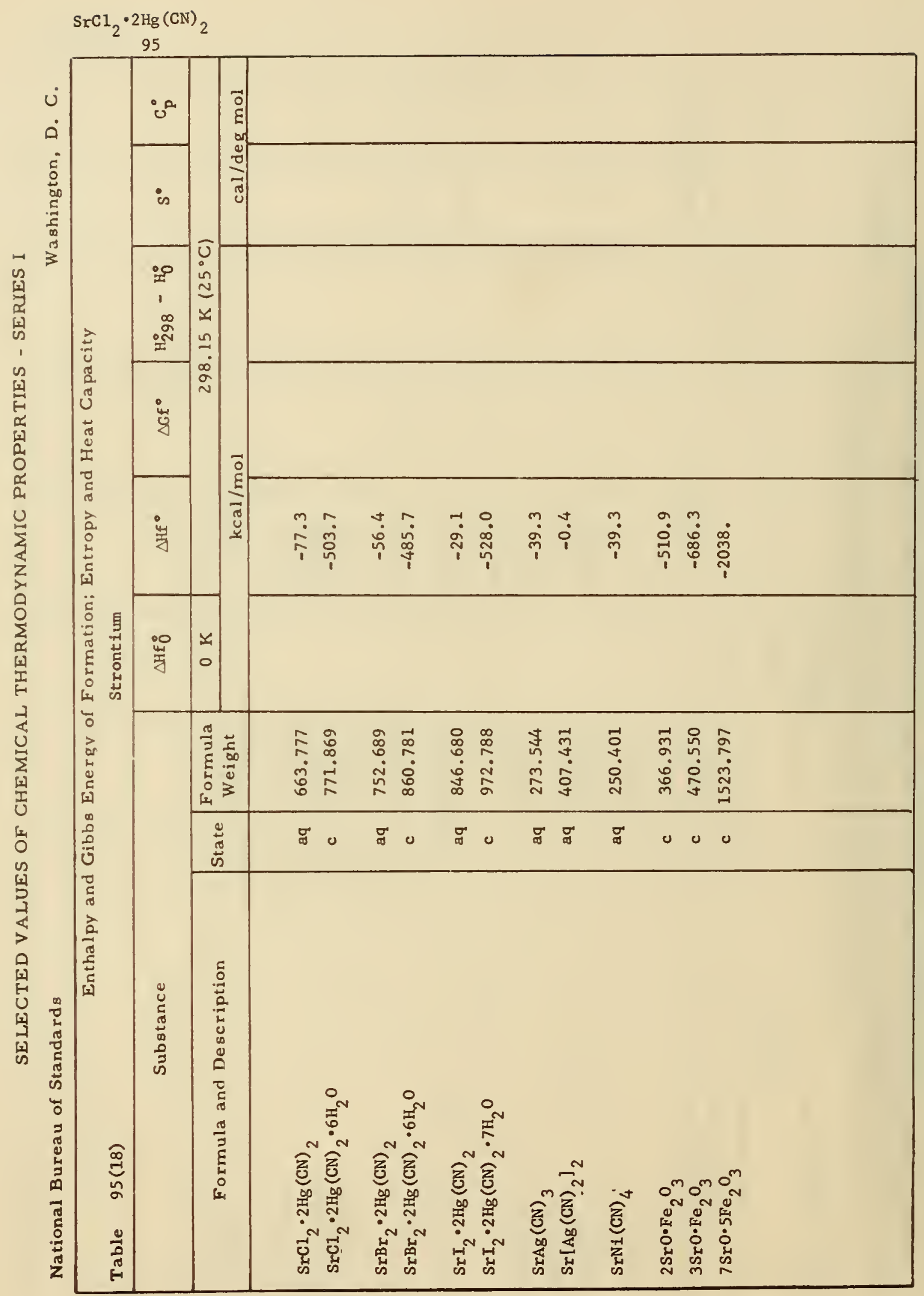




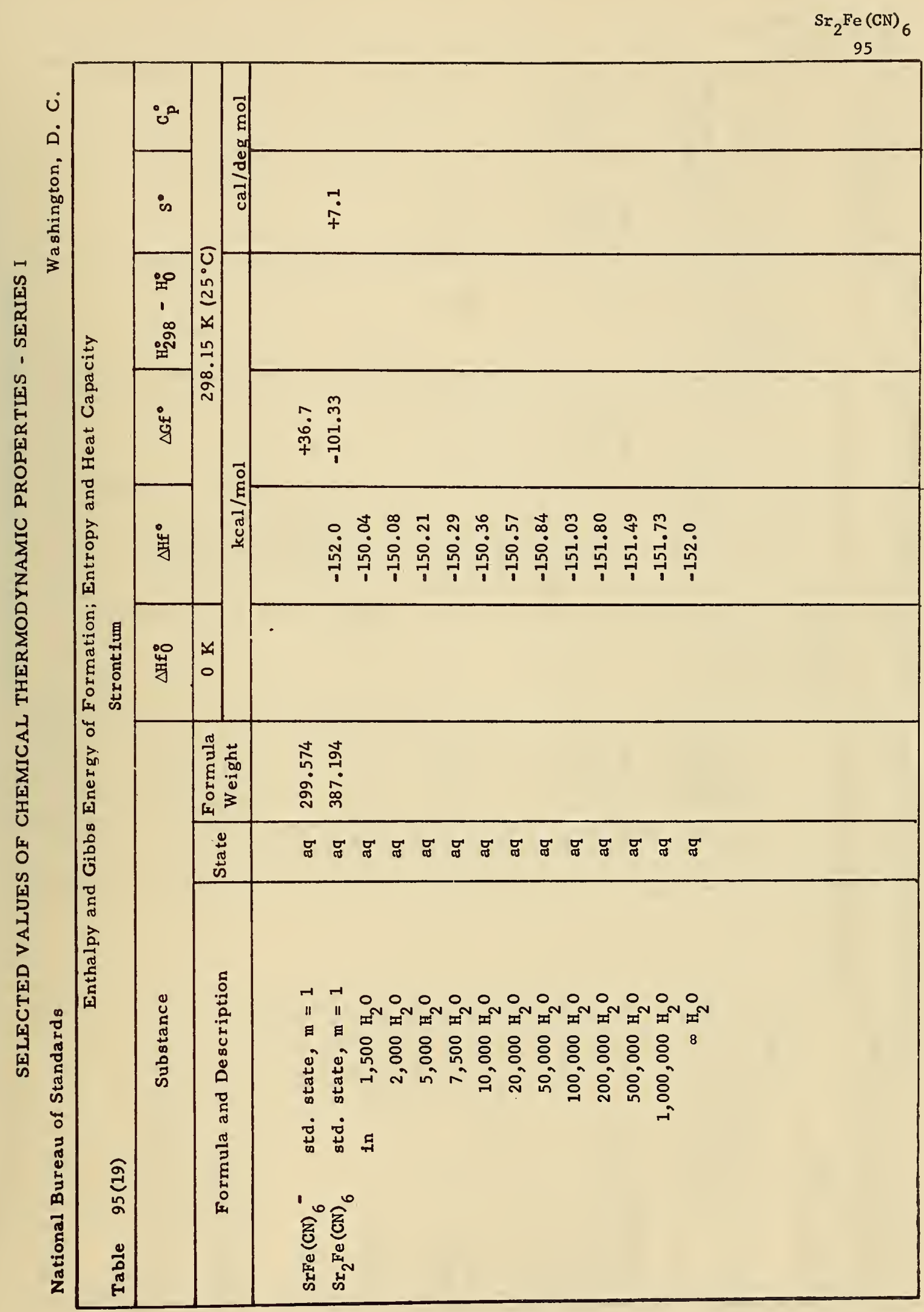




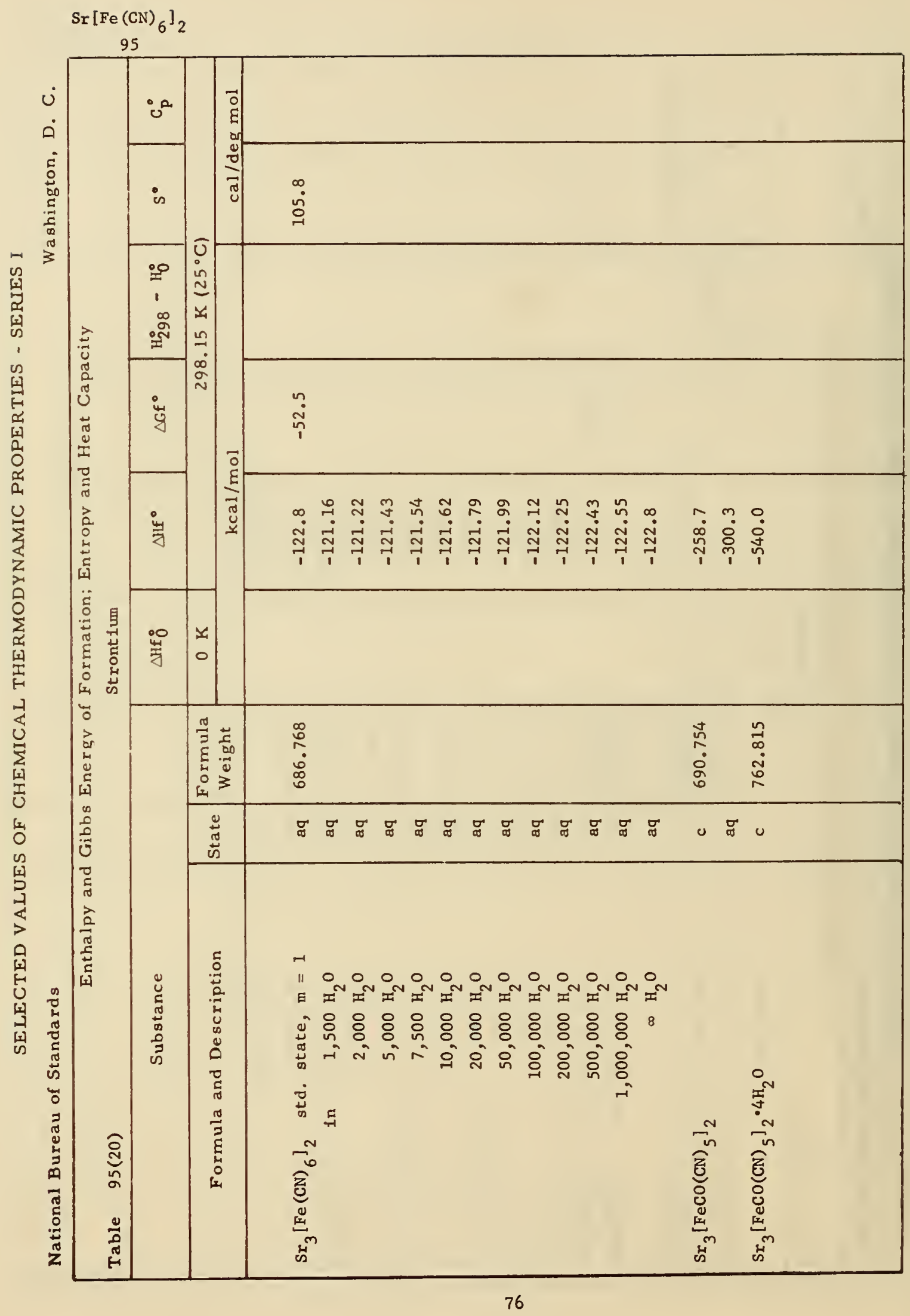




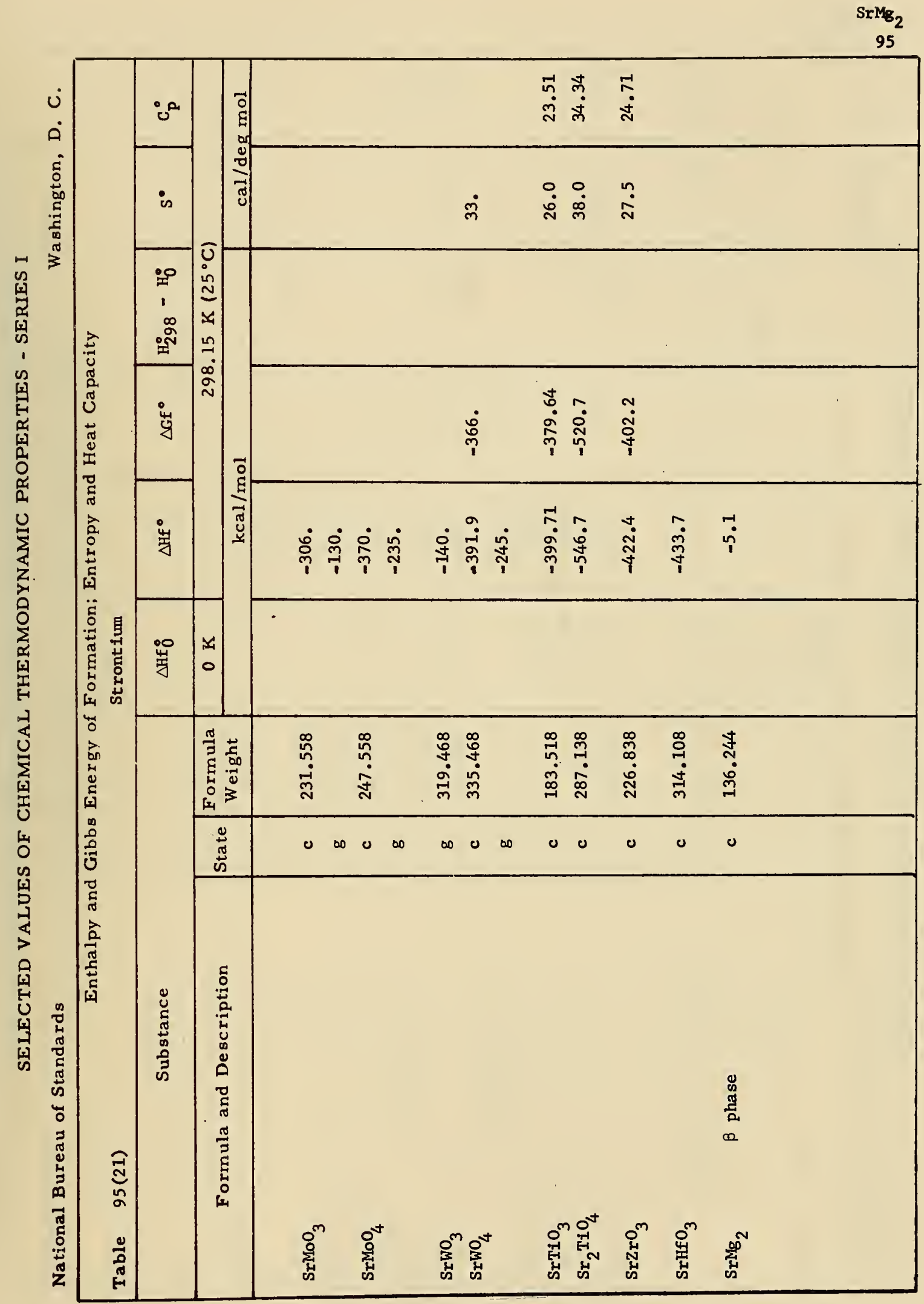




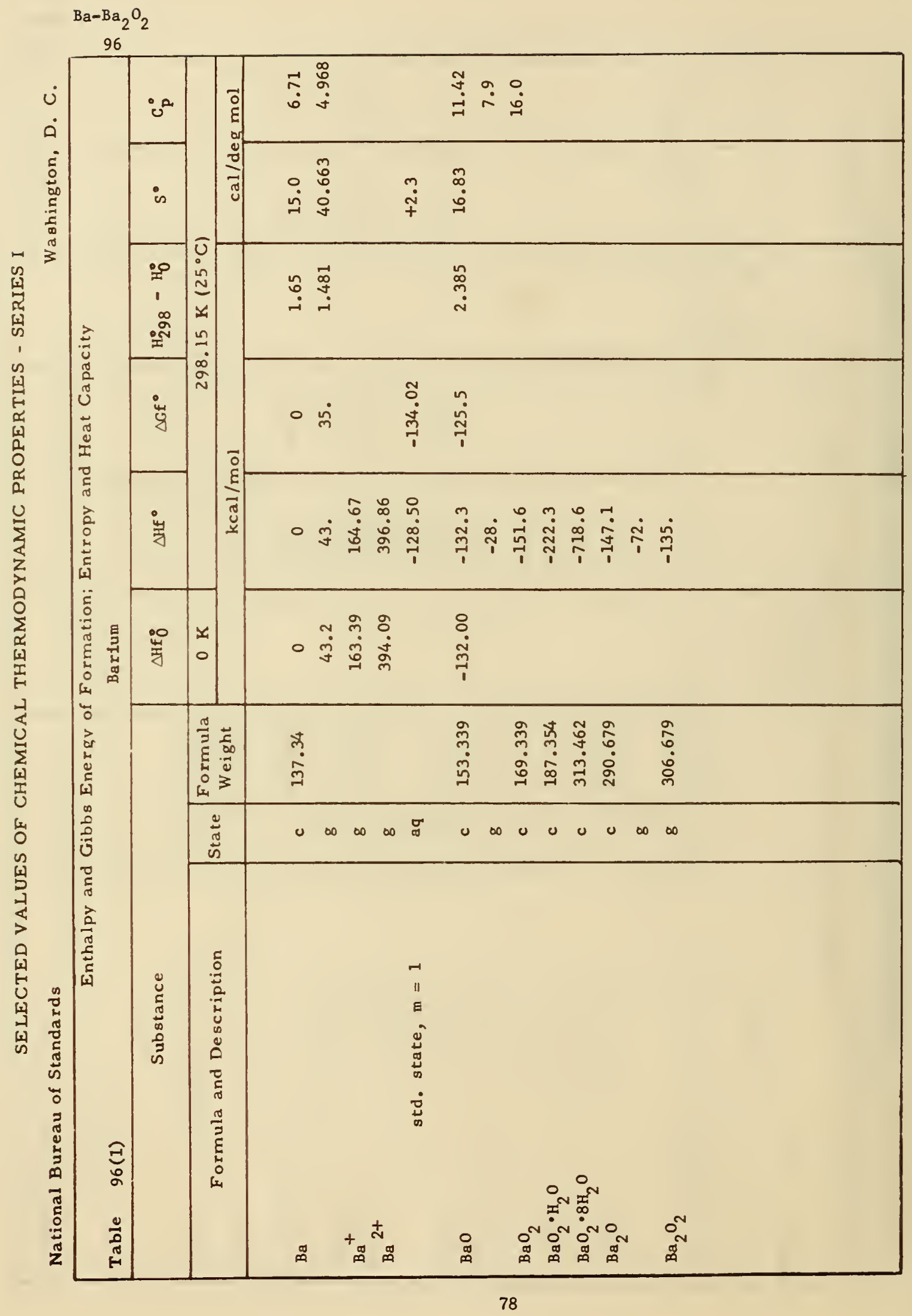




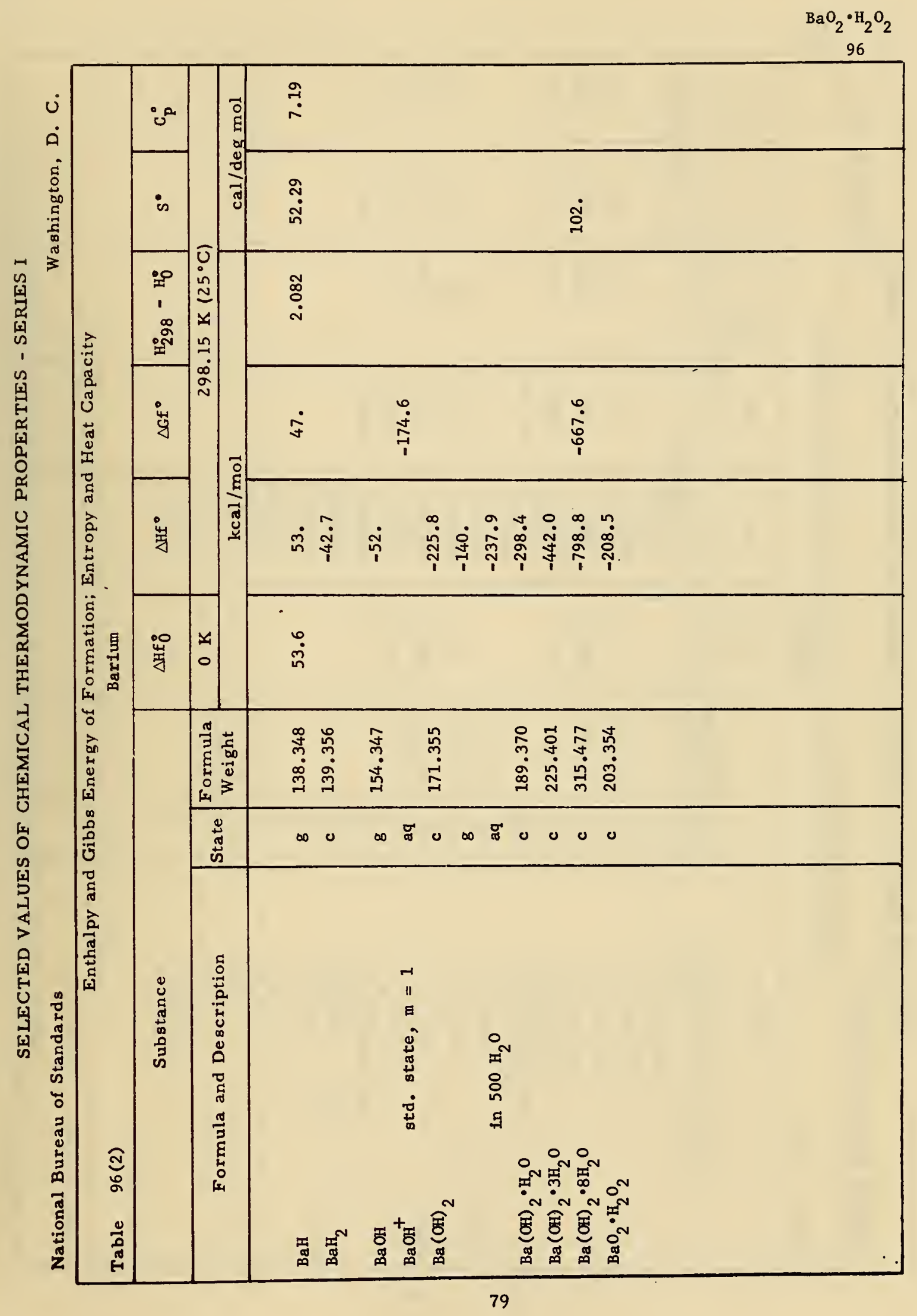




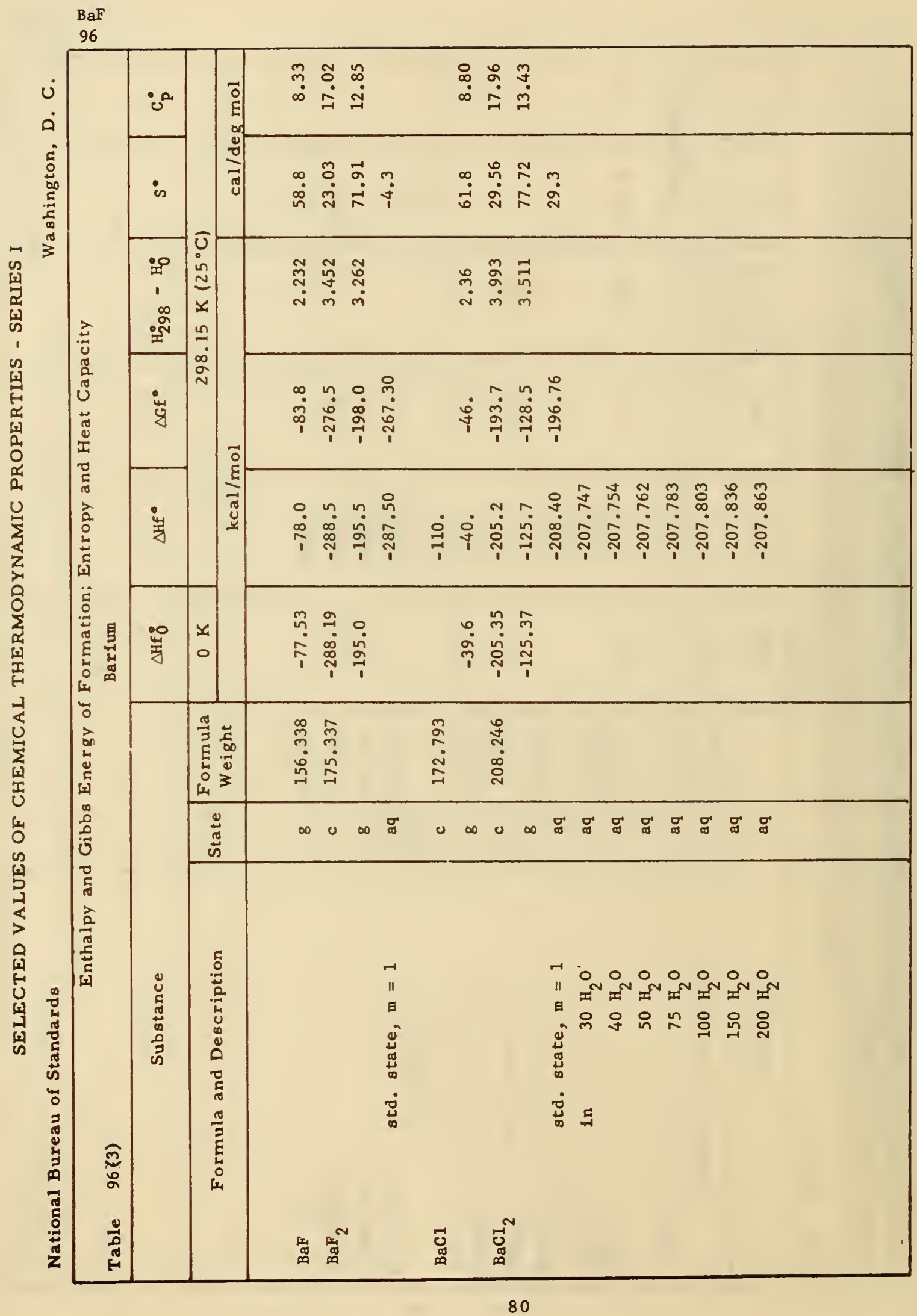




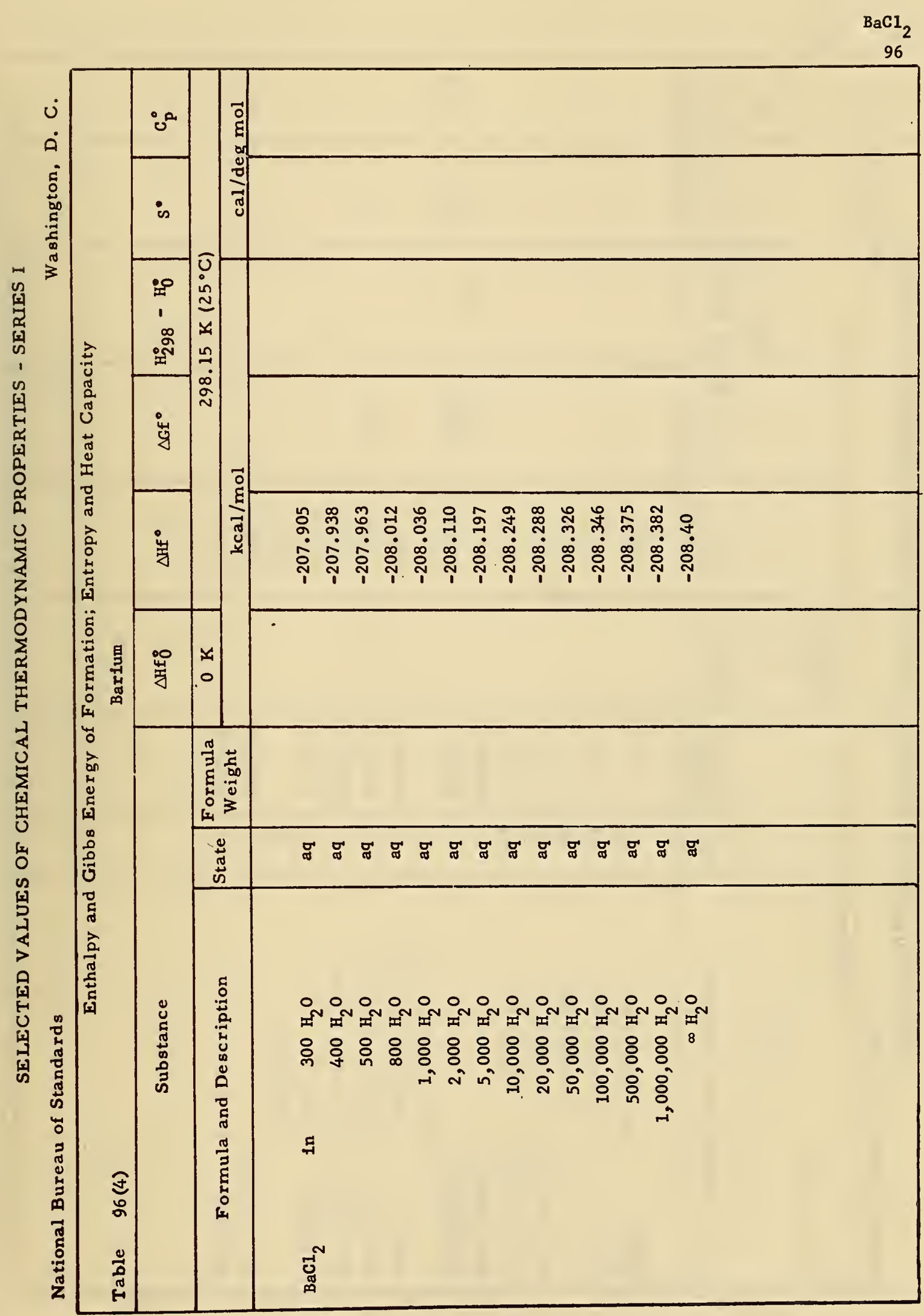




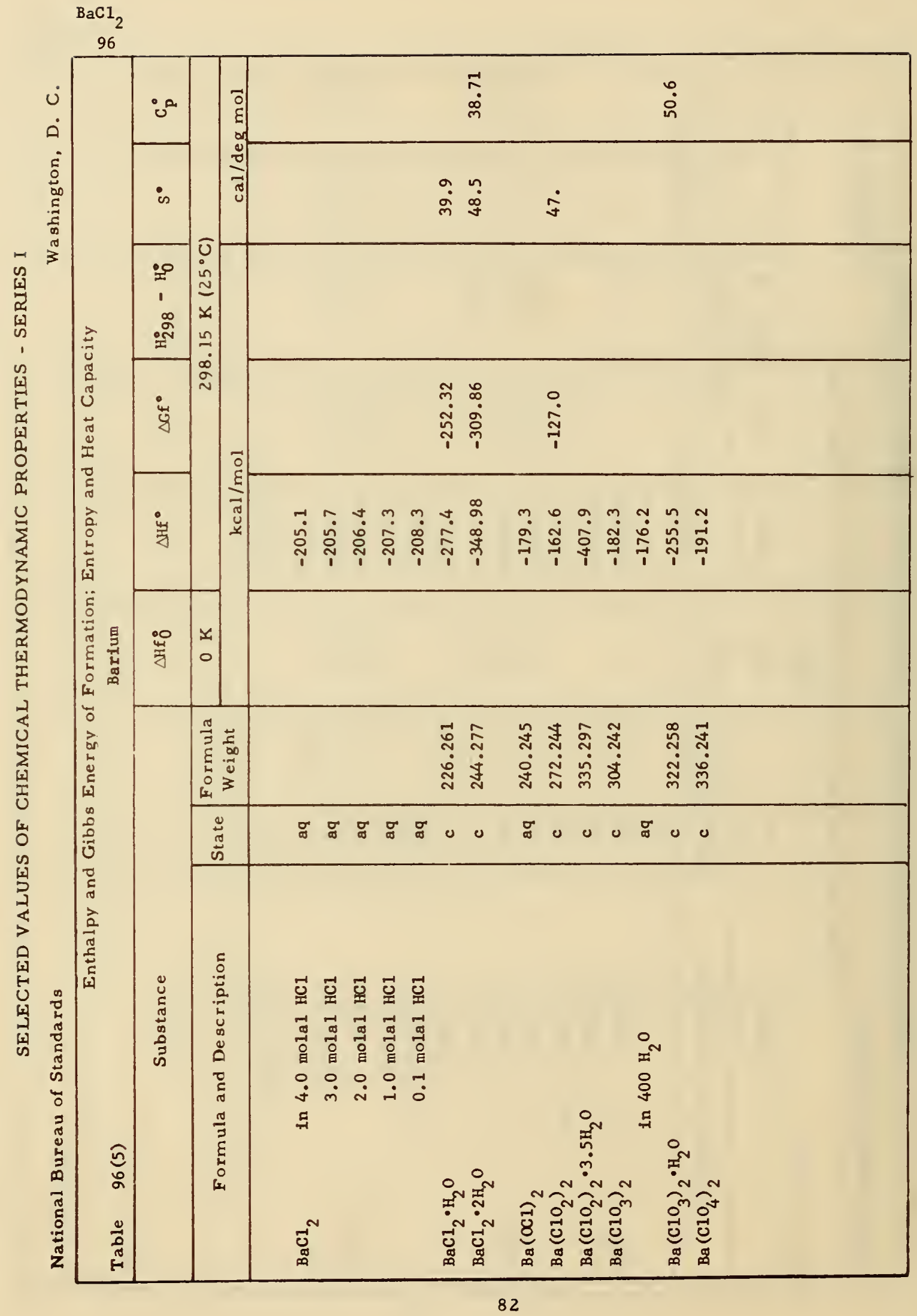




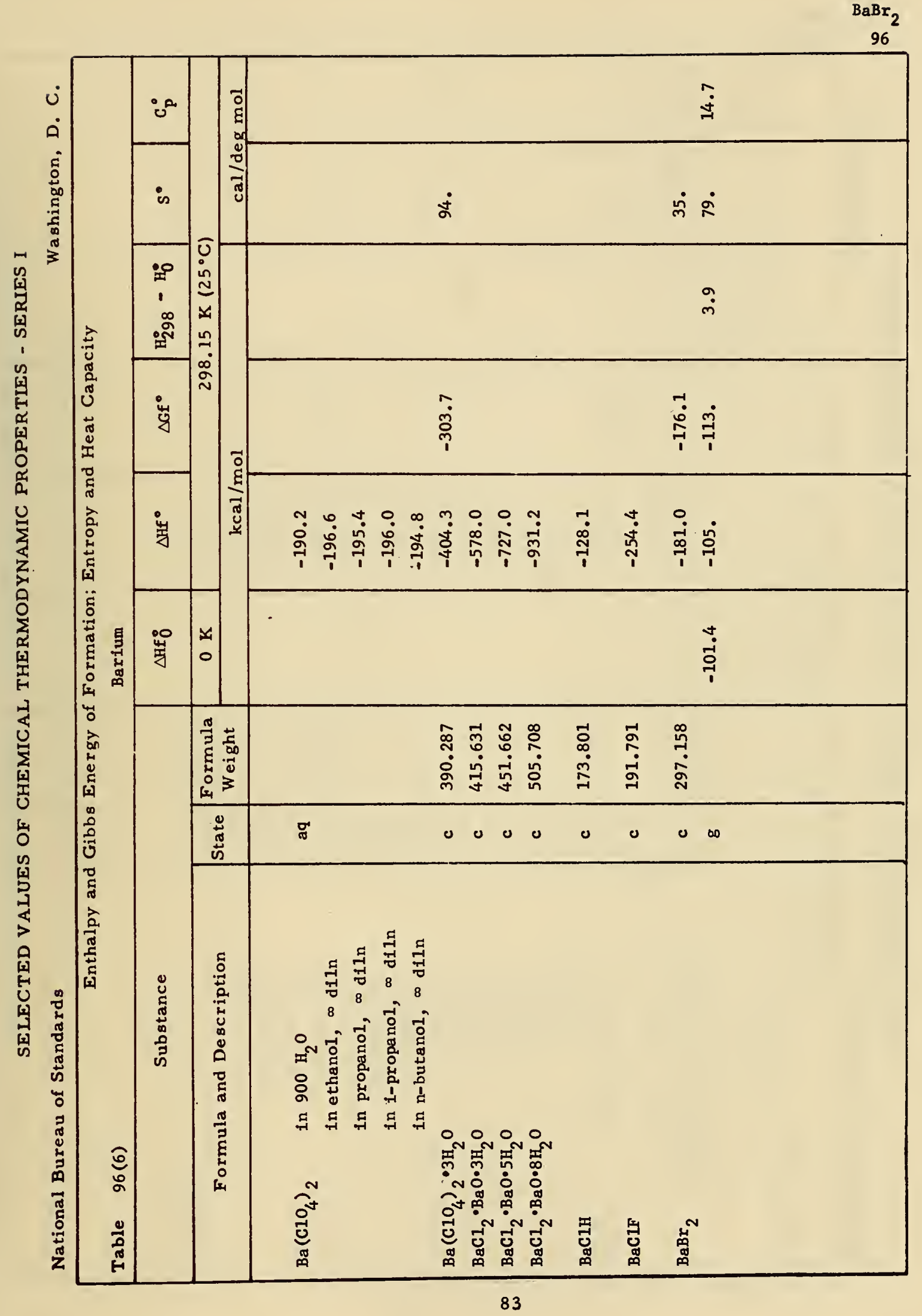




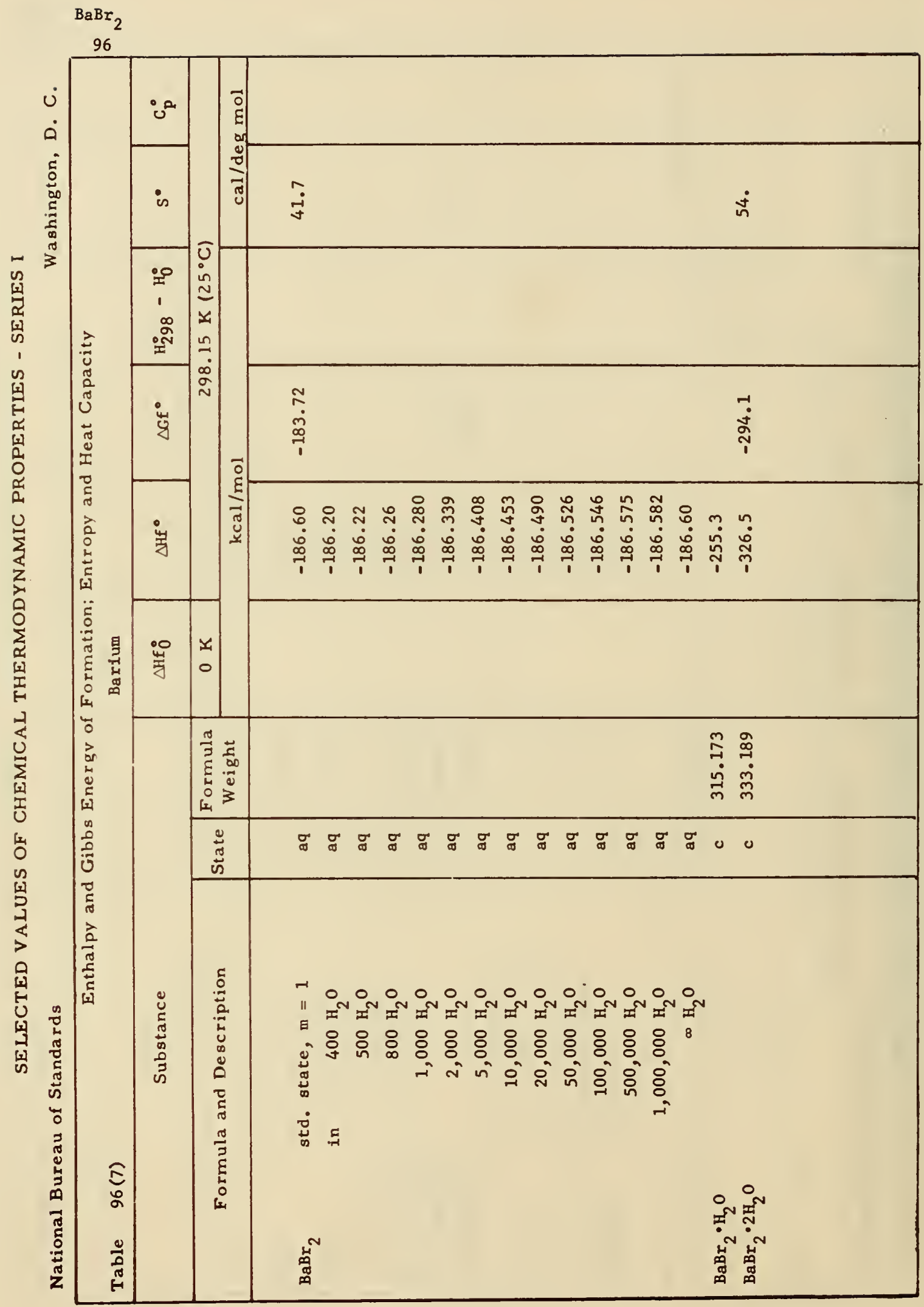




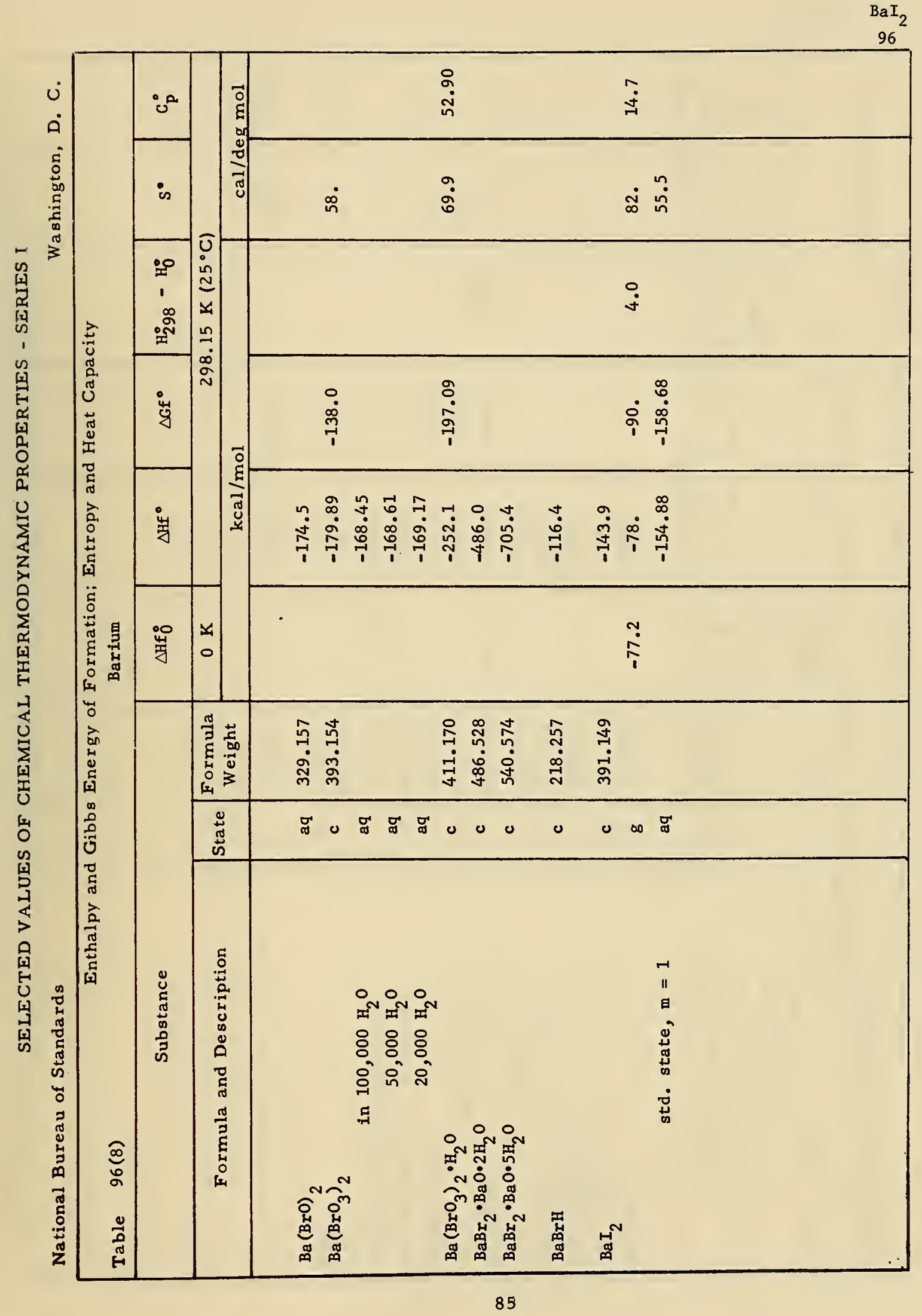




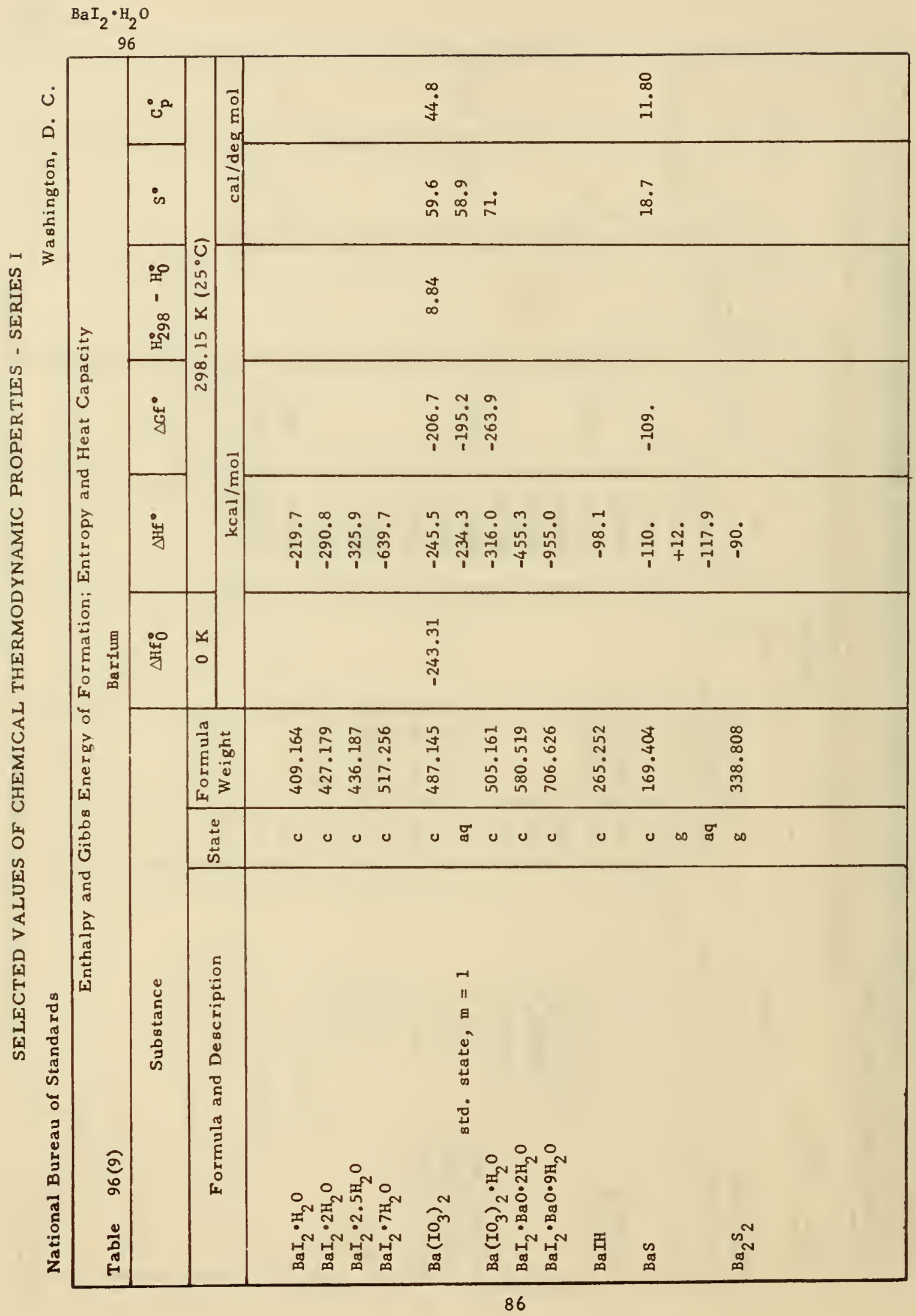




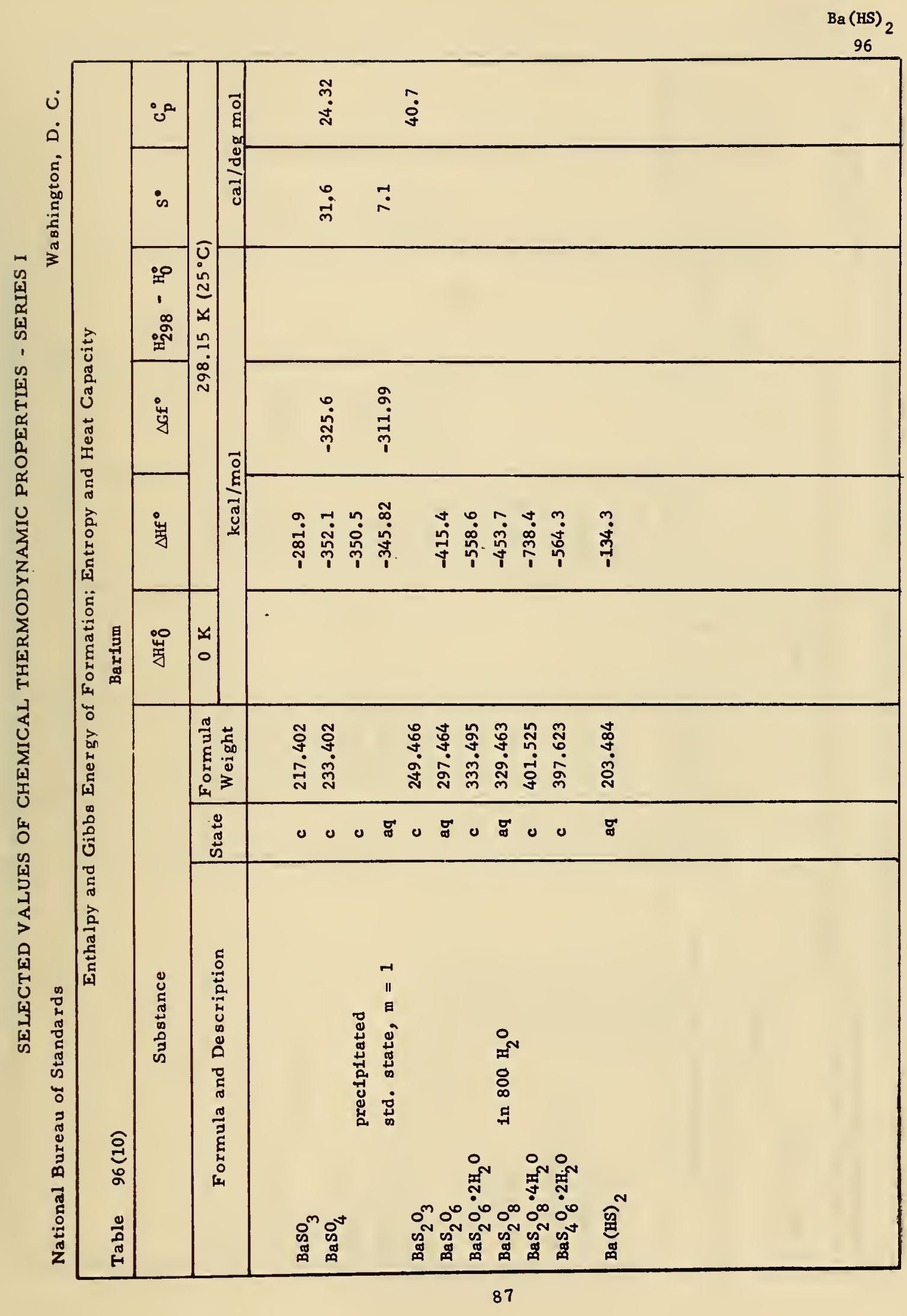




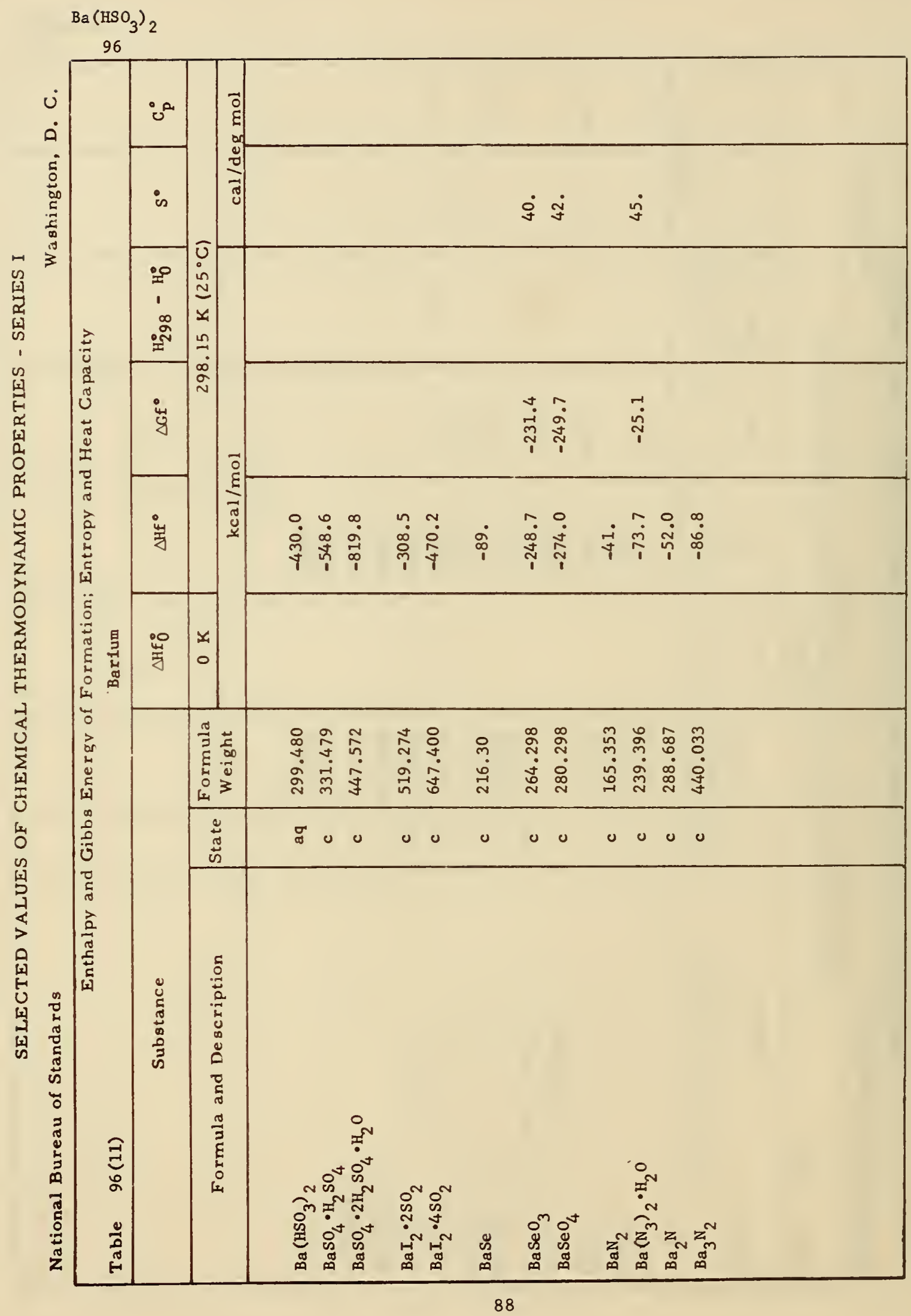




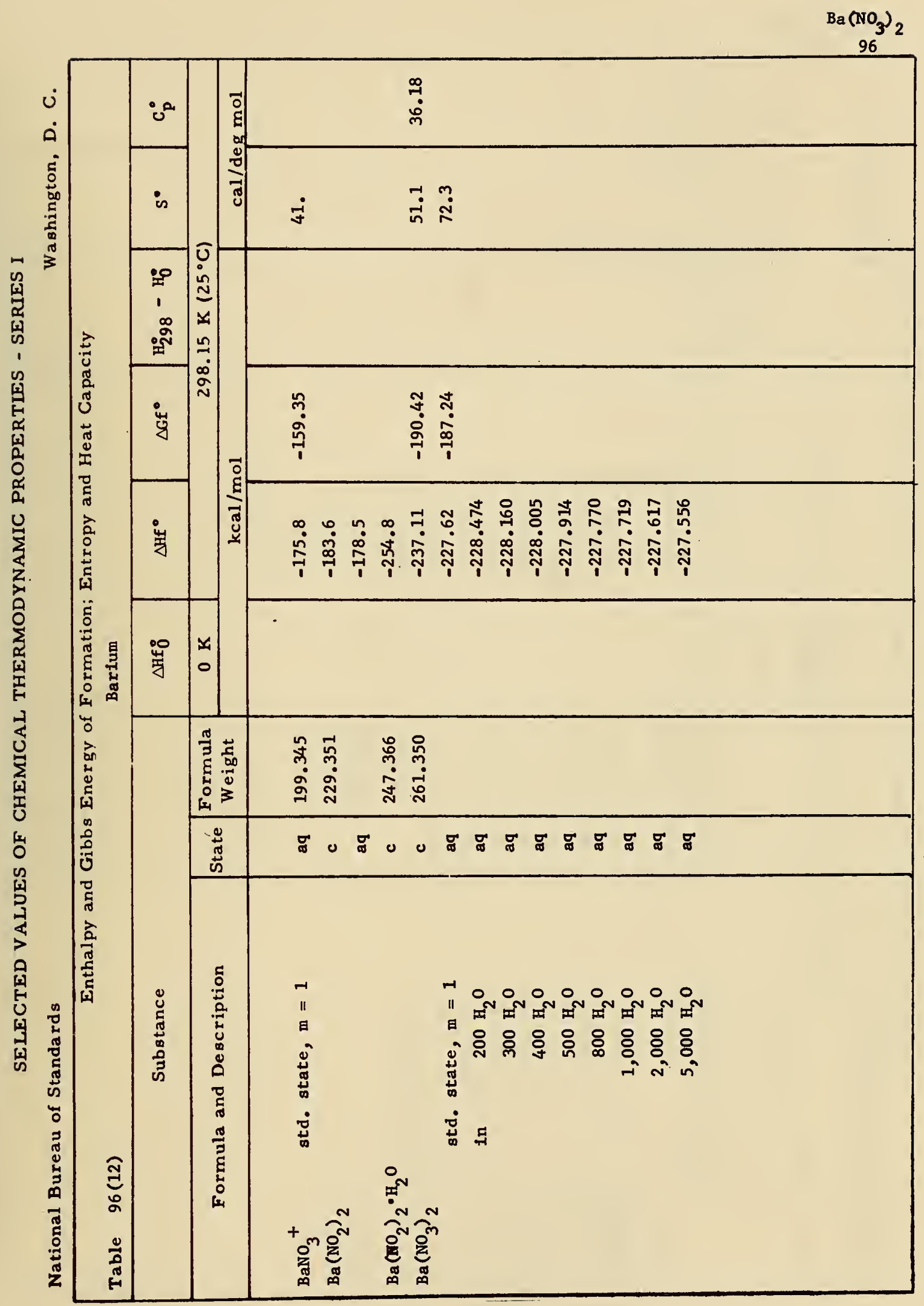




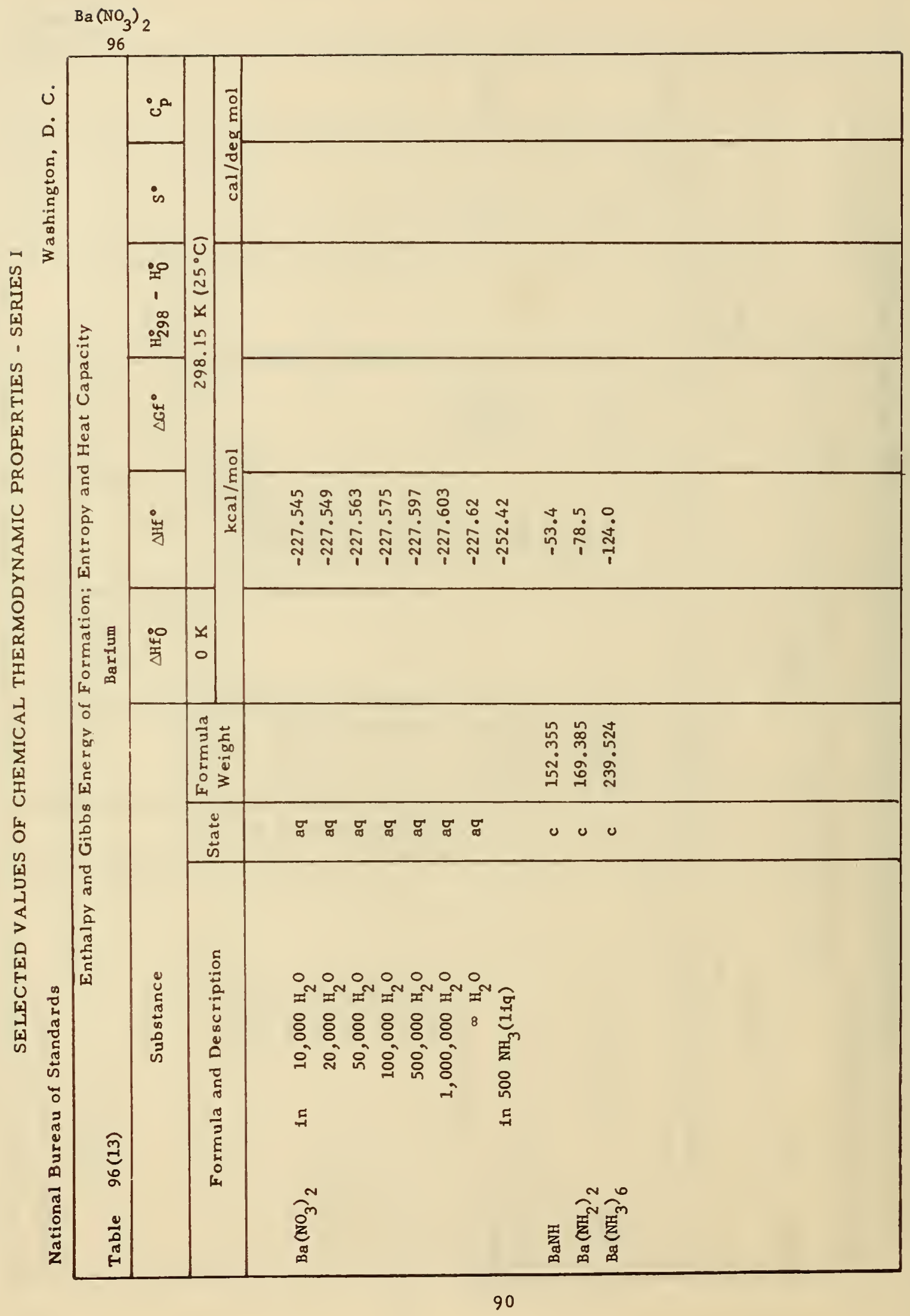




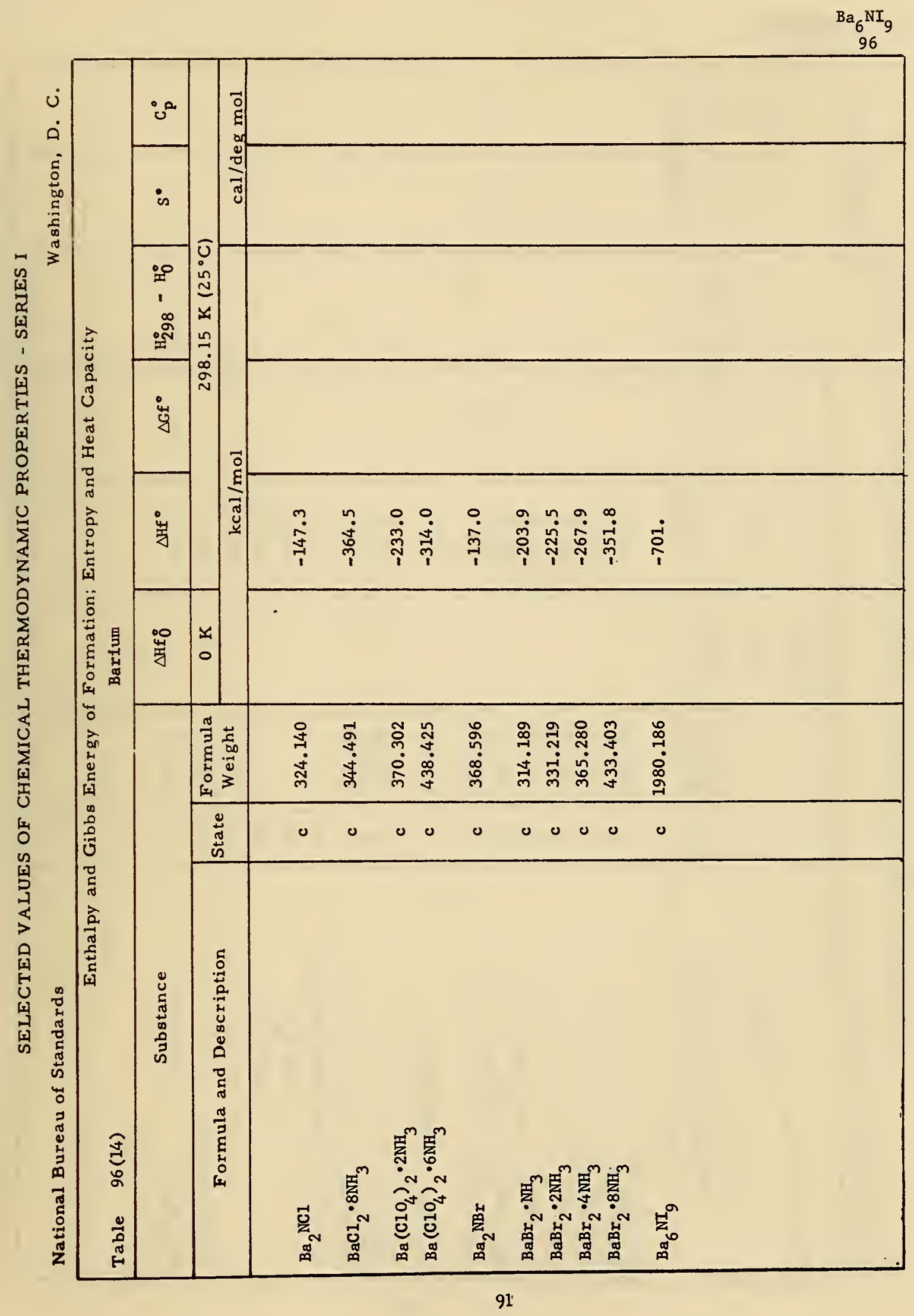




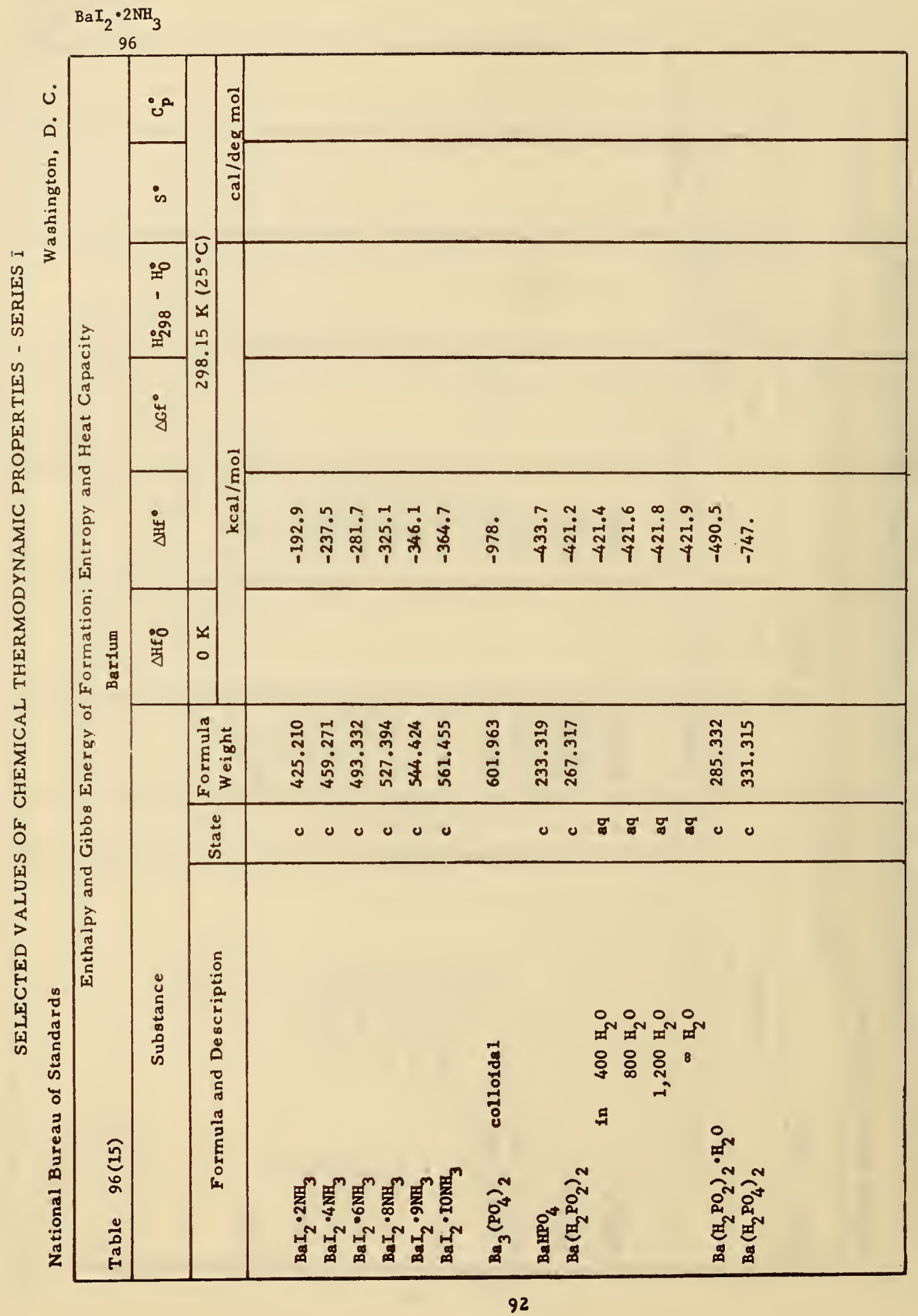


$\mathrm{BaC}_{2} \mathrm{O}_{4} \cdot 3.5 \mathrm{H}_{2} \mathrm{O}$

96

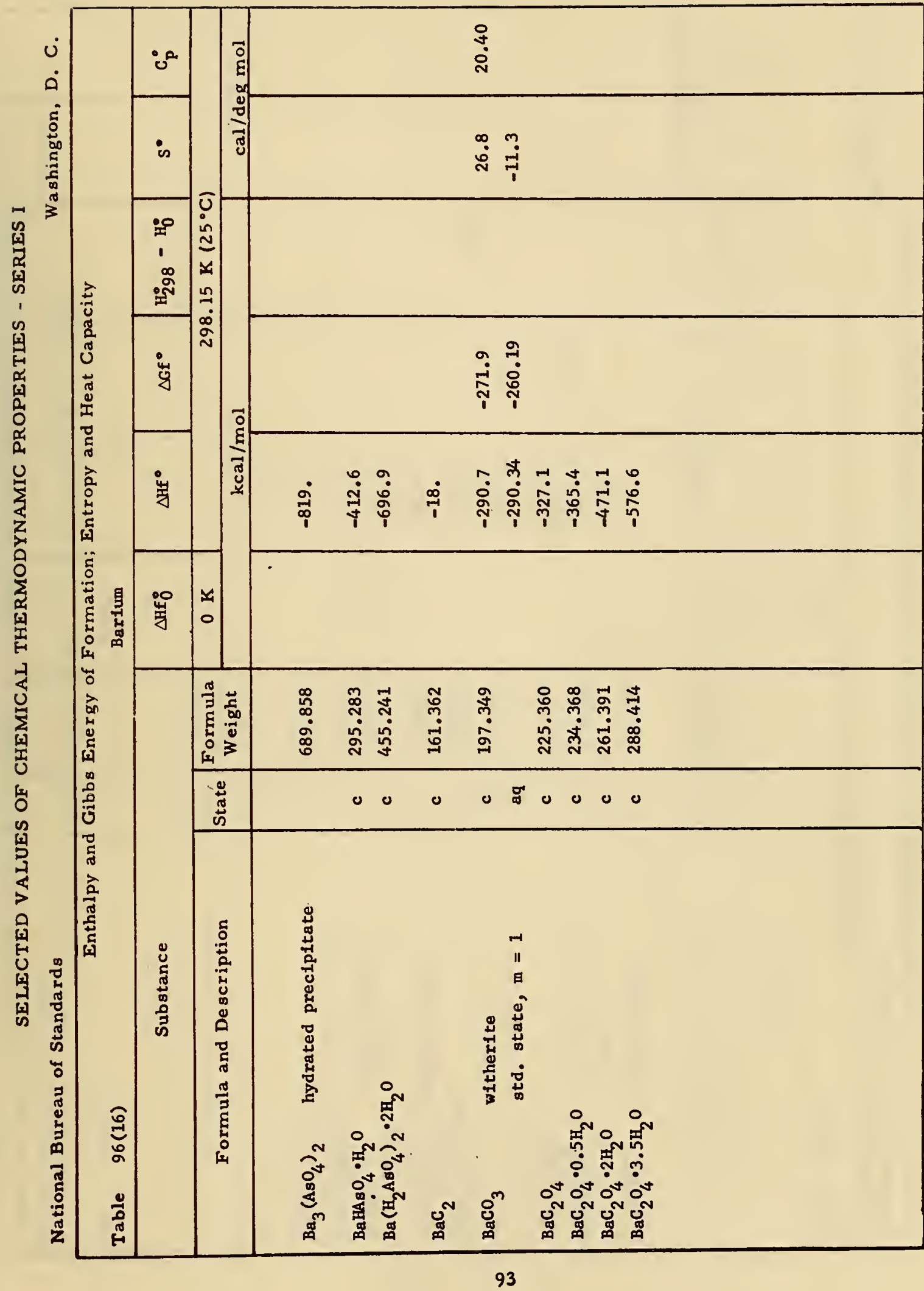




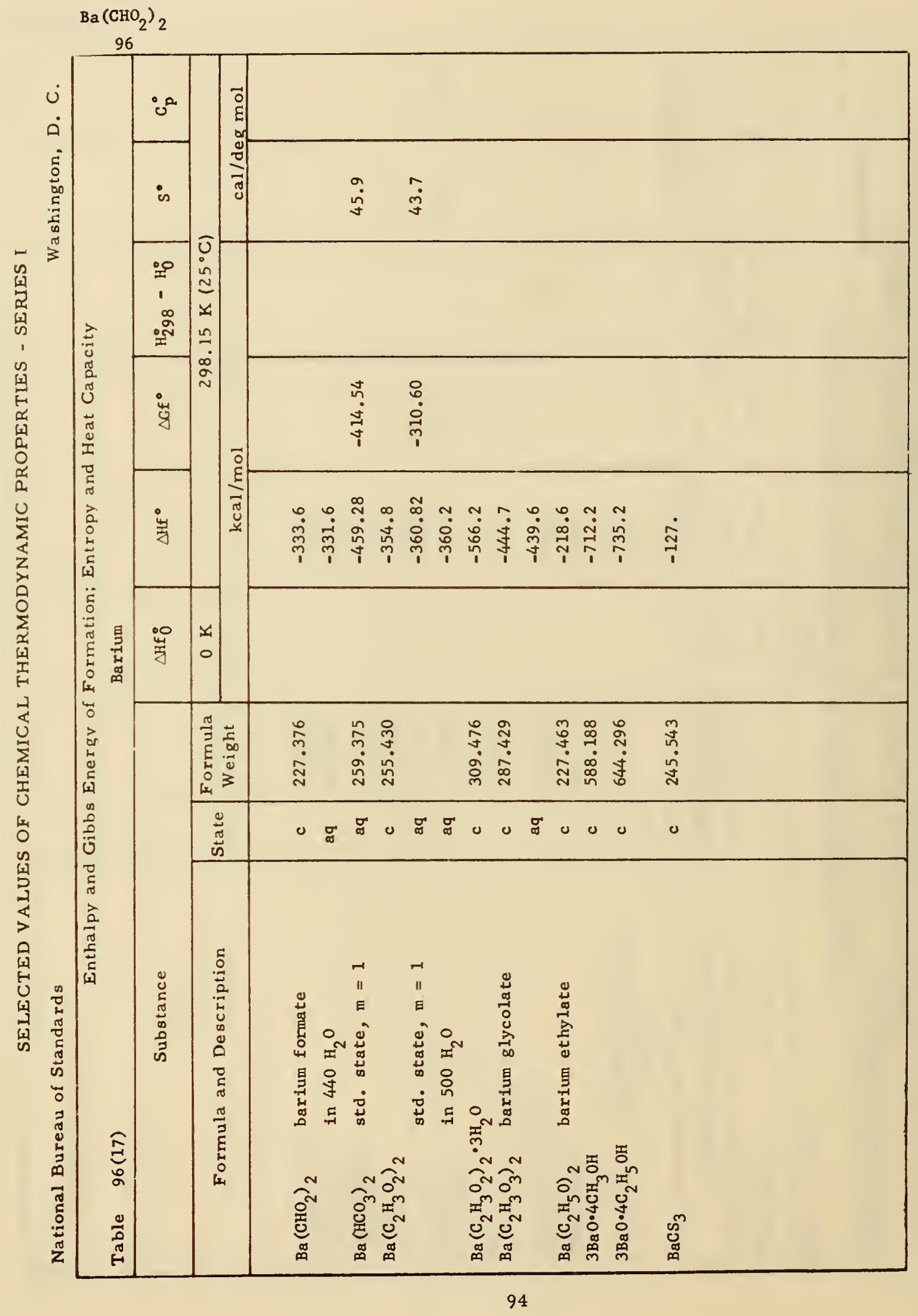




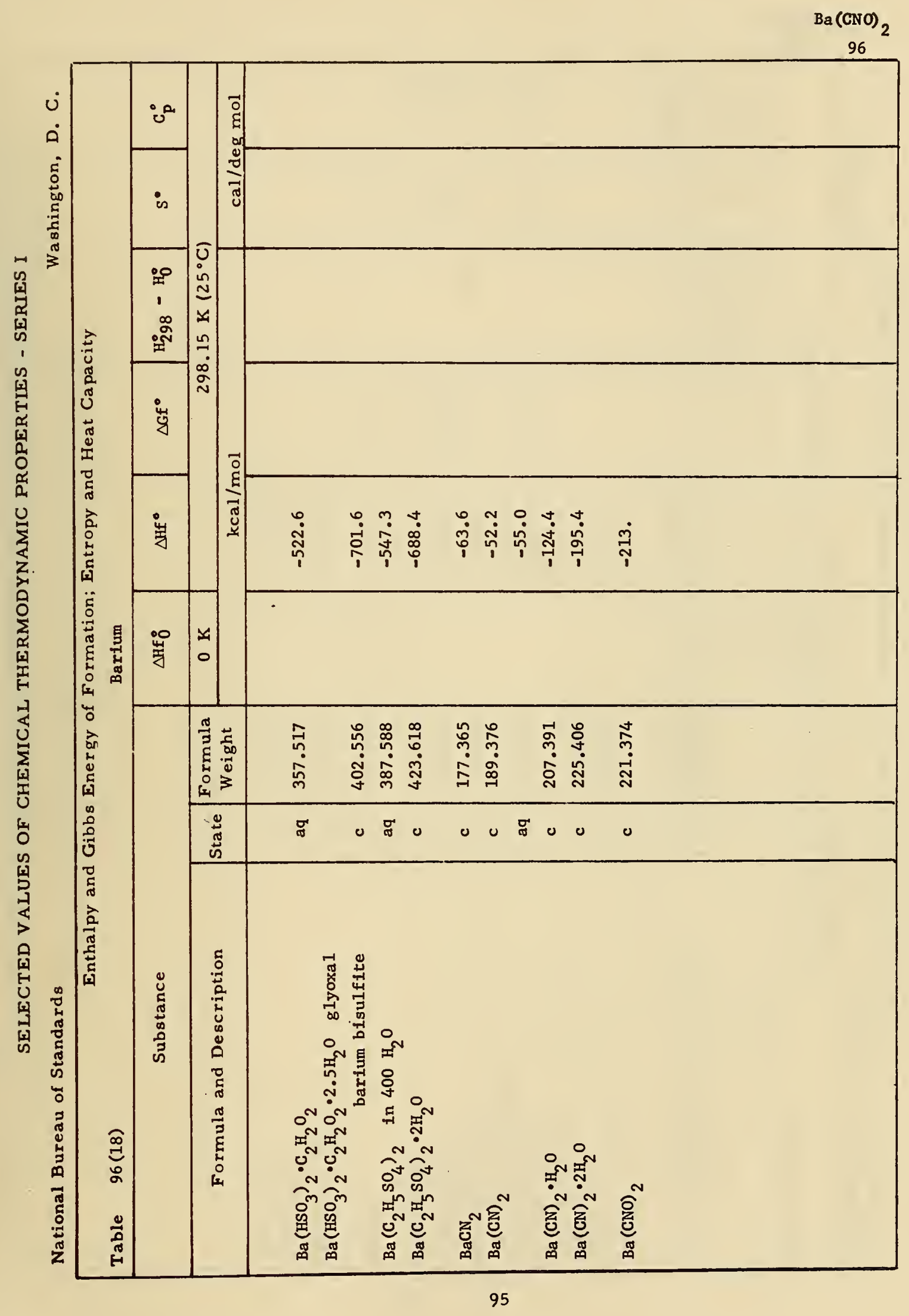




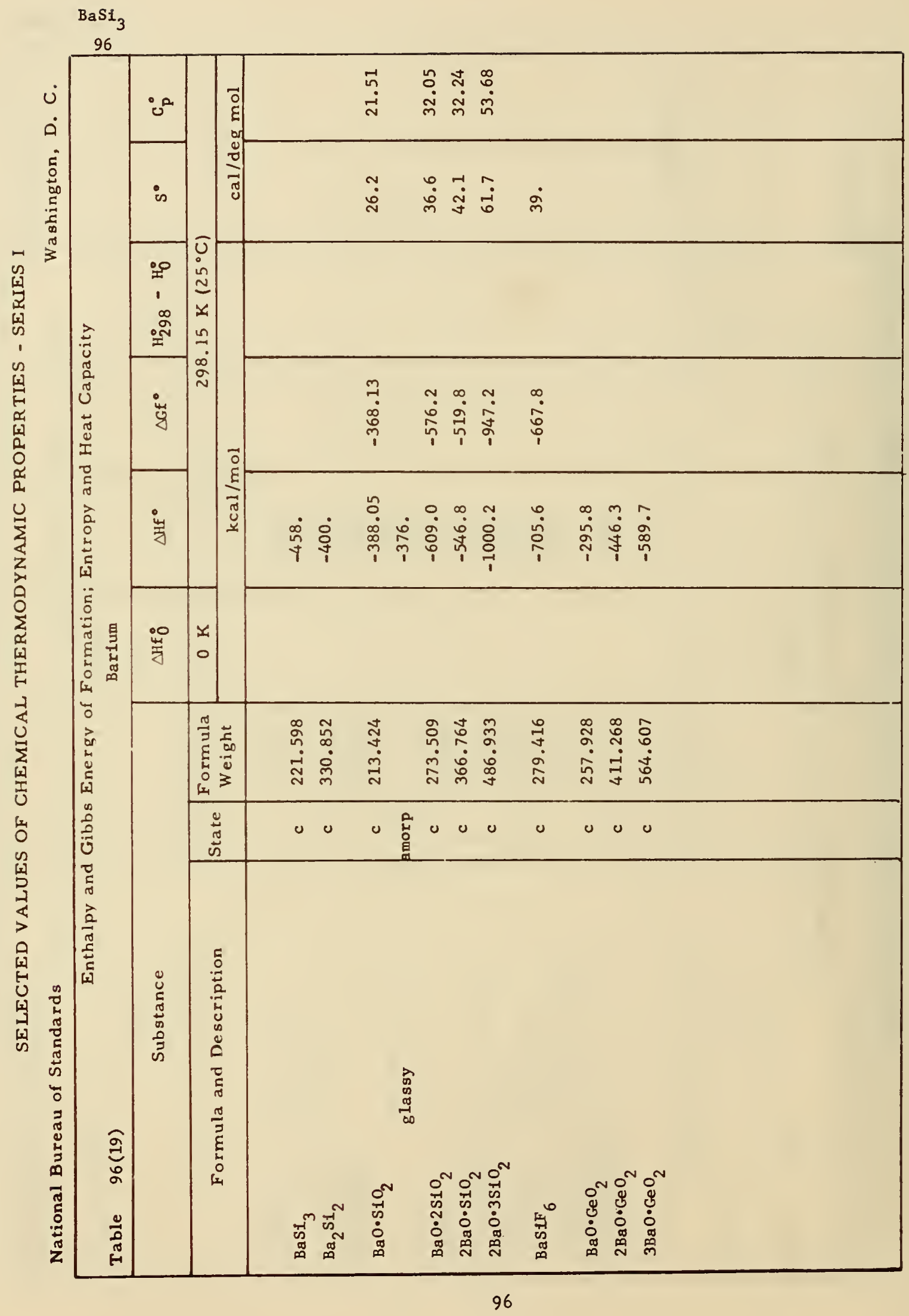




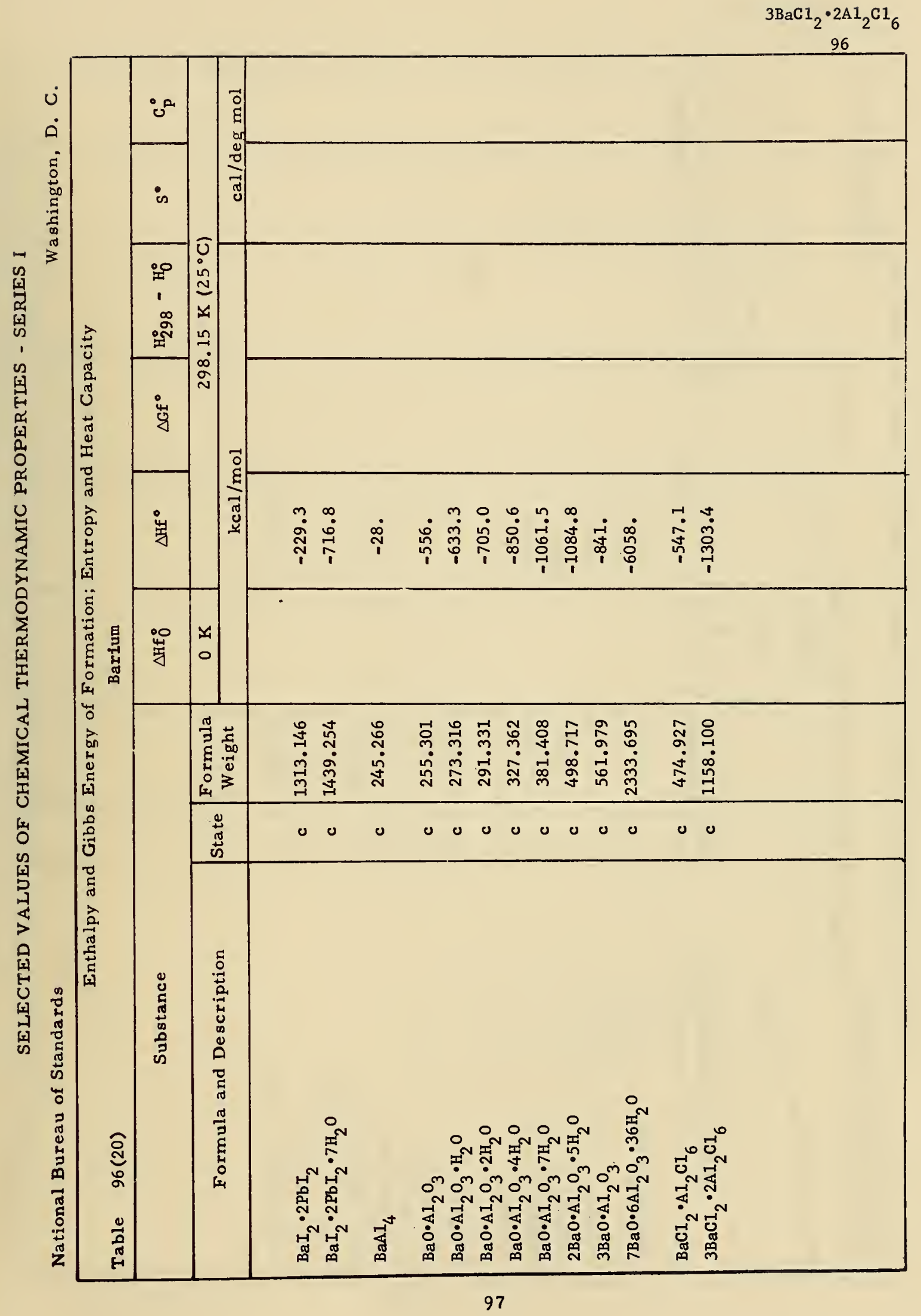




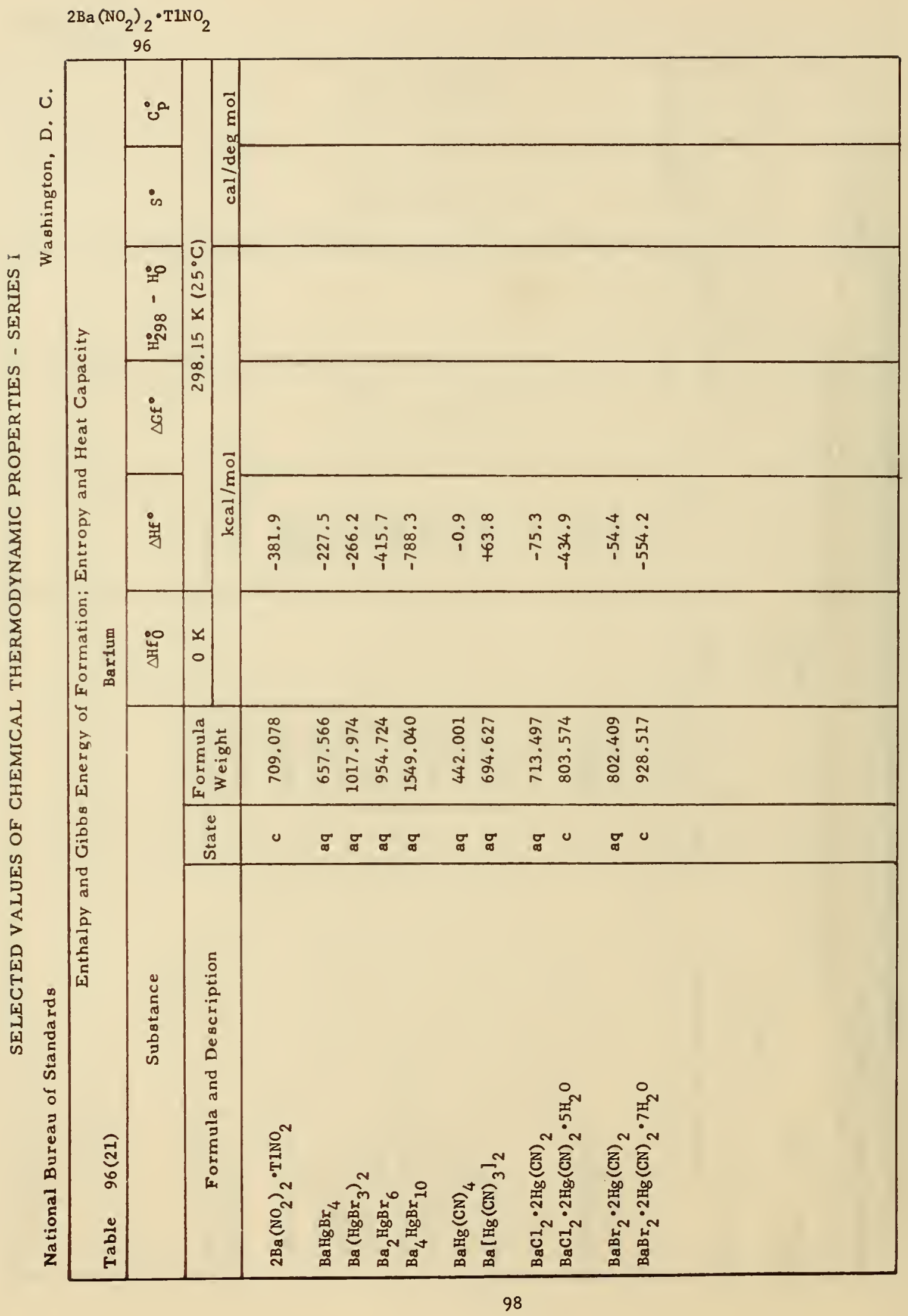




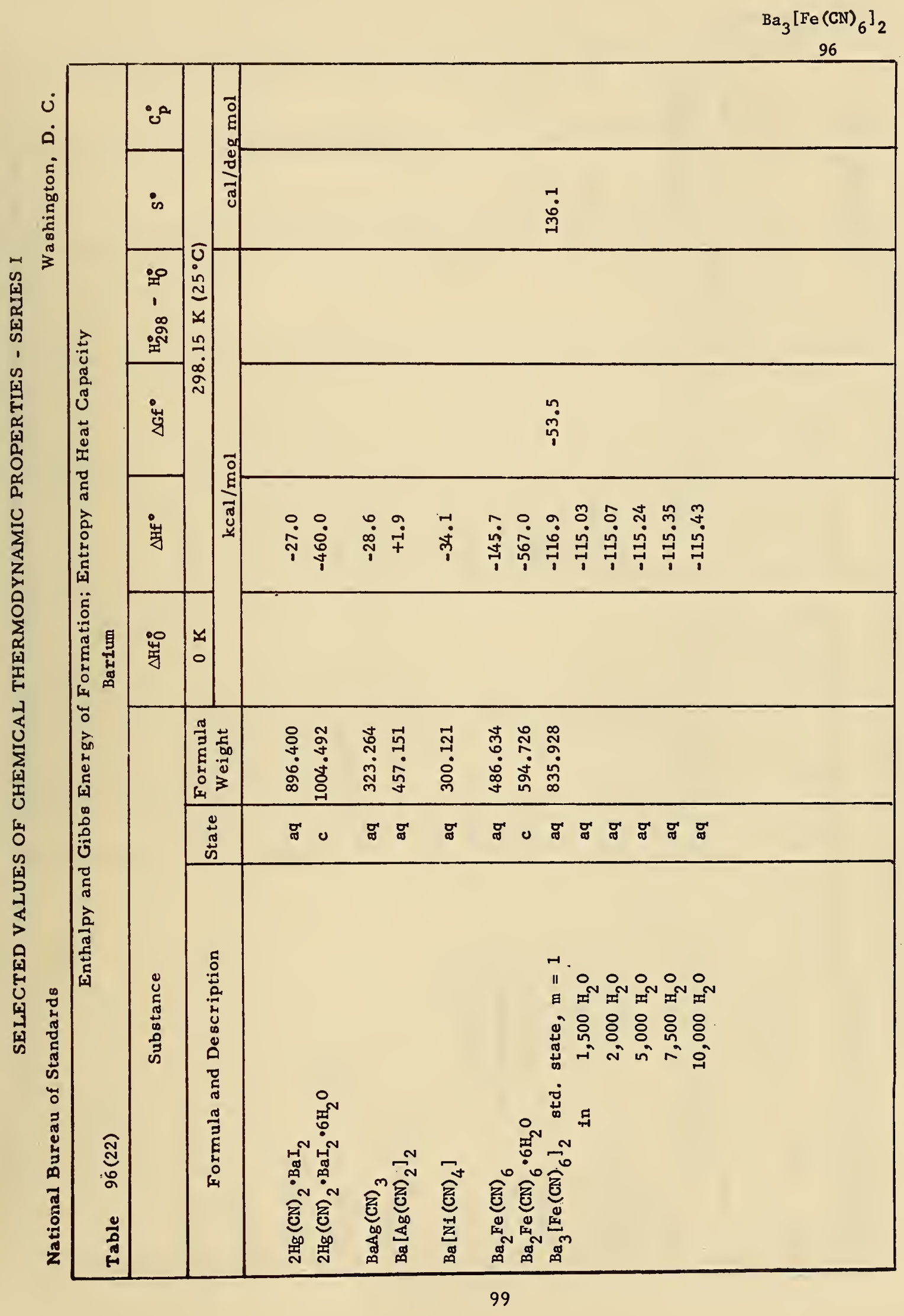




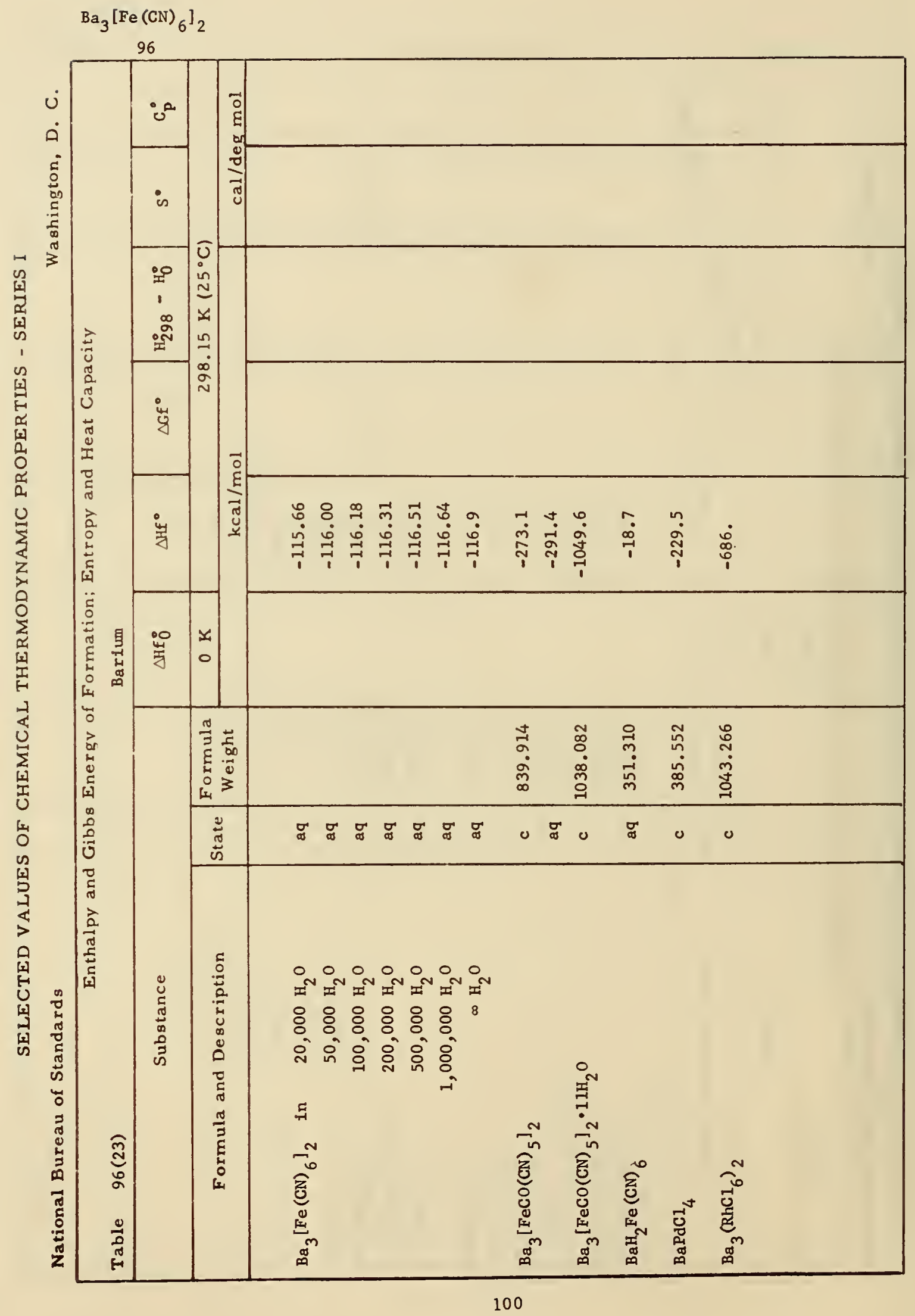




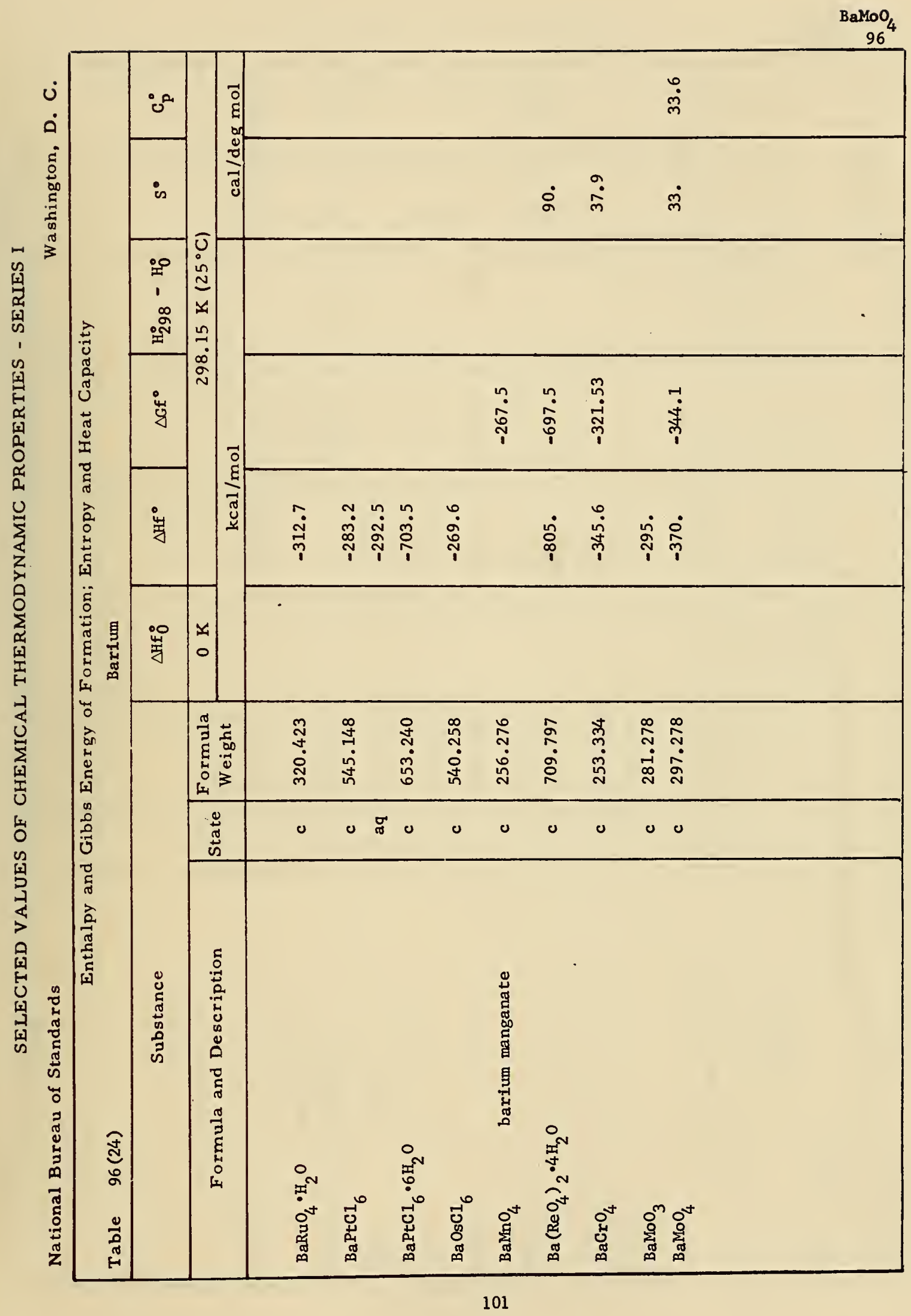




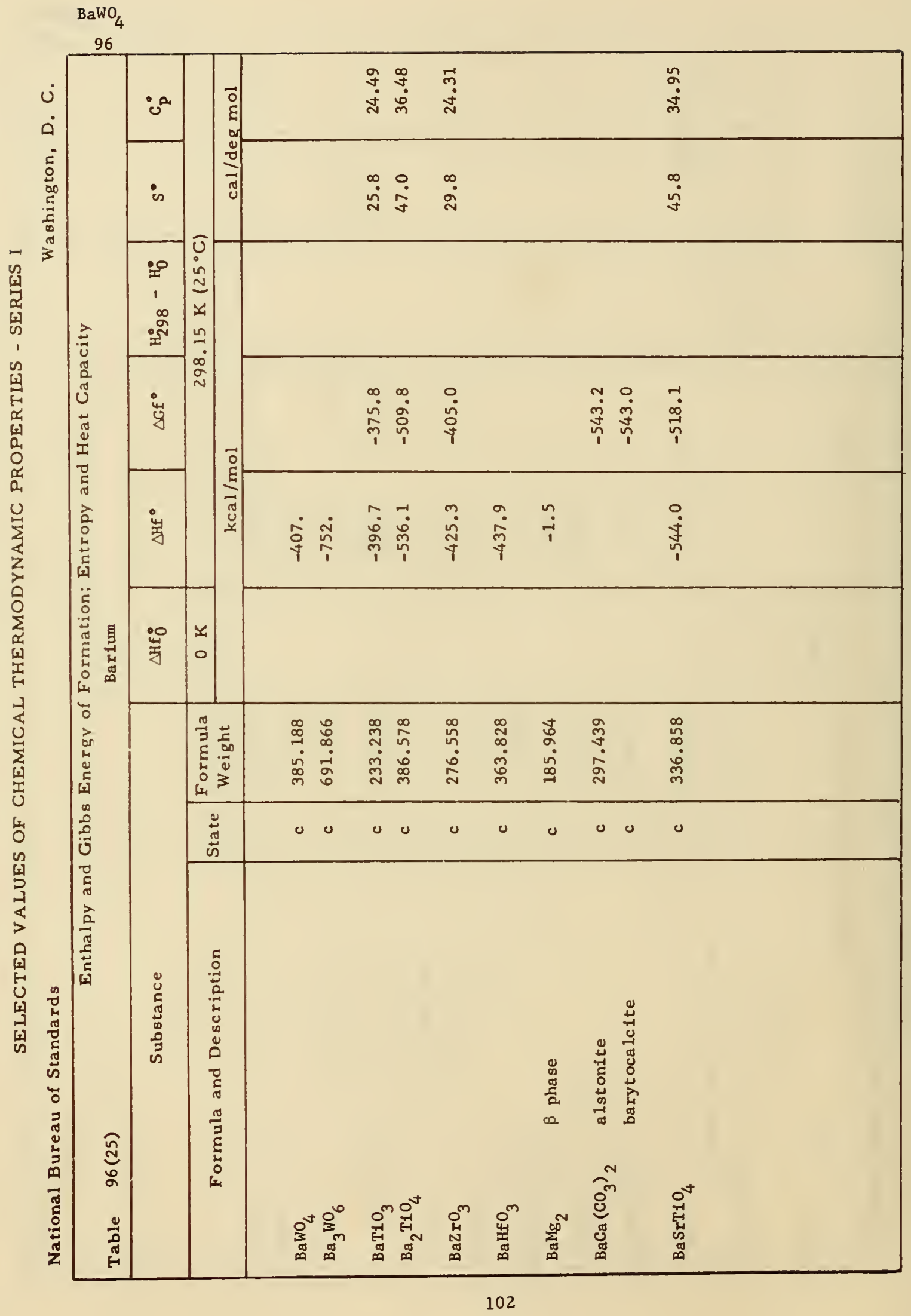




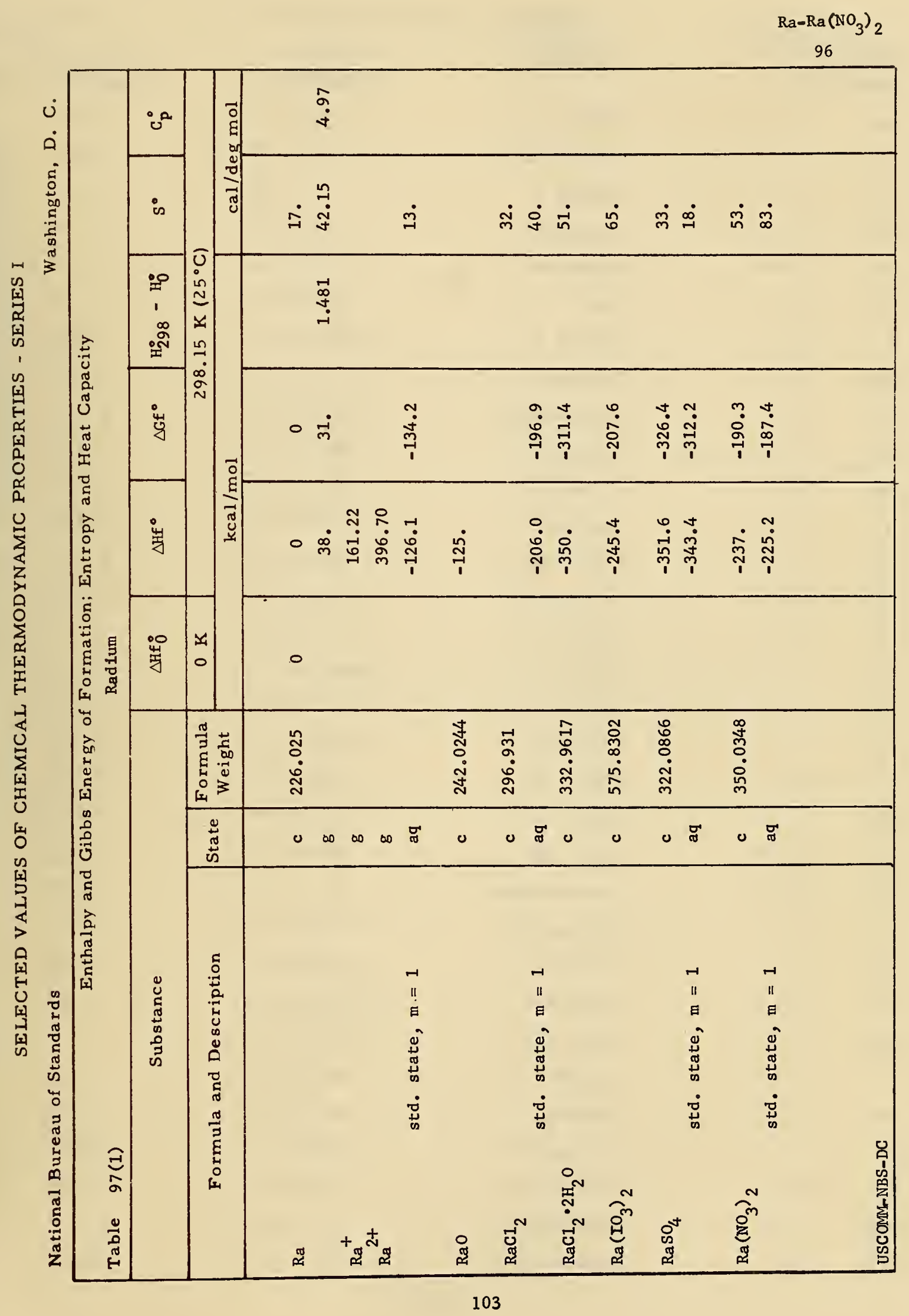


INDEX OF CONTENTS

Chemical

Symbol

Ag

Al

Ar

As

At

$\mathrm{Au}$

B

$\mathrm{Ba}$

$\mathrm{Be}$

$\mathrm{Bi}$

$\mathrm{Br}$

C

$\mathrm{Ca}$

$\mathrm{Cd}$

$\mathrm{Cl}$.

Co

$\mathrm{Cr}$

$\mathrm{Cu}$

F

$\mathrm{Fe}$

$\mathrm{Ga}$

$\mathrm{Ge}$

$\mathrm{H}$

$\mathrm{He}$

$\mathrm{Hf}$

$\mathrm{Hg}$

I

In

Ir

$\mathrm{Kr}$

$\mathrm{Mg}$

$\mathrm{Mn}$
Element

Silve r

Aluminum

Argon

Arsenic

Astatine

Gold

Bor on

Barium

Beryllium

Bismuth

Bromine

Carbon

Calcium

Cadmium

Chlorine

Cobalt

Chromium

Copper

Fluorine

Iron

Gallium

Germanium

Hydrogen

Helium

Hafnium

Mercury

Iodine

Indium

Iridium

Krypton

Magnesium

Manganese
Table

Number

37

29

5

20

13

38

28

96

92

22

11

23

94

34

10

40

51

36

9

41

30

25

2

3

59

35

12

31

46

6

93

48
Volume Page Number

$4-29$

3-207

3- 17

3- 95

$3-42$

$4-39$

$3-196$

$6-78$

$6-1$

$3-103$

$3-31$

3-106

$6-30$

$3-248$

$3-24$

$4-54$

$4-120$

$4-13$

$3-21$

$4-74$

$3-218$

$3-177$

$3-12$

$3-15$

$5-22$

$4-1$

$3-36$

$3-223$

$4-103$

3- 18

$6-9$

4-106 
Chemical

Symbol

Mo

$\mathrm{N}$

$\mathrm{Nb}$

$\mathrm{Ne}$

$\mathrm{Ni}$

O

Os

$P$

$\mathrm{Pb}$

Pd

Po

Pt

$\mathrm{Ra}$

$\mathrm{Re}$

$\mathrm{Rh}$

$\mathrm{Rn}$

$\mathrm{Ru}$

$\mathrm{S}$

$\mathrm{Sb}$

$\mathrm{Sc}$

$\mathrm{Se}$

$\mathrm{Si}$

$\mathrm{Sn}$

$\mathrm{Sr}$

$\mathrm{Ta}$

Tc

$\mathrm{Te}$

$\mathrm{Ti}$

T1

V

W

$\mathrm{Xe}$

$\mathrm{Y}$
Element

Molybdenum

Nitrogen

Niobium

Neon

Nickel

Oxygen

Osmium

Phosphorus

L ead

Palladium

Polonium

Platinum

Radium

Rhenium

Rhodium

Radon

Ruthenium

Sulfur

Antimony

Scandium

Selenium

Silicon

Tin

Strontium

Tantalum

Technetium

Tellurium

Titanium

Thallium

Vanadium

Tungsten

Xenon

Yttrium
Table

Number

52

18

55

4

39

1

47

19

27

42

17

45

97

50

43

8

44

14

21

60

15

24

26

95

56

49

16

57

32

54

53

7

61
Volume Page Number

$4-129$

$3-61$

$5-6$

$3-16$

$4-43$

$3-11$

4-104

$3-84$

3-187

$4-90$

$3-60$

$4-96$

$6-103$

$4-117$

$4-93$

$3-20$

$4-94$

$3-43$

$3-99$

$5-24$

$3-56$

$3-171$

$3-181$

6- 57

$5-10$

$4-116$

3- 58

5- 12

$3-227$

5- 1

4-134

3- 19

5- 28 
Chemical

Symbol

$\mathrm{Zn}$

$\mathrm{Zr}$
Element

Zinc

Zirconium
Table

Number

33

58
Volume Page Number

3-233

5- 18 
Announcement of New Technical Notes on

Selected Values of Chemical Thermodynamic Properties

Superintendent of Documents

Government Printing Office

Washing ton, D. C. 20402

Dear Sir:

Please add my name to the announcement list of new publications to be issued in the series: NBS Technical Note 270 - Selected Values of Chemical Thermodynamic Properties.

Name

Company

Address

City

State

Zip Code

(Notification key 341) 

U.S. DEPT. OF COMM.

BIBLIOGRAPHIC DATA

SHEET

1. PUBLICATION OR REPORT NO. NBS-TN 270-6
2. Gov't Accession No.

4. TIT LE AND SUBTITLE

Selected Values of Chemical Thermodynamic Properties,

Tables for the Alkaline Earth Elements (Elements 92

through 97 in the Standard Order of Arrangement)

7. $A U T H O R(S)$

V.B. Parker, D.D. Wagman, W.H. Evans

9. PERFORMING ORGANIZATION NAME AND ADDRESS

NATIONAL BUREAU OF STANDARDS

DEPARTMENT OF COMMERCE

WASHINGTON, D.C. 20234

12. Sponsoring Organization Name and Address

Same

8. Performing Organization

10. Project/Task/Work Unit No.

1510110

i1. Contract/Grant No.

13. Type of Report \& Period Covered

Final

14. Sponsoring Agency Code

16. ABSTRACT (A 200-word or less factual summary of most significant information. If document includes a significant bibliography or literature survey, mention it here.)

Contains tables of values for the standard heats and Gibbs (free) energies of formation, entropies and enthalpies at $298.15 \mathrm{~K}$ and heats of formation at $\cap \mathrm{K}$ for compounds of beryllium, magnesium, calcium, strontium, barium, and radium (elements 92-97 in the Standard Order of Arrangement). These tables are a continuation of the comprehensive revision of NBS Circular 50n.

17. KEY WORDS (Alphabetical order, separated by semicolons)

Enthalpy; entropy; Gibbs energy of formation; beryllium compounds; magnesium compounds; calcium compounds; strontium compounds; barium compounds; radium compounds.

18. AVAILABILITY STATEMENT

X UNL IMIT ED.

FOR OFFICIAL DISTRIBUTION. DO NOT RELEASE TO NTIS.

\begin{tabular}{|l|c|}
\hline $\begin{array}{c}\text { 19. SECURITY CLASS } \\
\text { (THIS REPORT) } \\
\text { UNCL ASSIF IED }\end{array}$ & 119 \\
\hline $\begin{array}{c}\text { 20. SECUR ITY CLASS } \\
\text { (THIS P AGE) }\end{array}$ & 22. Price \\
UNCL ASSIFIED & $\$ 1.25$ \\
\hline
\end{tabular}



JOURNAL OF RESEARCH reports National Bureau of Standards research and development in physics, mathematics, chemistry, and engineering. Comprehensive scientific papers give complete details of the work, including laboratory data, experimental procedures, and theoretical and mathematical analyses. Iilustrated with photographs, drawings, and charts.

Published in three sections, available separately:

\section{- Physics and Chemistry}

Papers of interest primarily to scientists working in these fields. This section covers a broad range of physical and chemical research, with major emphasis on standards of physical measurement, fundamental constants, and properties of matter. Issued six times a year. Annual subscription: Domestic, $\$ 9.50 ; \$ 2.25$ additional for foreign mailing.

\section{- Mathematical Sciences}

Studies and compilations designed mainly for the mathematician and theoretical physicist. Topics in mathematical statistics, theory of experiment design, numerical analysis, theoretical physics and chemisty, logical design and programming of computers and computer systems. Short numerical tables. Issued quarterly. Annual subscription: Domestic, $\$ 5.00$; $\$ 1.25$ additional for foreign mailing.

\section{- Engineering and Instrumentation}

Reporting results of interest chiefly to the engineer and the applied scientist. This section includes many of the new developments in instrumentation resulting from the Bureau's work in physical measurement, data processing, and development of test methods. It will also cover some of the work in acoustics, applied mechanics, building research, and cryogenic engineering. Issued quarterly. Annual subscription: Domestic, $\$ 5.00 ; \$ 1.25$ additional for foreign mailing.

\section{TECHNICAL NEWS BULLETIN}

The best single source of information concerning the Bureau's research, developmental, cooperative, and publication activities, this monthly publication is designed for the industry-oriented individual whose daily work involves intimate contact with science and technology-for engineers, chemists, physicists, research managers, product-development managers, and company executives. Annual subscription: Domestic, $\$ 3.00 ; \$ 1.00$ additional for foreign mailing.
Applied Mathematics Series. Mathematical tables, manuals, and studies.

Building Science Series. Research results, test methods, and performance criteria of building materials, components, systems, and structures.

Handbooks. Recommended codes of engineering and industrial practice (including safety codes) developed in cooperation with interested industries, professional organizations, and regulatory bodies.

Special Publications. Proceedings of NBS conferences, bibliographies, annual reports, wall charts, pamphlets, etc.

Monographs. Major contributions to the technical literature on various subjects related to the Bureau's scientific and technical activities.

\section{National Standard Reference Data Series.}

NSRDS provides quantitative data on the physical and chemical properties of materials, compiled from the world's literature and critically evaluated.

Product Standards. Provide requirements for sizes, types, quality, and methods for testing various industrial products. These standards are developed cooperatively with interested Government and industry groups and provide the basis for common understanding of product characteristics for both buyers and sellers. Their use is voluntary.

Technical Notes. This series consists of communications and reports (covering both other agency and NBS-sponsored work) of limited or transitory interest.

Federal Information Processing Standards Publications. This series is the official publication within the Federal Government for information on standards adopted and promulgated under the Public Law 89-306, and Bureau of the Budget Circular A-86 entitled, Standardization of Data Elements and Codes in Data Systems.

Consumer Information Series. Practical information, based on NBS research and experience, covering areas of interest to the consumer. Easily understandable language and illustrations provide useful background knowledge for shopping in today's technological marketplace.

NBS Special Publication 305, Supplement 1, Publications of the NBS, 1968-1969. When ordering, include Catalog No. C13.10:305. Price $\$ 4.50$; $\$ 1.25$ additional for foreign mailing. 
UNITED STATES

GOVERNMENT PRINTING OFFICE PUBLIC DOCUMENTS DEPARTMENT WASHINGTON, DC. 20402

OFFICIAL BUSINESS
POSTAGE AND FEES PAID U.S. GOVERNMENT PRINTING OFFICE

U.S.MAIl

PENALTY FOR PRIVATE USE, \$300 